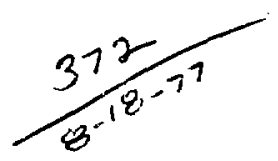

\title{
TORNADO STRUCTURE INTERACTION: A NUMERICAL SIMULATION
}

Tia Hilıon

May 20, 1977

\section{MhSTER}

Propared for U.S. Energy Research a Development Administration under contract No. W-7405-Eng-48
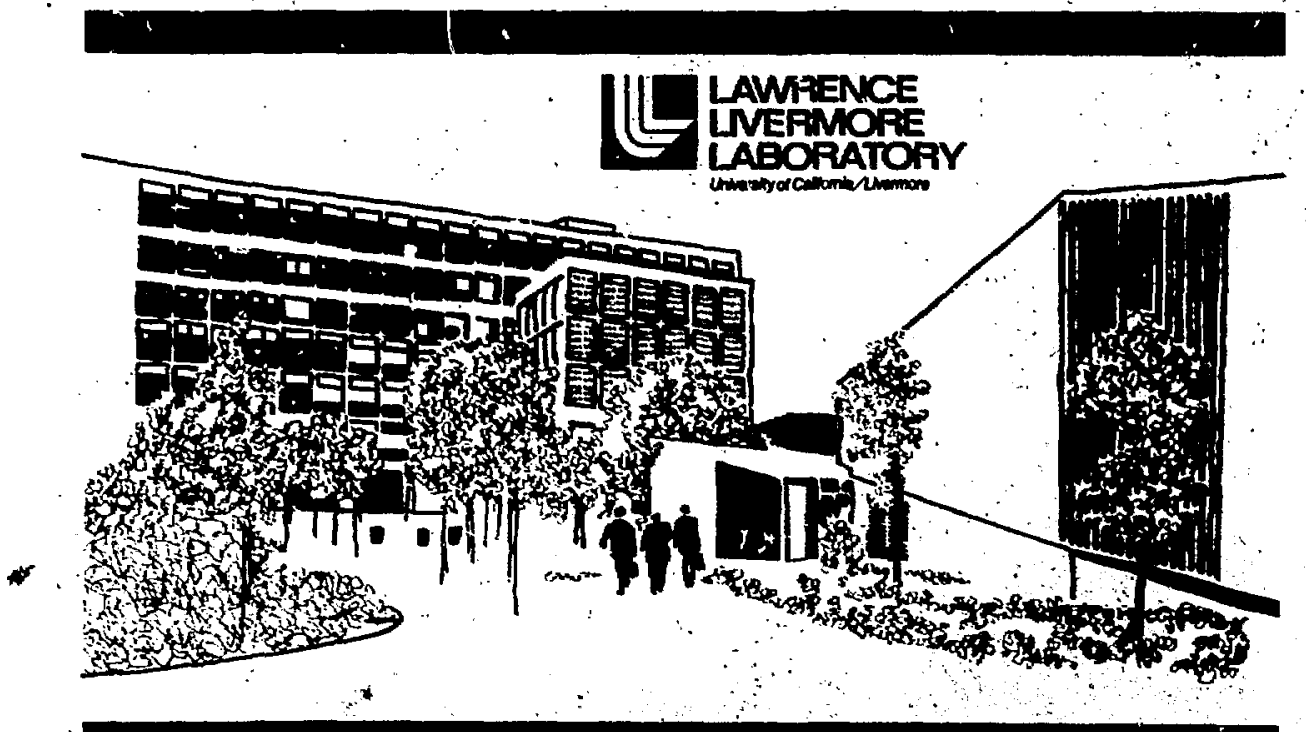

\section{Finge}

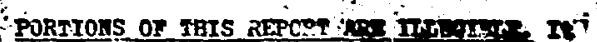
has been reproduced from the best avallablo copy to pernit the broadost possible availebllity. 


\section{NOTICE}

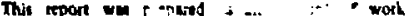
ponsored by the Unined States Gowmmnat. Nelther the Unted Shles no th thind States Bromy Revert - Demboment Adminluntion, no ay of thetr rephoyent, wor ay of their contuctom, wbeantracton, or thit steployer, mines ay wetcaty, expres or

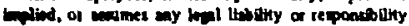

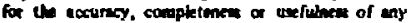
informetion, 4puratus, product of procen dieched, or

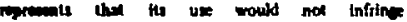
privelyowoed ithte.

\section{MOTICE}

Refire to a company or product nume doet nor mply approwl or reconmendation of the product by

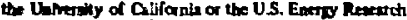

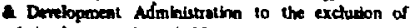
othint the my be witble.

Printed in the United States of America Avaitable from

National Technical Information Semice

US. Department of Commerce

5285 Port Royal Roxd

Springlield, VA 22161

Price: Printed Copys : Microfiche $\mathbf{3 3 . 0 0}$

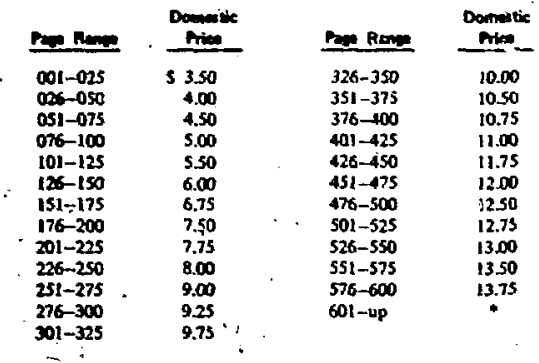

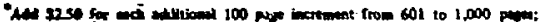

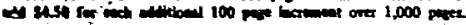




\section{近 \\ LAWRENCE LIVERMORE LABORATORY \\ unversify of Caltoma Lnermore. Calitoma 94550}

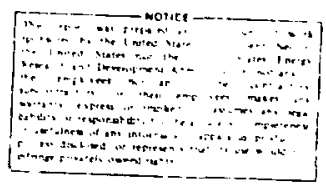

UCRL- 52207

\section{TORNADO STRUCTURE INTERACTION: \\ A NUMERICAL SIMULATION}

Tim Wilson

MS. dace: May 20, 197 ; 


\section{Contents}

dbstract . . . . . . . . . . . . . . . . . . . . . . 1

Introduction . . . . . . . . . . . . . . . . . . . . . 1

Tornado Characteristics . . . . . . . . . . . . . . . . . . . . 2

Windspeeds and Classification of Tornadoss . . . . . . . . . . . . 3

Tornado Structure Interaction . . . . . . . . . . . . . . . . . . . 5

Tornado simulation . . . . . . . . . . . . . . . . . . . . . 11

Numerical Yodeling of Iornado Structure Interaction . . . . . . . . . 20

Discussion of Resules . . . . . . . . . . . . . . . . . . . 36

Suggestions for Future Effort . . . . . . . . . . . . . . . . . 45

References . . . . . . . . . . . . . . . . . . . . 49

Appendix A: Nomenclature . . . . . . . . . . . . . . . 55

Appendix B: Procedure for Calculating Wind Loads for Straight Winds. . . 57

Appendix C: External Pressure Cieficients for Walls for

Straighe Winds . . . . . . . . . . . . . . . . 58

Appendix D: Time-History Labulation of Building Surface Pressures

and Force Coefficients . . . . . . . . . . . . . 59 


\title{
TORNADO STRUCTURE INTERACTION: \\ A NUMERICAL SIMULATION
}

\begin{abstract}
We examine the effects of tornadoes on buildings to determine the wind forces on structures. The American National Standards lnstitute (As.T) has developed guidelines for building code requirements for the minimum wind loads a building musc be designed to withstand. We attempt to evaluate the conservat $1 \mathrm{sm}$ or noncoisservatism on the ANSI approach by simulating tornado-structure interaction numerically with a twodimensional fluid dynamics computer code and a vortex model. Only

external pressures are considered. The computer calculat: nns yield the following percentages of ie ANSI design pressures: rigid frame, 50 to $90 \%$; Individual wall panels, 75 to $200 \%$; and wall corners, 50 to $75 \%$. Although the computer program does have 1 ts limitations, we conclude that the ANSI approach is a justifiable method for determing reasonable building design loads. In addition, a margin of safety does exist when buildings are designed with this method.
\end{abstract}

\section{Introduction}

The most violent of all atmospheric phenomena are found in the short-lived swirling storms known as tornadoes. Although they occur in all parts of the world, the rast majority of tornadoes are found in the eastern half of the Unites States. occurring most frequently in late spring and early sumer. Approximately 700 tornado strikes are reported each year in this country.

our primary interest is the effects of tornadoes on buildings. The nuclear power community is currently addressing the problem of tornadostructure interaction (TSI) to design facilities to relfably withstand a cornado strike. To calculate tornado-induced loads, the structural engineer must be provided with the signfficant physical properties of a tornado and with an acceptable method to arrive at resulting forces incidert on a structure. Tornado properties constitute a Design Basis Tornado (DBT), to be discussed later.

In general, wind forces on structures are calculated using the guideilnes in the American National Standards Inscitute (ANSI) publication, "Building Code Requirements for Minimum Design Loads in Buildings 
and Other Structures," (ANSI A5B.11972) or in ASCE paper No. 3269 , "Wind Forces on Structures," (1961). It is important to note that neither publication addresses tornadic winds. The ANSI Standard approach (see Appendix A) involves the conversion of a mean-velocity profile in a straight, quasi-steady wind field to a design load using the wind-velocity pressure and emplrically defined pressure coefticients for the building shape in question. The extension of the ANSI approach to tornado winds has been made by several investigators; (see McDonald, et al., 1975; Rotz, et al., 1974; and Shanahan, 1976).

Here, we have attempted to evaluate the conservatism or nonconservatism in an ANSI approach to calculations of tornado-wind loadings. This is accoraplished by simulating tornadostructure interaction numerically with a two-dimensional fluid dynamics computer code ( $B B C$ ) and a suitable vortex model. In this regazd, only external pressures are considered. Seven cases of numericial TSL are examined. In each ase, the vortex flow field is allowed to engulf the structure long enough for the important fluid-dynmic effects to develop.

To place these calculations in proper perspective, we must consider the tornado phenumenon as a whole. The next two sections give a brief meteorological description of the phenomenon we are trying tu model. Current engineering practice to determine tornado design-wind loading is aiscussed in a chird section. Because our knowledge of cornadoes is far trom complete, there remains considerable question over what constitutes a tornado flow field. Any attempt to model a tornado vortex must address this question and we consider this problem in a separate section. Previous efforts at modeling tornadoes theoretically, numerically, and experimentally are also discussed.

\section{Tornado Characteristics}

A precise description of the torrido, its cause, or source of energy and rotation has yet to be developed. In.general, tornadoes are spawned from thunderstorm systens. The energy source is generally believed to be buoyant potential energy that is derived from condensing water vapor in an unstable atmosphere (Lilly, 1969; Fulks, 1962). The mature cornado is an intense vortical storm characterized by a rapidly rotating, central air column known as the "core" and an outer rugion of essentially irrotational fluw which extends radially away from the core. 
Typically, the core region is a few hundred yards in diameter with peak tangential wind speeds of approximately: $200 \mathrm{mph}$.

Physically, the tornado is most frequently seen to excend downward from the parent cloud, being made vistble by the condensation of water droplets. This vistble funnel cloud may take on a wide range of appearances from a nearly vertical cylinder to a long ropelike pendant to the more familiar, tapering funnel. At times, a tornado may ex'ibit no visible fuanel (e.g., the Xenia, Ohio, tornado of April 3, 1974!. The aajority of tornadoes last only a few minutes and traverse a path of up to $15 \mathrm{mi}$ with a typical path width of $1 / 4$ mile. The most violent tornadoes are much longer-lived. On May 26, 1917, a cornadu traveled $293 \mathrm{mi}$ across Illinols and Indiana, lasting $7 \mathrm{hr}$ and $20 \mathrm{~min}$ (ESSA, 1969). Table l lists typical tornado characteristics. A mure complete review of tornado characteristics and the attendant meteorology is given by Davies-Jones and Kessler $(19 / 4)$.

\section{Windspeeds and Classificztion of Tornadoes}

From 1953 to 1972, tornadoes were responsible for approximately 113 deaths and over $\$ 75$ million in property damage annually (DaviesJones and Kessler, 1974). To rationally apply tornado statistics, we need a means of specifying the incensity and affected area of a tornado scrike as well as the atcendent probabilities. The probability, $P$, of a tornado strike in a year's time may be defined as

$$
P=\frac{\text { (area of average damage patir) } \times \text { (frequency) }}{\text { (geographical area) }} .
$$

For a given location in the most tornado-prone area of the country, $P=0.0363$ (ESSA, 1969). Further discussions of tornado strike and damaḡe probabilities are given by Abbey and Fujica (1975), Wen and Chu (1973), Doan (1970),
NcDonald et al. (1974, 1975), Abbey (.976), and Markee et al. (1974). Hart (1976) discusses structural damage and dollar loss probabilities.

A knowlıdge of the maximum cangential wintspeed is essential for 
Table 1. Tornado characteristics.

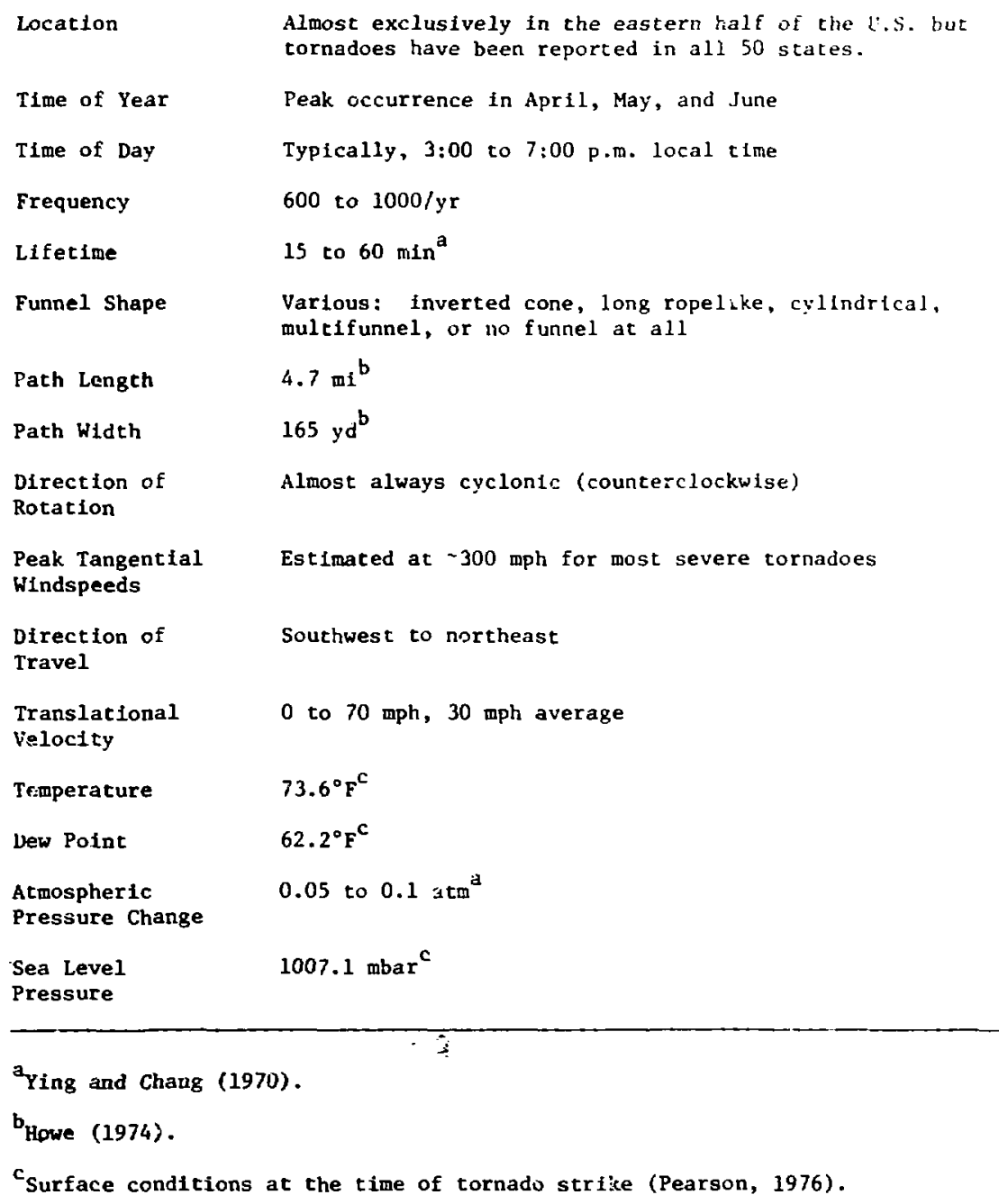

Almost exclusively in the eastern half of the $1 . S$. but

Varlous: inverted cone, long ropelike, cyllndrlcal,

$165 \mathrm{yd}^{\mathrm{b}}$

Almost always cyclonic (counterclockwise)

Estimated at $-300 \mathrm{mph}$ for most severe tornadoes

WIndspeeds

Direction of

Southwest to northeast

Translational

Velocity

Temperature

עew Point

Atmospheric

0.05 to $0.1 \mathrm{~atm}^{\mathrm{a}}$

Sea Level

1007.1 mbar $^{c}$

Qing and chang (1970).

$b_{\text {Howe }}(1974)$.

${ }^{c}$ Surface conditions at the time of tornado strike (Pearson, 1976). 
d.e. : toint tornado antensity As noted eirlier, a gap remaine in our kinuledge at the physics of cornadoes. yiuld data is scarce and hence, even the value of windspeeds is of considerable doubt. Meteorological instrumerss, even if properly located, aranct be expected to survive a severe iornado. Highest estimates for maximum tangential windspeeds range around 354 mph. Yost cstimates are 50 to 100 mph lower. lolden (1975) has reviewad malny uf these ast fmates and suggests $\therefore 4$ to 250 mph as the peak windspeed. current methods for estimating wirdspeeds include photogrammetric analysis of motion pictures and still pictures of tornafoes, damage surveys, analysis of ground marks, doppler radar ard lidar, and aircraft probes of water spouts.

A general characterization of toinado intensity has been deve:oped by Fujita and Pearson (:973). Their FPP scale (Tables 2 and 3) reflects maximum windspeeds, path length, and math width as nbtalred from danage surveys. An F-scale rating from 0 to 6 can be assigned to a tornado, reflecting windspeeds and expected danage.
Table 2. Fujita scale rafter Fujita, 1971).

\begin{tabular}{|c|c|c|}
\hline F Scale & $\begin{array}{l}\text { Windspeeds } \\
\text { (mph) }\end{array}$ & Datnage \\
\hline FO & $40-12$ & 1 isht \\
\hline$F 1$ & $73-112$ & moderace \\
\hline 12 & $123-15 \vec{i}$ & considerable \\
\hline 153 & $158-276$ & severe \\
\hline F 4 & $207-200$ & devastating \\
\hline$F 5$ & $261-318$ & inoredible \\
\hline $\mathrm{Fo}$ & 3ly-snnic speed & inconceivable \\
\hline
\end{tabular}

iable 3. Pearson path lengtin and width siale (after fujlta and Pearson, 1973).

\begin{tabular}{lll} 
Scile & $\begin{array}{c}\text { Path Lengih } \\
(\mathrm{mi})\end{array}$ & \multicolumn{1}{c}{$\begin{array}{c}\text { Path Width } \\
\text { (yd) }\end{array}$} \\
0 & $0.3-0.9$ & $6-17$ \\
3 & $1.0-3.1$ & $18-55$ \\
3 & $3.2-9.9$ & $56-175$ \\
4 & $10-31$ & $176-556$ \\
& $32-99$ & $560-1584$ \\
5 & & $(0.3-0.9 \mathrm{mi})$ \\
6 & $100-315$ & $1760-5456$ \\
& & $(1.0-3.1 \mathrm{mi})$ \\
& $315-999$ & $5632-17,424$ \\
& & $(3.2-9.9 \mathrm{mi})$
\end{tabular}

\section{Tornado Structure Interaction}

Tornado-resistant design is now required for all niclear facilities. A recent ISNRC publication, "Design Basis Tornado for Nuclear Power
Plants" (Regulatory Guide 1.76, AEC, 1974), lists the requirements for tornado-safe designs and the physical parameters of a Desiga Basis Tornado 
(DBI). In part, the report states that "Nuclear power plants must be designed so that the plants ramain in a safe condition in the event of the most severe tornado that can reasonably be predicted to occur at a site as a result of severe meteorological conditions." Hence, absolute protection is required. Supplemental information to Regulatory Guide 1.76 may be found in AEC standard Review Plans $3.3 .1(1974), 3.3 .2(1974)$, and in Markee et al. (1974).

Structural damage resulting from cornadoes is usually divided into two categories, wind effects and missileimpact effects. Wind effects are further broken down into pressures induced by the wind flowing over and around the building and pressures induced by the low-pressure core region of the tornado. (Missilerelated forces and damages are not considered in this report.)

The DBT characteristics currently in use are given in Table 4 and the geographic-intensity regions are shown in Fig. 1. This list is far from complete but it does provide a starticiz point for tornado-resistant design. A complete listing and discussion $0^{\circ}$ USNRC and industry criteria has been given by Stevenson (1976).

Additionally, a suitable vortex model is needed to define the flow field. Regulatorv Guide 1.76 does not provide such a model. The most frequently used model is the Raskine Combined Vortex in which the tangential-velocity field is given by an inner region of solid-body rotation and an outer potential-flod region. Here,

$$
\begin{aligned}
& v=\frac{r v_{m}}{r_{m}}, 0 \leq r \pm r_{a i j} ; \\
& v=\frac{r_{m} v_{m}}{r}, \quad r_{m} \therefore r<a ;
\end{aligned}
$$

where $v_{m}$ is the maximum angential velocity and $r_{m}$ is the radius where $v_{\text {in }}$ occurs. Definitions of other terms are presented in the Nomencliture section. The use of chis madel is based or: the work of Hoecker (1960, 1961) who photogrammetrically analyzed the Dallas tornoto of April 2, 1957. Further qualitative justittcation for this model has been provided by more recent photogrammetric studies (Golden, 1976), field studies on dust devils (Sinclair, 1973), an' velocityfield mi asurements made on laboratory vorte: flows (Chang, 1969, 1971). From Hoec'ter's work, approximate expressicus for raclal and vertical velocity are

$$
\begin{aligned}
& u=\frac{v}{2}, \\
& w=\frac{2 v}{3} .
\end{aligned}
$$

The rotational component of the wind is usually defined as the vector 


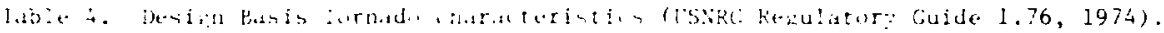

\begin{tabular}{|c|c|c|c|c|c|c|c|}
\hline but & 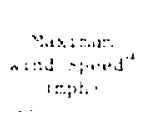 & 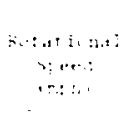 & $\begin{array}{c}a . \cdots \\
\because \ldots \\
4 \times x-\ldots\end{array}$ & 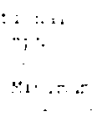 & 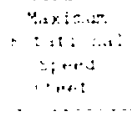 & 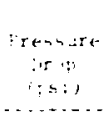 & 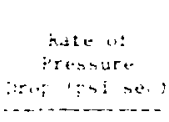 \\
\hline i & $\cdots$ & $\therefore+1$ & & & $\therefore .$. & : , & $\therefore y$ \\
\hline i! & [N, & $\therefore \cdots$ & $\therefore$ & & : . & $\ldots$ & $\therefore \ldots$ \\
\hline$\therefore:$ & $\therefore+$ & 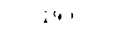 & & & . & $\therefore \therefore$ & 1.. \\
\hline
\end{tabular}

T:he -

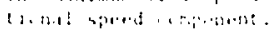

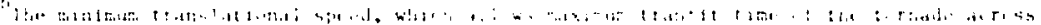

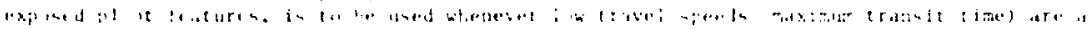

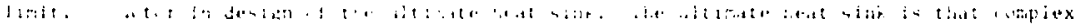

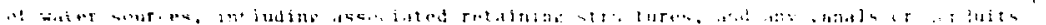

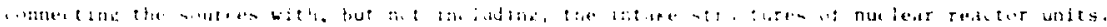

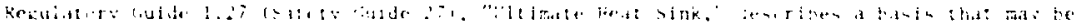

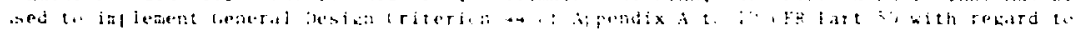

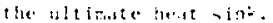

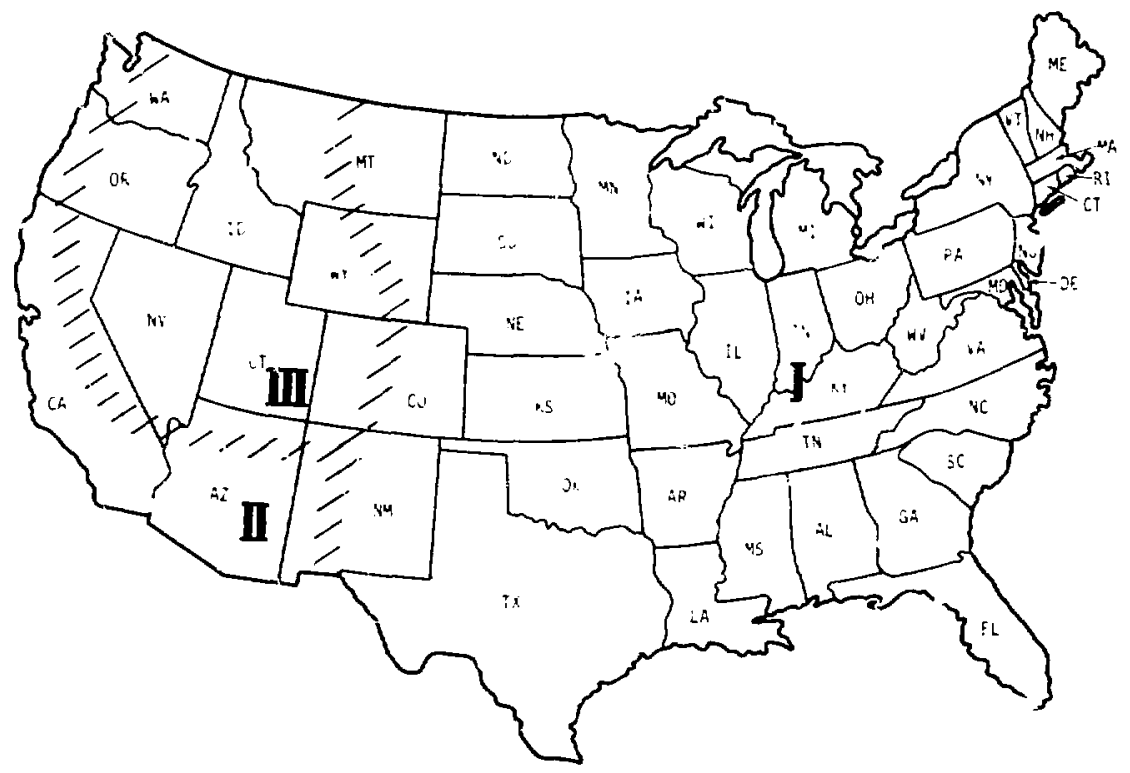

Fig. 1. Tornado intensity regions of the continental inited States. 
sum of the radial and tangintial conponents:

$$
v_{\text {rot }}=\sqrt{u^{2}+v^{2}} .
$$

The maximum windspeed $v_{\text {max }}$ is obtained with the addition of the translation speed of the tornado:

$$
v_{\max }=v_{\text {rot }}+v_{\text {trans }} .
$$

Equations (1) and (5) form the basts for most engineering wind-velocity pressure calculations.

To account for atmospheric pressure change (APC) effects, one additional equation is needed. If the cornado flow field is assumed to be axisymmetric and tangential, the radial momentum equation reduces to the cyclostrophic wind equation:

$$
\frac{\partial P}{\partial r}=\frac{\rho v^{2}}{r}
$$

This relationship may be thought of as a balance between inward pressure forces and outward centrifugal forces. Substituting Eq. (1) into Eq. (6) and integrating yields, the pressure field is abtained: '

$$
\begin{aligned}
& P=P_{0}-\frac{\sigma v^{2}}{2}\left(2-\frac{r^{2}}{r_{\pi}^{2}}\right), \\
& 0 \leq r \leq r_{m} ;
\end{aligned}
$$

$$
\begin{gathered}
p=P_{0}-\frac{\rho v_{m}^{2}}{2}\left(\frac{r_{m}^{2}}{r^{2}}\right), \\
r_{m} \leq r<w ;
\end{gathered}
$$

where $P_{0}$ is the ambient atmospheric pressure. Hence, the second term on the right side of each expression may be thought of as a pressure deviation (APC) from ambient conditions.

With the DBT and torwado vortex model thus defined, all that remains is to convert the wind field paraneters into external structural pressuras. Design forces obtained with an ANSI Standardlike approach are outlined below.

\section{CALCULATING velocity PRESSURES}

The velocity (stagnation) pressure is related to velocity by

$$
P=\frac{1}{2} \rho v^{2} \text {. }
$$


lpon substitution of the rotational and tangential components of the vortex flow into Eq. (8), we obtain an expression for velocity pressure as a function of radial distance from the center oi the rornado:

$$
p(r)=\frac{i}{2} n\left[v_{\operatorname{rot}}(r)+v_{\text {trans }}\right]^{2} \text {, }
$$

ar

$$
r(r)=\frac{1}{2}:\left(\sqrt{u^{2}+v^{2}}+v_{\text {trans }}\right)^{2} .
$$

From the Rankine vortex model,

$$
\begin{aligned}
& P(r)=\frac{1}{2}:\left[\frac{r}{r_{m}} v_{\operatorname{rot}}(\max )\right]^{2}, \\
& 0 \leq r \leq r_{\text {r }} ;
\end{aligned}
$$

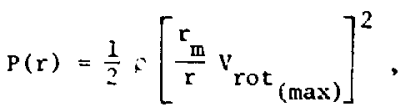

$$
\begin{aligned}
& r \leq r \leq \infty \text {. }
\end{aligned}
$$

Hence.

$$
p_{\max }=\frac{1}{2}: V^{2} \operatorname{rot}(\max )
$$

or

$$
\mathrm{p}_{\text {max }}=0.00256 \mathrm{v}^{2} \text { rot }_{(\text {max })} \text {, }
$$

where $p_{\text {max }}$ is the maximum velocity pressure (psf) and $V_{\text {rot }}$ (max) $_{\text {is che }}$ is che maximum wind speed (mph). The constant term $U .00256$ incorporates the standari sea-level density of air (0.07651 pc: at $760 \mathrm{~mm}$ of mercury and at $15^{\circ} \mathrm{Cj}$. \& plot of velocity pressure and APF vs radius is given in Fig. 2 .

CALC.ULATING BUILDING SIZE COEFFICIENT

From Eq. (12), we see that veiocity pressure is not uniform. For design purposes, it is conventent to define a size coefficient, $\mathrm{C}_{\mathrm{s}}$, as

$$
c_{s}=\frac{p_{\text {avg }}}{P_{\max }} .
$$

We obtain $C_{s}$ by integrating $P(r)$ over the contributing width, $L$, of the building:

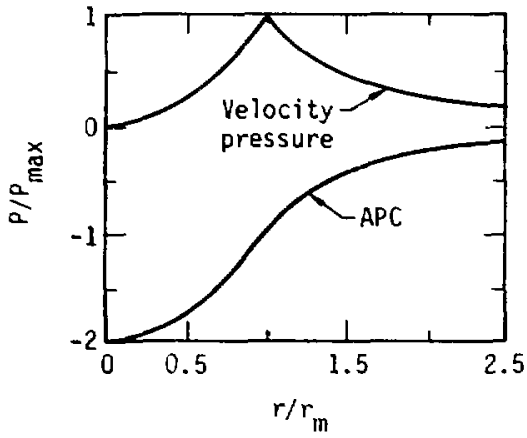

Fig. 2. Velocity pressure and APC for a Rankine vortex. 


$$
\begin{aligned}
P_{\text {avg }} & =\frac{\rho v_{\text {rot }}^{2}}{2 \mathrm{Lax})} \\
& \times\left(\frac{4 \mathrm{r}_{\mathrm{m}}}{3}-\frac{\mathrm{a}^{3}}{3 \mathrm{r}_{\mathrm{m}}^{2}}-\frac{\mathrm{r}_{\mathrm{m}}^{2}}{\mathrm{~b}}\right) .
\end{aligned}
$$

This integraitrn is maximized when $a b=r_{m}^{2}$ and the design-size coefficient becomes

$$
c_{s}=\frac{4 r_{m}^{3}-a^{3}-3 a r_{m}^{2}}{3 L r_{m}^{2}}
$$

where

$$
a=-\frac{L}{2}+{\sqrt{\frac{L^{2}}{4}+r_{m}^{2}}}^{2}
$$

\section{DETERMINING JESIGN VELOCITY PRESSURES}

External pressure coefficients, $C_{p}$, are used to obtain design forces on exterior walls and corners. Values for $C_{p}$ are given in Section 6.5 of the ANSI Standard and are listed here in Appendix B. Pressure coefficients are experimentally obtained for stralght wind flows around rectangular structures. The design pressure for rigid frames is

$$
P=C_{s} C_{p} P_{\text {max }} \text {, }
$$

while the design pressure for individual wall panels is

$$
P=C_{p} P_{m a x} \text {. }
$$

From Eq. (7), the maximum change in atmospheric pressure is fcund to be

$$
\mathrm{AP}_{\text {max }}=\mathrm{v}_{\mathrm{m}}^{2} .
$$

\section{COMBINING WIND LUADING FEFECTS}

Tornado wind-loiading effects are accounted for by ipplying the following definitions :

$$
\begin{aligned}
& w_{t}=w_{q}, \\
& w_{c}=w_{a} . \\
& w_{t}=w_{q}+\frac{1}{2} w_{a} .
\end{aligned}
$$

where $k_{c}=$ design load, $w_{q}=1$ load due to wind velocity, and $k_{a}=$ luad due to APC. Equation (22) arises when summing $W_{q}$ and $w_{a}$ at $r=r_{m}$. Here, the APC is exactly half of its maximur. value.

The furegoing discussion assumes a desigr vor:ex model that has no vertical variation in $u$ or $v$. Most current design models are based on Hoecker's analysis and some include vertical varistions in $v$ near the grount. Shanahan (1976) has developed several design-purpose mcjels that include velocity components and gradients; a basic Rankine profile is used as a basis, 


\section{Tornado Simulation}

\section{THEORETICAL MODELS}

The tornado flow field can be visualized in four regions (Lewellen, 1976) which are shown in Fig. 3. In brief, these regions may be described as follows:

- Region I: The core-flow region;

it extends radially from the cornado centerline out to perhaps a few thousand meters. Vertically, it extends from about a hundred meters above ground co the cloud ceiling.

- Region II: The boundary-layer region; flow is sirongly influenced by the ground.
- Region III: The corner-flow region; approximate $r$ and .: dimensions are 200 and $100 \mathrm{~m}$. Boundary effects are dominant here also. All components of velocity and velocity gradient are important.

- Region IV: The top layer; flow extends from the top of Region I into the thunderstorm cell.

The continuity and momentum equations for axisymetric, incompressible flow are given in the following cylindrical coordinate form:

$$
\begin{aligned}
& \frac{1}{r} \frac{\partial(r u)}{\partial r}+\frac{\partial w}{\partial z}=0 ; \\
& \frac{\partial u}{\partial t}+u \frac{\partial u}{\partial r}+w \frac{\partial u}{\partial z}-\frac{v^{2}}{r}=-\frac{1}{0} \frac{\partial P}{\partial r}+v\left(\frac{\partial^{2} u}{\partial r^{2}}+\frac{1}{r} \frac{\partial u}{\partial r}-\frac{u}{r^{2}}+\frac{\partial^{2} u}{\partial z^{2}}\right), \\
& \frac{\partial v}{\partial t}+u \frac{\partial v}{\partial r}+w \frac{\partial v}{\partial z}+\frac{u v}{r}=v\left(\frac{\partial^{2} v}{\partial r^{2}}+\frac{1}{r} \frac{\partial v}{\partial r}-\frac{v}{r^{2}}+\frac{\partial^{2} v}{\partial z^{2}}\right), \\
& \frac{\partial w}{\partial t}+u \frac{\partial w}{\partial r}+w \frac{\partial w}{\partial z}=-\frac{1}{P} \frac{\partial P}{\partial z}+v\left(\frac{\partial^{2} w}{\partial r^{2}}+\frac{1}{r} \frac{\partial w}{\partial r}+\frac{\partial^{2} w}{\partial z^{2}}\right)-g .
\end{aligned}
$$




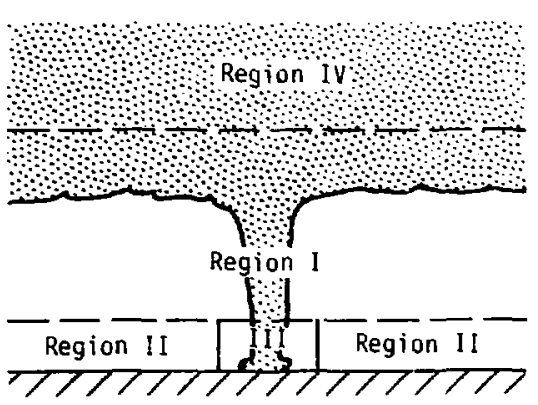

Fig. 3. Tornado flow regions (after Lewellen, 1976).

Neglected in this formulation is background rutation of the earth, thermodynamic effects, and spatial variation of the diffusion (viscosity) coefficient.

If $u$ and $w$ are neglected, the simplest solution to Eqs. (23-26) that is applicable to Region I is given by the Rankine vortex model. Eq. (1). Angular momentum is satisfied everywhere except in the transition region where $r=r_{m}$. The pressure distribution follows from Eq. (24) as given in : 6 . (7). The Rankine formulation is usually completed by assuming a hydrostatic pressure balance in the vertical direction where

$$
\begin{array}{ll}
\mathrm{v}=\frac{\mathrm{r}_{\mathrm{m}}}{\mathrm{r}} \mathrm{v}_{\mathrm{m}}, & 0 \leq \mathrm{r}<\mathrm{r}_{\mathrm{m}} ; \\
\mathrm{v}=\frac{\mathrm{r}}{\mathrm{r}_{\mathrm{m}}} \mathrm{v}_{\mathrm{m}}, & \mathrm{r}_{\mathrm{m}} \leq \mathrm{r}<\infty ;
\end{array}
$$

$$
\begin{aligned}
& \frac{\partial p}{\partial r}=\frac{v^{2}}{r} \\
& \frac{\partial p}{\partial z}=-\partial g .
\end{aligned}
$$

In the Rankine vortex model, the following assumptions are made: axisymmetric flow, incumpressible flow, steady flow, $u=w=0$, and all $u$ and $w$ gradjents are zero.

inother simple solution th tis. (23-26) that includes all velucity components is the Burgers-Rott vortex mudel. This model was ubtained independently by Burgers in 1948 ans by Rote in 1958. Here,

$$
\begin{aligned}
& u=-a r, \\
& v=\frac{r_{a}}{2 \pi r}\left[I-\exp \left(-\frac{a r^{2}}{2 v}\right)\right], \\
& w=2 a z, \\
& P(r, z)=v(0,0)+\int_{0}^{r} \frac{v^{2}}{r} \\
& \therefore d r-\frac{a^{2}}{2}\left(r^{2}+4 z^{2}\right),
\end{aligned}
$$

where $\Gamma_{\infty}=r v_{\mid r}=\infty$, a constant called the circulation, and $2 \mathrm{a}=$ horizontal convergence, a constant. The BurgersRott model gives maximum velocity and pressure drops of 


$$
\begin{aligned}
& v_{\mathrm{m}}=\frac{0.72}{2 \pi r_{\mathrm{m}}}\left(\mathrm{r}_{\mathrm{m}}=1.12 \sqrt{2 v / \mathrm{a}}\right) . \\
& \Delta \mathrm{P}_{\max }=1.68 \rho v_{\mathrm{m}}^{2} .
\end{aligned}
$$

A third, more general series of lutions is given by Donaldson and slivan (1960) and Sullivan (1959) gives a two-celled solution with the following velocity components:

$$
\begin{aligned}
u= & -a r+\frac{6 v}{r} \\
& \times\left[1-\exp \left(-\frac{a r^{2}}{2 v}\right)\right], \\
v= & \frac{\Gamma_{\infty}}{r}\left[\frac{H\left(a r^{2} / 2 v\right)}{H(\infty)}\right], \\
w= & 2 a z\left[1-3 \operatorname{cxp}\left(-\frac{a r^{2}}{2 v}\right)\right],
\end{aligned}
$$

where,

$$
\begin{aligned}
H(x)= & \int_{0}^{x} \exp [-t+3 \\
& \left.\times \int_{0}^{t} \frac{\left(1-e^{-s}\right)}{s} d s\right] d t .
\end{aligned}
$$

It should be noted that in this solution, $v$ is essentially decoupled from $u$ and $w$.

A comparison of the tangential velocity profiles for these three models is given in Fig. 4 where the Burgers-Rott and Sullivan models have been normalized to have the same $\Gamma_{\infty}$ and a/v ratio.

other vortex models are given by Gutman (1957), Long (1961), and Lewellen (1962). Two-celled models are developed by Sullivan (1959), Kuo (1966), and Bellamy-Knights (1970). Models dealing with the flow in Regions II and III are given by Smith and Smith (1965), Chi et al. (1969), Burggraf et al. (1971), Carrier (1971), Kuo (1971), and Serrtn (1972).

Advances in computing capability have enabled the development of several numerical models of the cornado vortex. The vortex is modeled as an axisymmetric flow in the $r, z$ plane. Incompressibility is usually assumed. The type of numerical scheme, the treatment of boundary conditions, and the treatment if viscous effects vary from model to roodel.

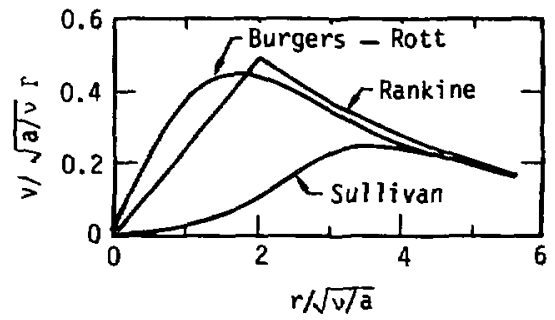

Fig. 4. Comparison of tangential velocity profiles (after Lewellen, 1976). 
Computer programing of the continui:y, momentum, and energy equations is accomplished by various finite-difference techniques. The equations are usually cast in a vorticity-stream function form or in the so-called primitive-variable form where $u, v, w$, and $P$ are computed directly. Results are strongly influenced by the choice of boundary conditions. Usually, one or more assumptions must be made concerning the velocity profiles at the $r$ and $z$ computational boundaries. The treatment of $v$, which must be regarded as an eddy viscosity, alsu strongly influences the results. Lewellen (1976) discusses the need for a better model of atmospheric turbulence in this regard.

Recent calculacions of vortex flow in and above the boundary layer, include Bode et al. (1975); Hsu and Tesfamariam (1976); Jischke and Parang (1975); Chi and Jih (1974); Harlow and Stein (1974); Mal'Bakhov (1972); Davies-Jones and Vickers (1971); and Wipperman et al. (1969).

\section{LABORATORY MODÉLS}

Laboratory vortex flows have provided valuable insight into the fluid dynamics of cornadoes. Numerous experiments have been undertaken, most in the last fifteen years. Historically, these efforts fall into two general categories, rotating tank experiments and wrtex chamber experiments. Yany of tis slows generated strongly resimble tornadues, at least outwardy. However, ls discussed by Davies-Junes $(1976)$, phosical appearance alone does not zuarantee that the model is similar to a tornado.

Similarity requirements betwen fult-scale and laboratory sinulations apply eciually to the more common "straigh: wind" situltion. Ciermak (1973) out lines the following similarity requirements inposed by the conservation of mass, momentum, and energy:

- Lndistorted scaling of genmetry.

- Equal Russby number, Ro $=L^{\prime} / \ldots$

- Equal Richardson number, $R i=(\therefore I / T)\left(I / L^{2}\right) g$.

- Equal Reynolds number, $\operatorname{Re}=\mathrm{LL} / \mathrm{L}$.

- Equal Prandel number, $\operatorname{Pr}=\because \because c_{p} / k$.

- Equal Eckert number, $E c=t^{2} / c_{p} \therefore T$.

Ad. :ionally, a similarity is required for the model surface and approach flow conditions (see rhang, 1971, for a discussion of similarity requirements for tornado (lows). 
In all probabilicy, no Iaboratury vortex mulel will ever be able to sat is iy every similarity requirement hut, fortunately for the engineer, titis may not be necessary. The kichardson, lrandt, and Eckert number requirements may be discarded lin the present in attempting to understand cornado-structure interlition. litimatelv, however, these purameters cimnot be ignored if all physidal elfects are to be considered. lormadoes are typlcally high-Rossbynumber thows based on the background rotation of the earth and typically are of $O\left(10^{3}-10^{4}\right.$ ) (Morton, 1966 ). Deiluing tangential and radial kevalds numbers, we have

$$
\begin{aligned}
& \text { Re }=: t_{t}, \\
& \text { Re }=u r_{m}:
\end{aligned}
$$

where $y=$ miss ilow rate. We see also that Ke, and he typically are if $O\left(10^{9}\right)$, based on the laminar value ut kinematic viscosity. hile Rossbynumber similarity can be obtained in the laboratory. (o) date, all models are several orders of magnitude low for Re, and Re, similarity. When considering the aerodynamics of buildings, Reynolds number will be important.

For laburatory models, only four independent nondimensional numbers exist (bavies-Jones, 1976). Referring to Figs. 5 and 6 , we define $r_{o} / r_{s}$ as the ratio of convergent and confluent zone radii, $h / r_{0}$ as $a$, the aspect ratio, $-r / 2 Q$ as $S$, the swirl ratio, and $Q / 2^{-}, h$ as $X$, the radial Re:nolds number for a liburatory vortex.

l.ong $(1956,1958,1961)$, Granger (1966, 197:), Turner and Lilly (1963), Turner (1966), amung others, have sonducted rotating tank experiments. In such experiments, water is extracted from the bottum or top of a cylindrical tank and vorticity is provided by rotating the tank. Turner and Lilly (1963) simulated buoyant effects by injecting suitable nuclei into carbonated water near the axis of rutation.

Sure recent experimental programs have consisted mostly of vorcex chambers. In these, air is used as the working tluid and, typically, a ian provides an uodraft. Vorticity is introduced mechanically by a rotating wire screen or disk and flow visualization is accomplished with smoke, drv ice, or helium bubbles. Figure 5 illustrates the vortex model used by Chang (1969), Ying and Chang (1970), and Wan and Chang (1972) at Catholic iniversity. Velocity and pressure measurements were made, respectively, with a hot-film anemometer and a static-sphere probe. The observations of ling and Chang (1970) include: 
- A core dlameter above the ground boundar, layer $r_{c} \approx 5 \mathrm{~cm}$.

- Turbulent flow in the boundary layer.

- A tangential velocity field that closely resembled a Rankine vortex in the three reported rests.

- Small u, except In tne lowest $10 \mathrm{~cm}$.

- A sharp, maximum radial-inflow velocity occurring close to the ground (at $z=0.6 \mathrm{~cm}$ ) and varying in proportion to the circulation strength.
- Small w outside of the core region with maximum vertical velocity occurring at the vortex centerline, increasing slowly with height.

- A pressure minimum at the core.

Perhaps the most frequently referenced vortex chamber is Ward's device at the Nationai Severe Storms

Laboratory (NOAA-NSSL) in Norman, Oklahoma. Experiments performed there are reported by Ward (1972), DaviesJones (1973), and Jischke and Parang (1974, 1975). Ward's device (see Fig. 6) attempts io model the radial

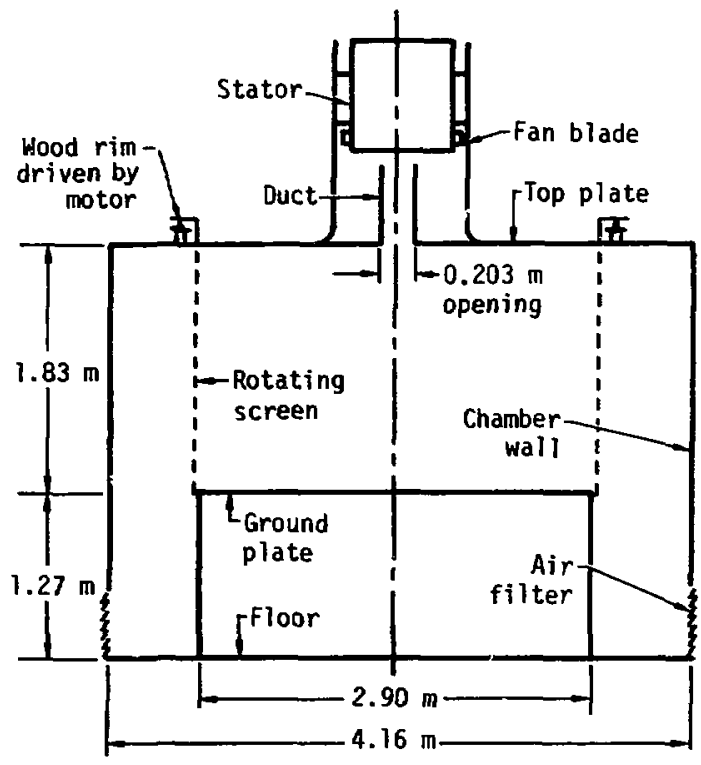

Fig. 5. The vortex chamber at Catholic Unive.'sity (after Wan and Chang, 1972). 


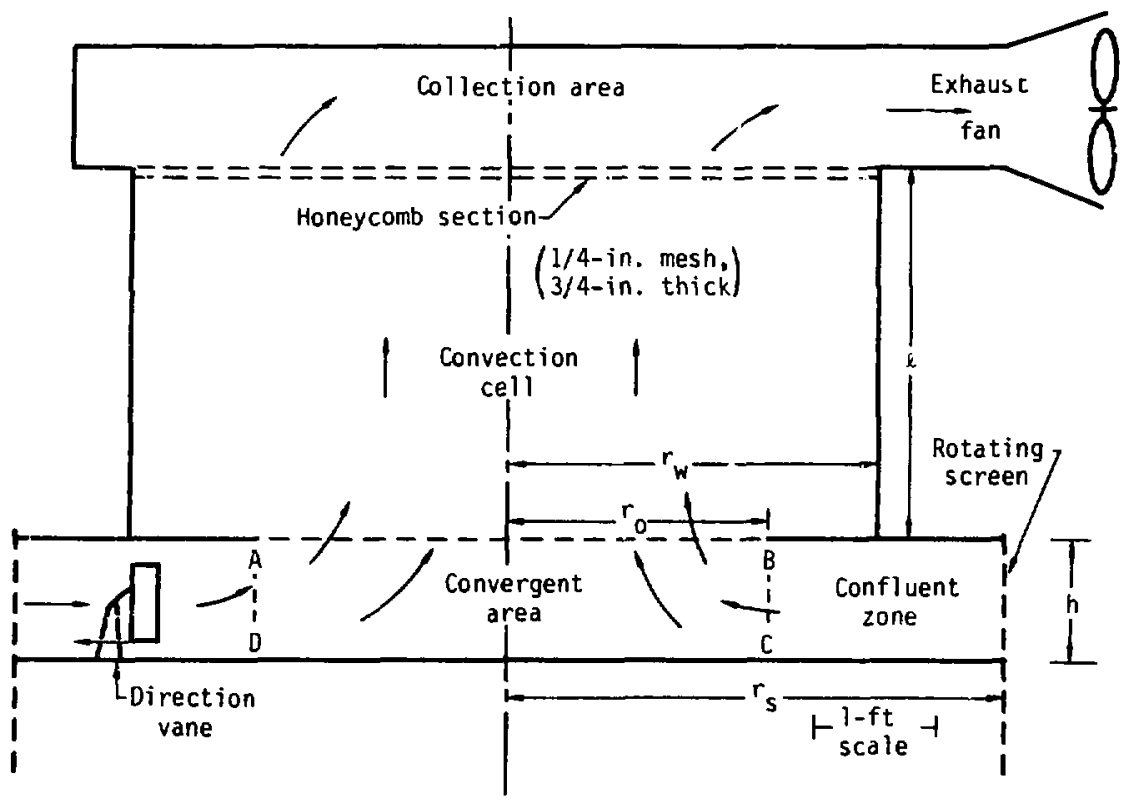

Fig. 6. Ward's vortex chamber (after Davies-Jones, 1973).

convergence and vertical updraft geometry of a thunderstorm in an attempt to induce a more realistic tornadolike vortex. Ward (1972) notes three characteristics of tornado vortex flow:

- A characteristic surface-pressure profile that includes a highpressure ring outside the lowpressure core. This profile arises when the pressure effects of purely tangential flow (cyclostrophic balance) are combined with purely radial flow.

- The tendency of the vortex core to bulge.

- Flow transition to multiple vortices. Ward concludes that this transition is sensitive to the inflow angle $\theta$ defined by the ratio $\theta=\tan ^{-1}(v / u)$ as measured at the rotating screen. 
From these experiments, Varo also concludes that for a given test geometry, the vortex-core size can also be found from the inflow angle. However, Davies-Jones (1973) shows that the volune flow rate, Q, must also be included. Defining the swirl ratio, $S$, as

$$
S=\frac{r_{0} \tan \theta}{2 h},
$$

or

$$
S=\frac{r_{0}{ }^{\top} \text { screen }}{20},
$$

Davies-Jones concludes, after a careful analysis of Ward's data, that the core radius is a function of the swirl ratio, alone, rather than of the inflow angle. This fact has important implications for vortex-building, geometric similarity in laboratory modeling of tornado-structure interaction.

The most extensive tests with ward's device have been made by Jischke and Parang (1975). Their findings include:

- A pressure minimum at the core.

- $u$ and $v$ vary as $1 / r$ and $w$ is negligible in the confluent zone (i.e., where $r$ is large).
- u varies as r, v varies as lir. and $w$ varies as $z$ in the convergent area (i.e., at incermediat. values of $r$ outside the sure).

The vortex chamber oi Hsu and Fattahi is Iowa state lniversity is shown in Fig. 7. In this model, a jet of air is forced dowmward by a fan. Vor:icity is introduced by rotating a honeycomb disk at $1700 \mathrm{rpm}$. Tests with and without the ground plate conducted by Hsi and Fat tahi (1975) show:

- A variable sized core with $r_{c}=0.5 \mathrm{in}$. near the ground. - $u$ is very small except in the core regiun at distances grenter than $13 \mathrm{in}$. above the grourd.

- The v profile is generally Rankine in nature near the ground; fur a greater than 13 in.. $v$ increases with $r$ and a j.mp transition is seen at $r=0$ in.

- $y$ is a function of $z$ only and increases with height; a jump transition is also seen at $r=6 \mathrm{in}$.

These three vortex chambers appear to be potentially the most applicable to the problems concerning tornadostructure interaction. Chang (1971) conducted a preliminary laboratory study to determine the feasibility of 


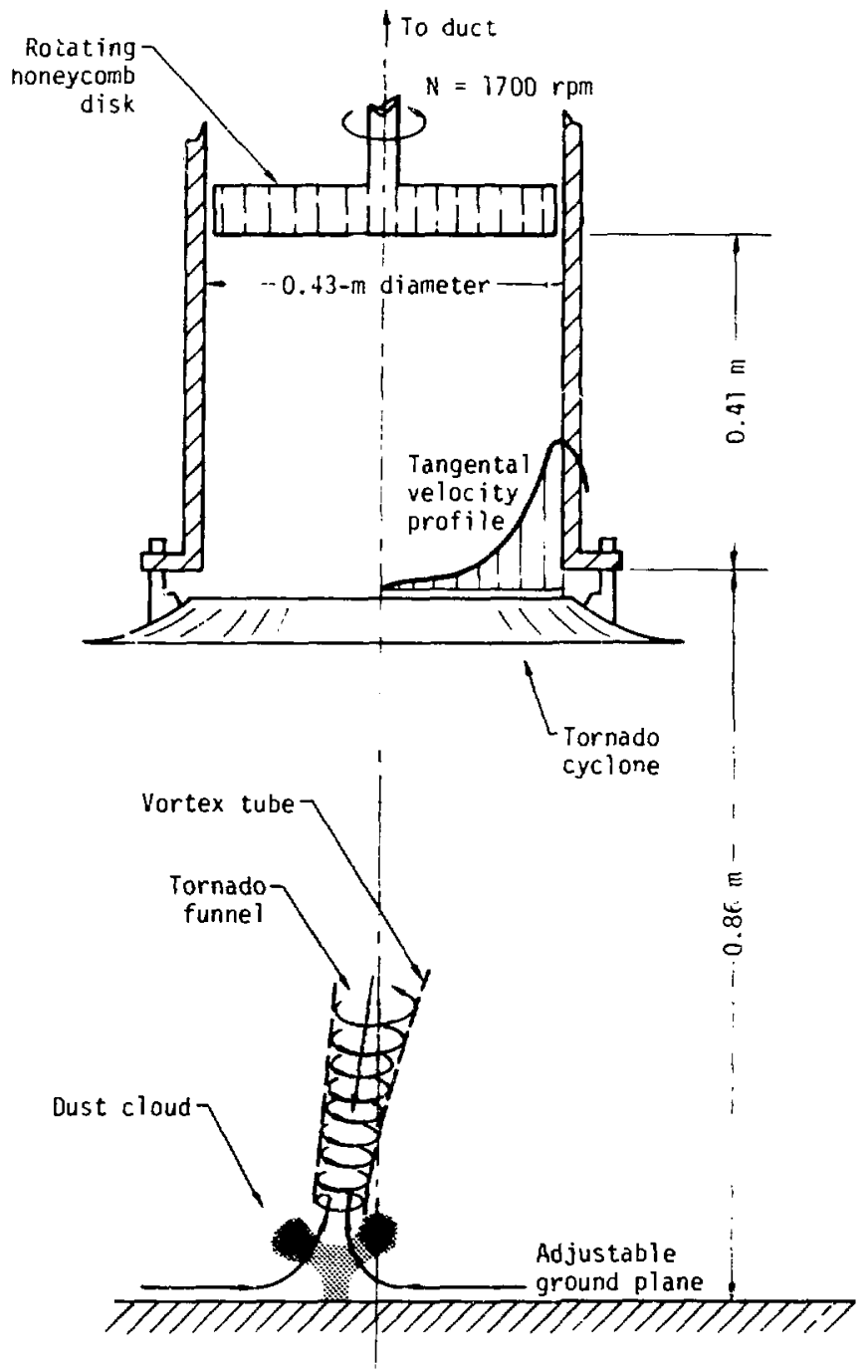

Fig. 7. Hsu's vortex chamber (atter lisu and Fattahi, 1976). 
a vortex simulator to study tornadowind loadings on a building. A 2-in. cube was instrumented with 80 pressure taps and was allowed to interact with a quasi-stationary vortex. The experimentally obtained pressure contours for both a high. and low-swirl ratio case yield pressure coefficient, $c_{p}$, contours ranging from 0 to -0.7 .
Net values of $C_{p}$ for each face of the cube are thetefore within this range. It is most interesting to note that no fositive pressures were recorded, indicating that the APC dominates tile dynamic forces everywhere. (See Davies-Jories, 1976, for a more complete discussion of lat vratory vortex models.)

\section{Numerical Modeling of Tornado Structure}

Numerical values for building surfaze pressures are obtafned by modeling the tornado-structure interaction phenomena in two dimensions on the ground plane. Hence, for purposes of this study, all vertical components of velocity, velocity gradient, and pressure gradient are Ignored. A rectangular building is placed in the flow field of the model tornado. In the series of numerical tests that follow, the rornado is Givin an initial horizontal velocity profile of a Rankine vortex with characteristics corresponding to the USNRC Design Basis Tornado.

The tornado is allowed to interact with the bullding for 5 to $10 \mathrm{sec}$, long enough for dynamic effects to develop. To calculate the flow fielc, we use a two-dimensional, multifluid, Eulerian hydrodynamics code, BBC. The physical characteris-
Lics of the problem are specified by rectangular zoning and an fintially specifled flow field. The problem is advanced in time by four Lagrangian subcycles with a zone remap at the end of each time cycle (Sutcliffe, 1974).

A plan view of a typical twodimensional building is shown in Fig. 8 together with the notation that describes the problem. Referring to Fig. 8, we define buflding-force coefficients $C_{F x}$ and $C_{F y}$ as

$$
\begin{aligned}
& C_{F_{x}}=\frac{F_{x}}{(1 / 2) \rho U^{2} W H}, \\
& C_{F_{y}}=\frac{F_{y}}{(1 / 2) \rho U^{2} L H} .
\end{aligned}
$$

We made seven TSI runs using three different building sizes. In four cases, the tornado translates into 


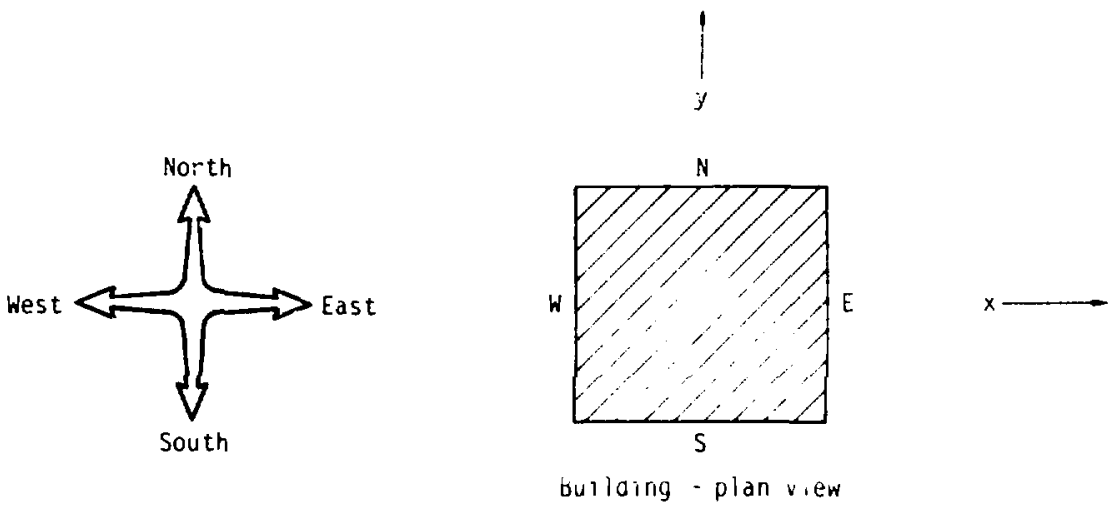

Fig. 8. Labeling conventions for tornaco-structure interaction studies.

the building while, in the three other cases, a stationary vortex is considered. Following is a gec:netric description of each run plus timehistory plots of the bullding surface pressures. We then draw a comparison with the ANSI Standard approach in three areas: design pressures for rigid frame, design pressures for individual wall panels, and design pressures for wall corners. In general, we made the most conservative comparison with AXSI design pressures. Ocher comparisons are possible and would be necessary if an actual structure were being designed. A tabular listing of pressures and force coefflclents is given in Appendix $\mathrm{C}$. 
TORNADO STRLCTIRE IXTERACTION:

RLX $\times 10,1$

Building aimensions:

$$
\begin{aligned}
& 200 \text { Et }(x), \\
& 200 \text { et }(y) .
\end{aligned}
$$

Initial vortex characteristics:

$$
\begin{aligned}
& v_{m}=290 \mathrm{mph}, \\
& v_{\text {rot }}=290 \mathrm{mph}, \\
& v_{\text {trians }}=0 \mathrm{mph}, \\
& r_{\mathrm{m}}=150 \mathrm{it} .
\end{aligned}
$$

Litial displacement of portex center $\therefore$ but building center:

300 it to the west.

ivuputational zone widch:

20 Et on all building. suriaces.

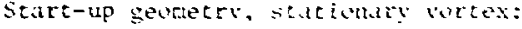
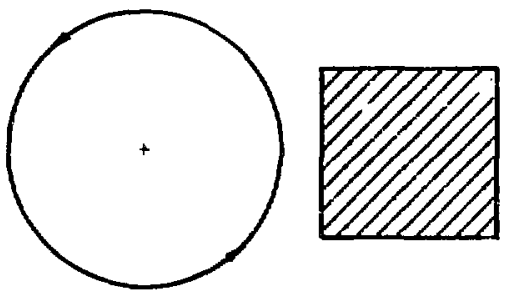

See Figs. 9 and 10 for pressure-time histories and ait flow patterns for this run.

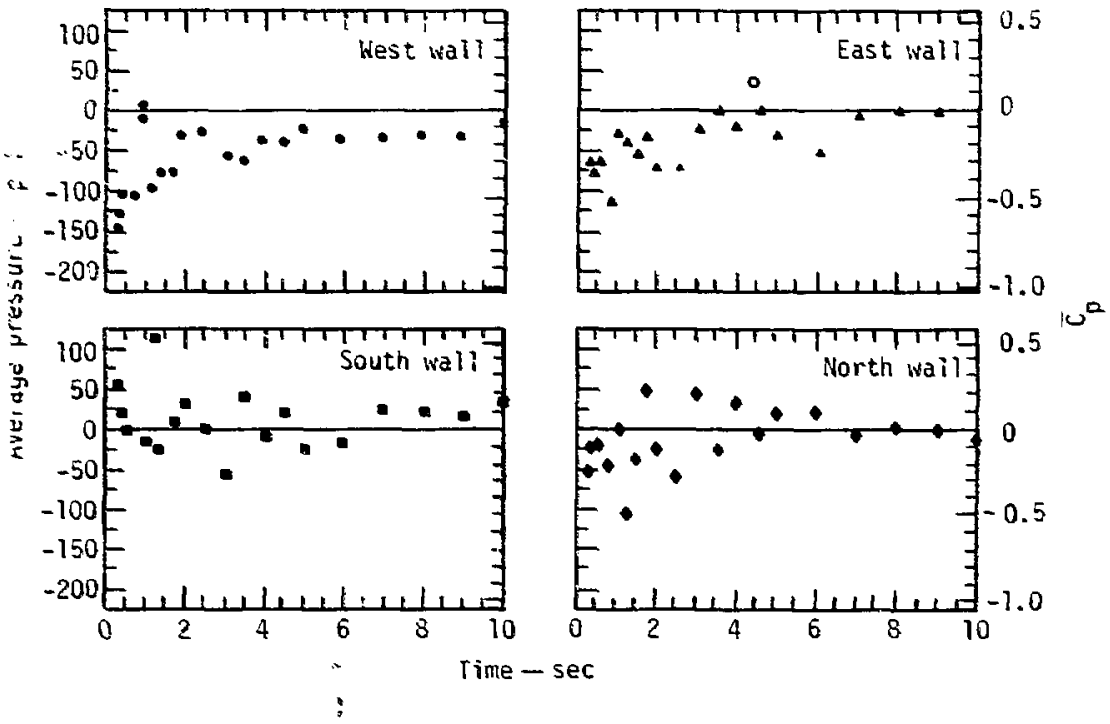

Fig. 9. Surface pressures for run No. 1. 

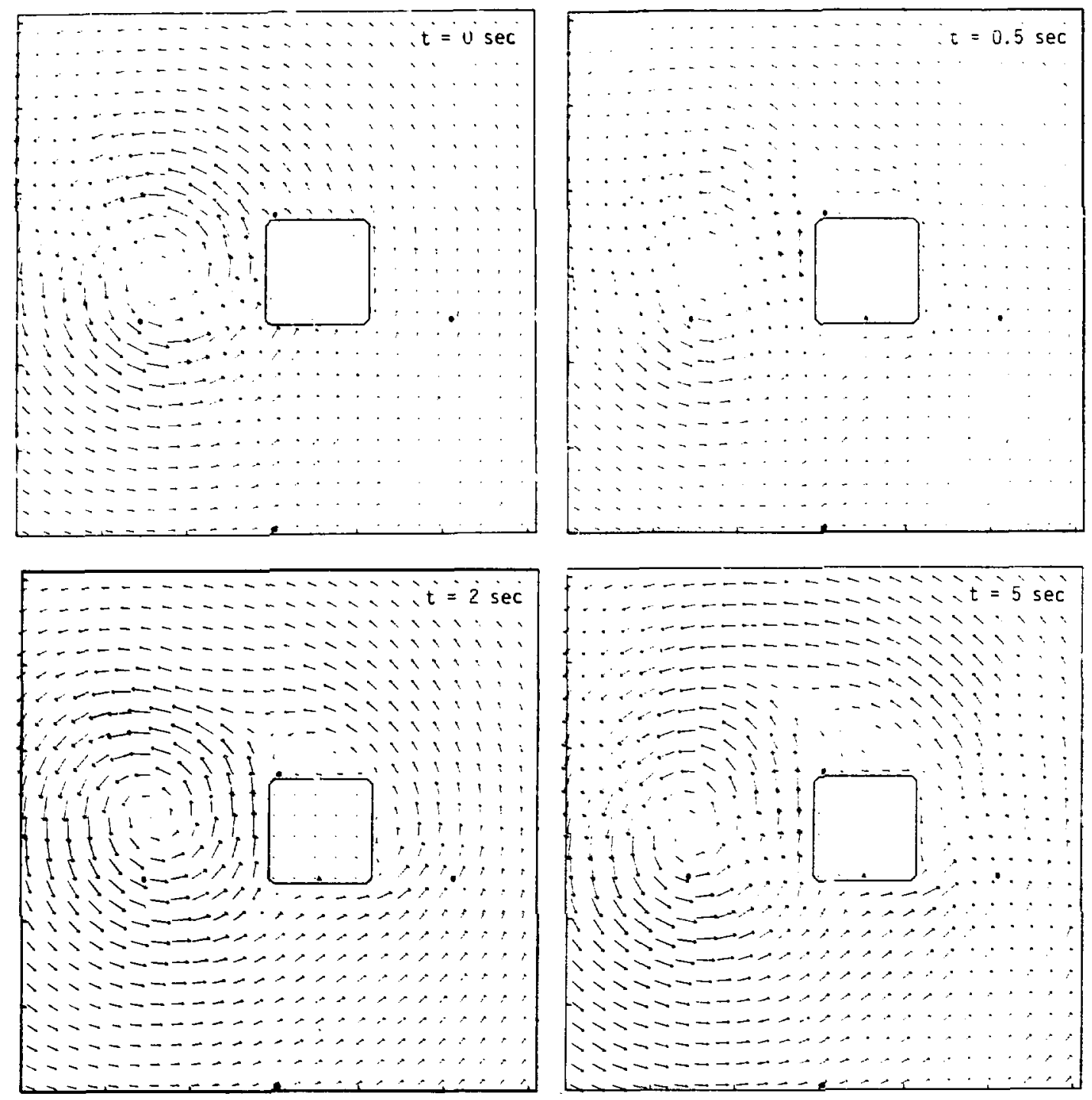
TORNADO STRUCTURE INIERACIION:

RUN No. 2

Building dimensions:

200 ft $(x)$,

200 ft $(y)$.

Initial vortex sharacteristics:

$$
\begin{aligned}
v_{m} & =290 \mathrm{mph}, \\
v_{\text {rot }} & =290 \mathrm{mph} . \\
v_{\text {trans }} & =70 \mathrm{mph} \text { (west to east), } \\
r_{\mathrm{m}} & =150 \mathrm{ft} .
\end{aligned}
$$

Initial displacement of vortex center from building center:

300 it to the west.

Computational zone width:

20 ft on all building surfaces.
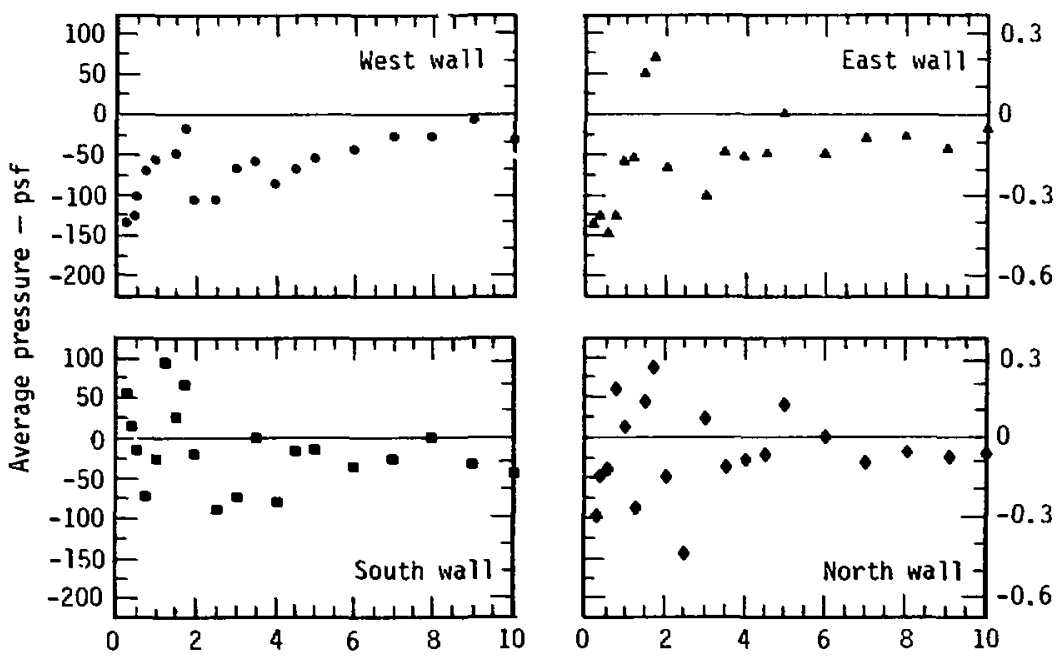

See Figs. 11 and 12 for pressure-time histories and air flow patterns for this run.

Time $-\sec$

Fig. 11. Su:face pressures for run No. 2 . 


$$
\text { ...... }
$$

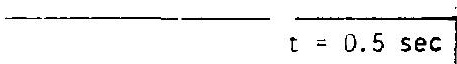



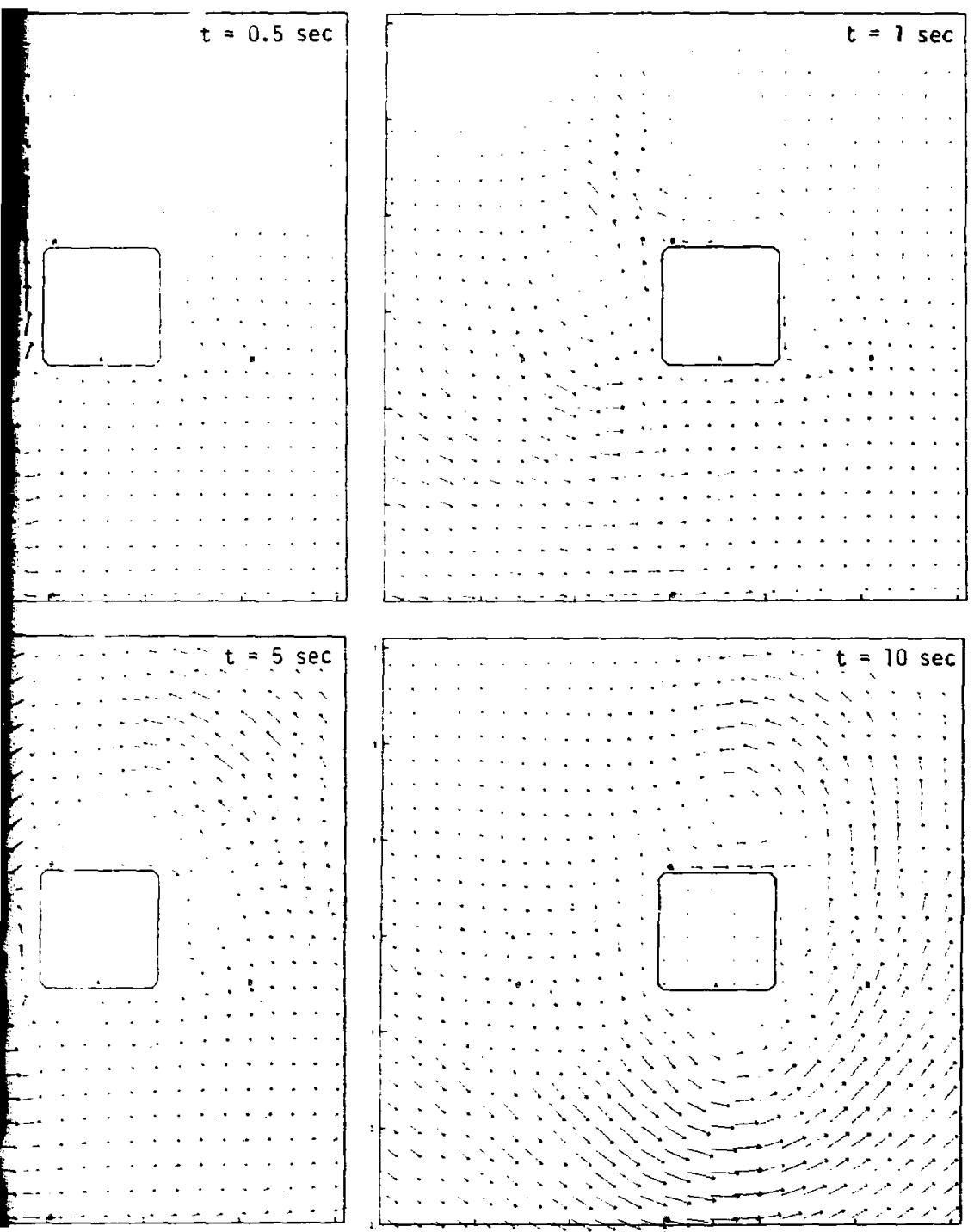

Fig. 12. Velocity vector plots for run No. 2. 
TORNADO STRUCTURE INTERACTION:

RUN NO. 3

Building dimensions:

200 ft $(x)$,

$200 \mathrm{ft}(y)$.

Initial vortex charactnristics:

$$
\begin{aligned}
& v_{m}=290 \mathrm{mph}, \\
& v_{\text {rot }}=290 \mathrm{mph}, \\
& v_{\text {trans }}=0 \mathrm{mph}, \\
& r_{m}=150 \mathrm{ft} .
\end{aligned}
$$

Initial displacement of vortex center from building center:

$100 \mathrm{ft}$ to the west,

$100 \mathrm{ft}$ to the south,

Vortex is positioned over the southwest corner of the building.
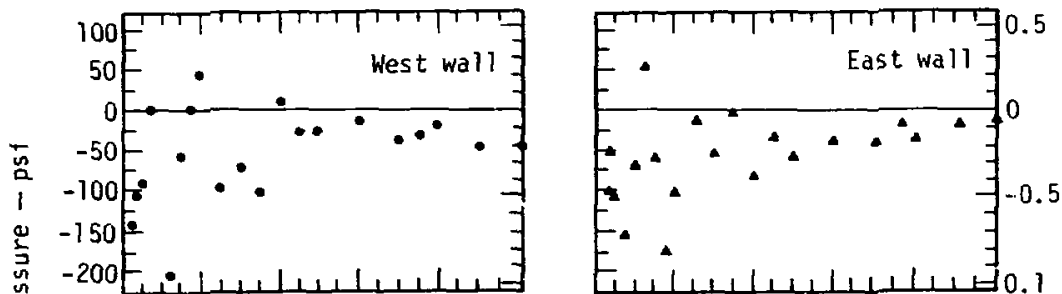

See Figs. 13 and 14 for pressuretime histories and air flow patterns for this run.

$20 \mathrm{ft}$ on all building surfaces.

Start-up geometry, stationary vortex:

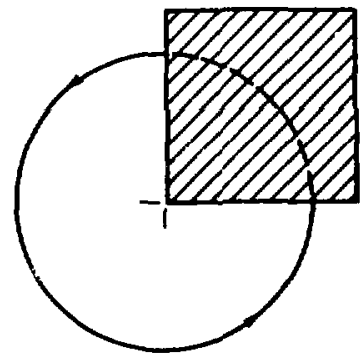



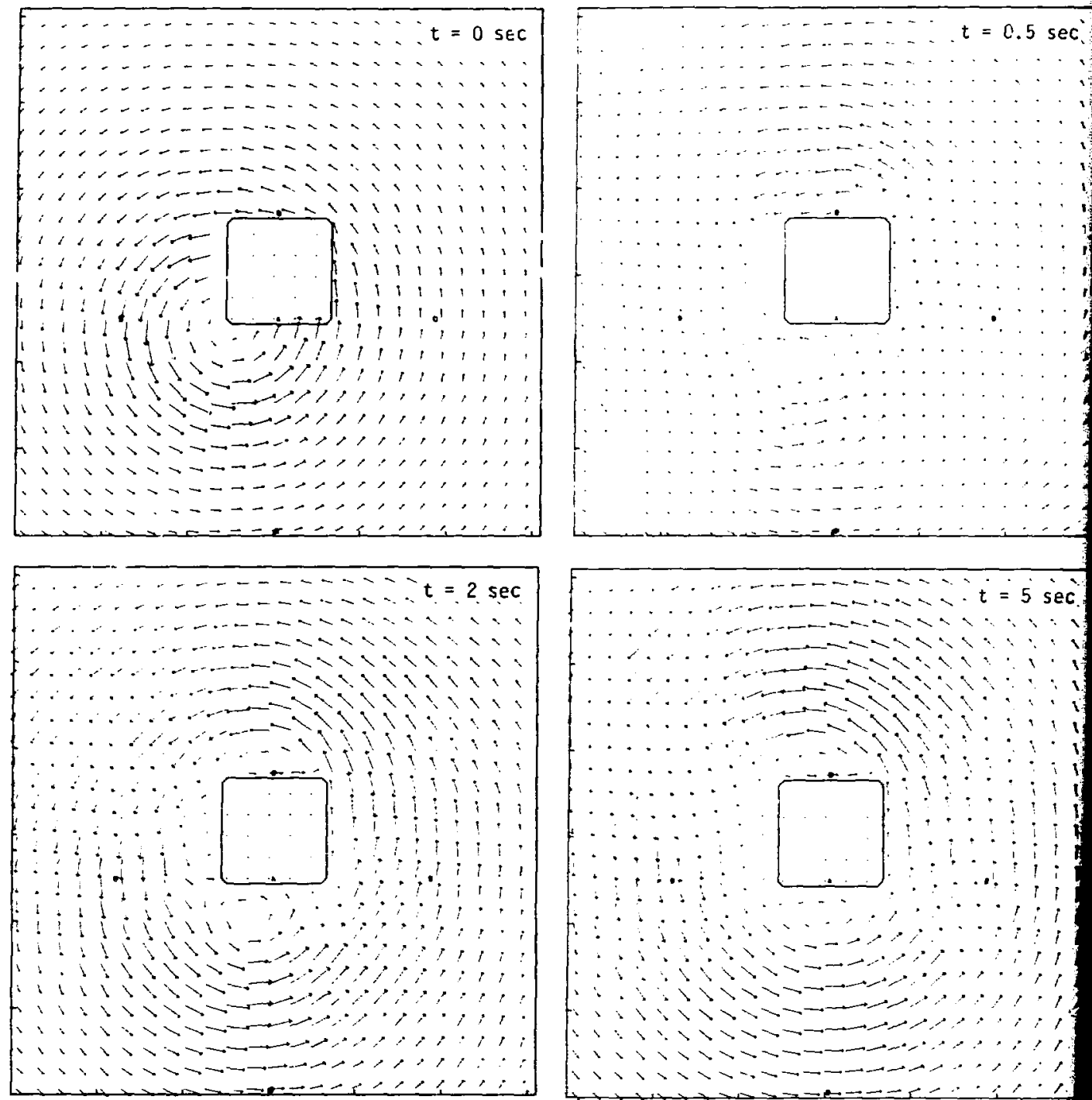
TORNADO STRUCTERE INTERACTIOS:

RUN NO, 4

Building dimensions:

200 ft $(x)$,

200 ft $(y)$.

Initial vortex characteristics:

$$
\begin{aligned}
& v_{m}=290 \mathrm{mph}, \\
& v_{\text {Iot }}=290 \mathrm{mph}, \\
& v_{\text {trans }}=0 \text { righ }, \\
& r_{m}=150 \mathrm{ft} .
\end{aligned}
$$

Inttial dispiacement of vortex center from building center:

None, vortex is centered over the building center.
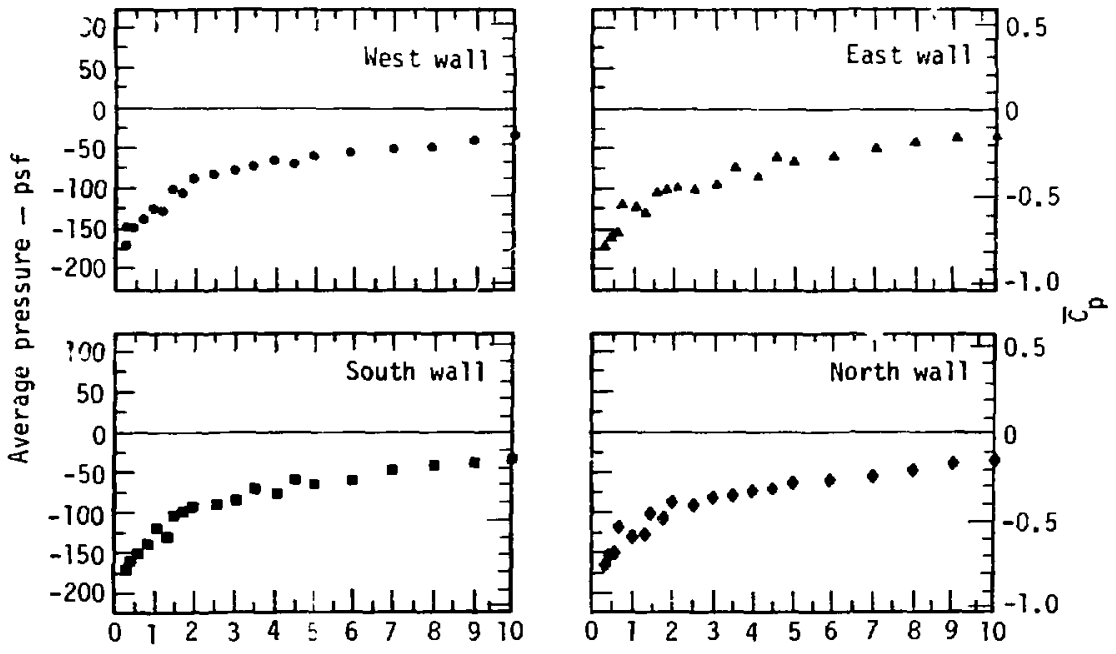

Time - sec
20 ft on all building surfaces.

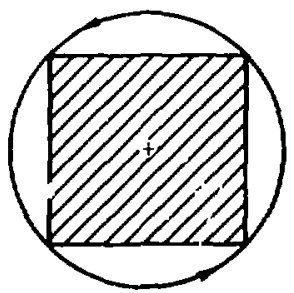

See FAgs, 5 and 16 tor pressuretime histories and aír flow patterns for this run.
Start-up geometry, stationary vortex:

Fig. 15. Surface pressures for run No. 4. 

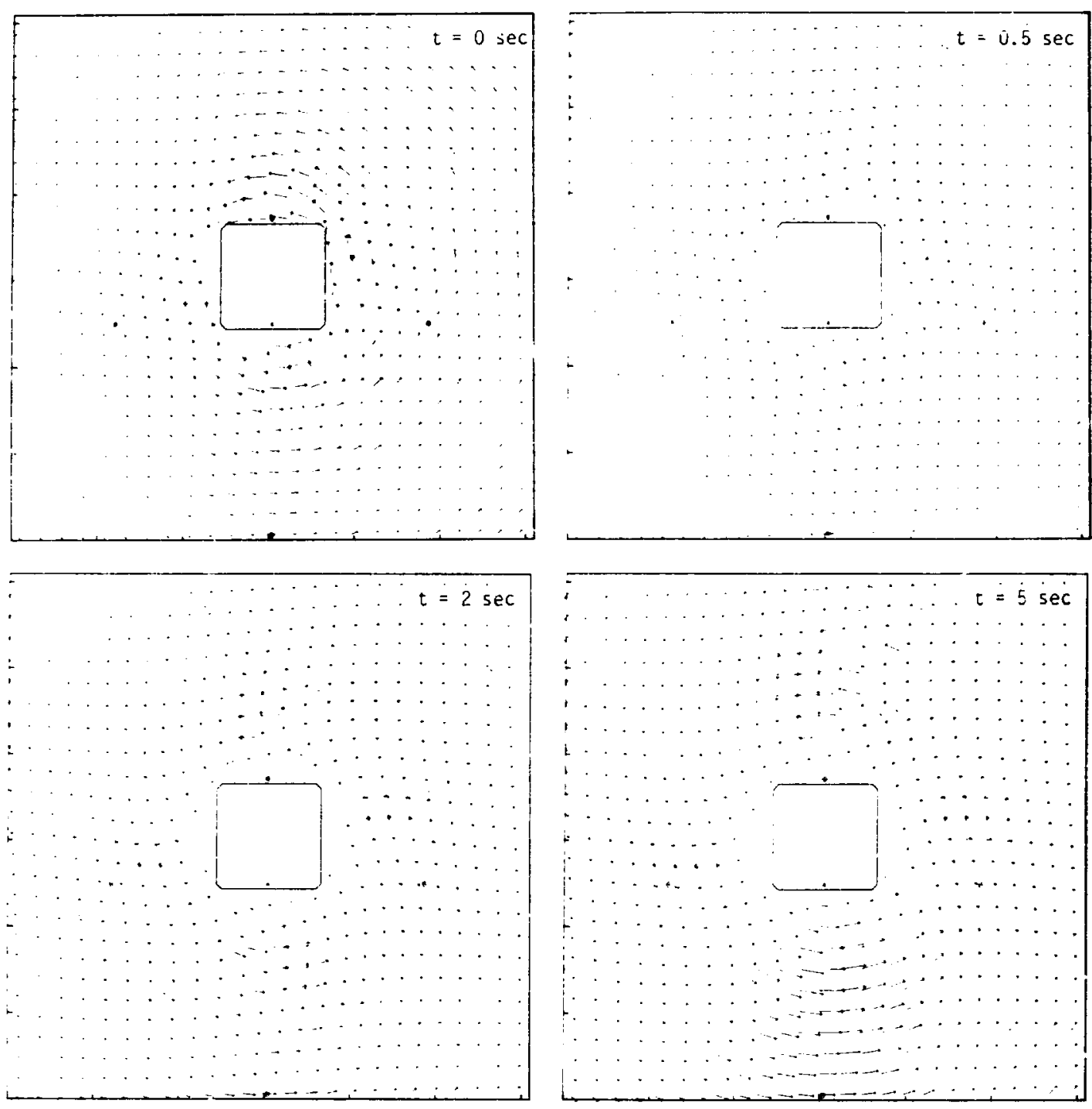
TORNAES STRECTLRE IXTERACTION:

RIN NO. 5

Building dimensions:

200 ft $(x)$,

200 fe $(y)$.

Initial vortex characteristics:

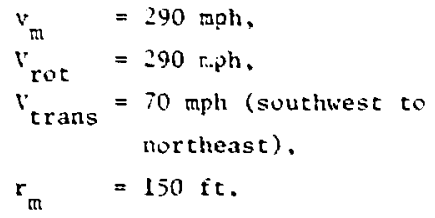

Initial displacement of vortex center from building center:

282.8 tit to the wast,

$282.8 \mathrm{ft}$ to the south.

Computational zone width:

20 ft on all building surfaces.
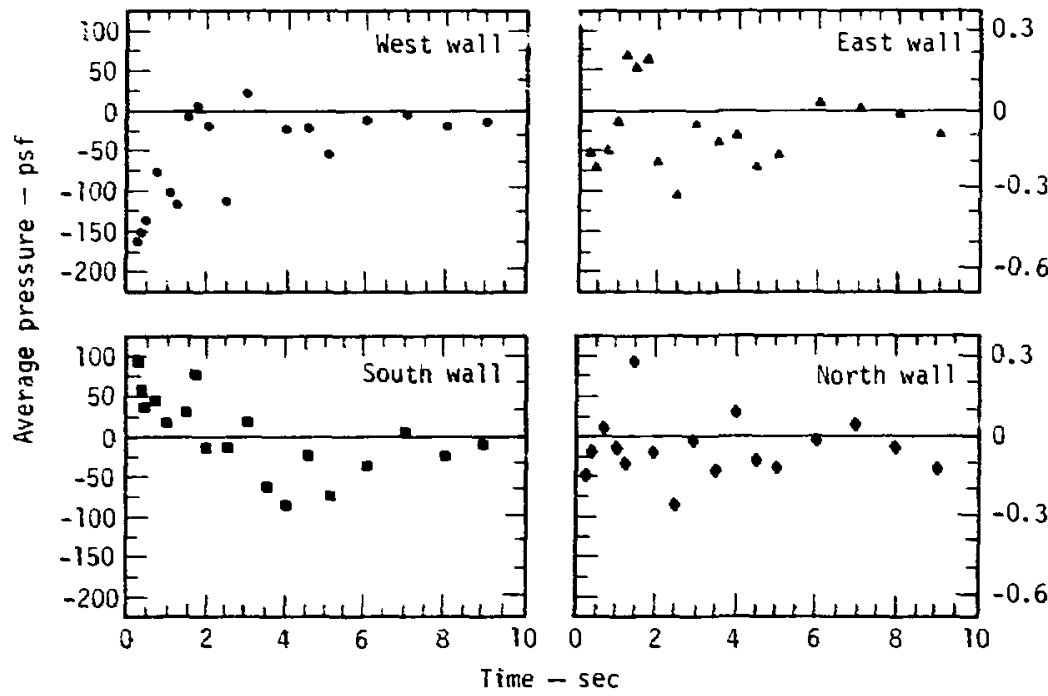

See Figs. 17 and 18 for pressuretime histories and air flow patterns for this run.

Fig, 17. SurEace pressures for run No. 5. 

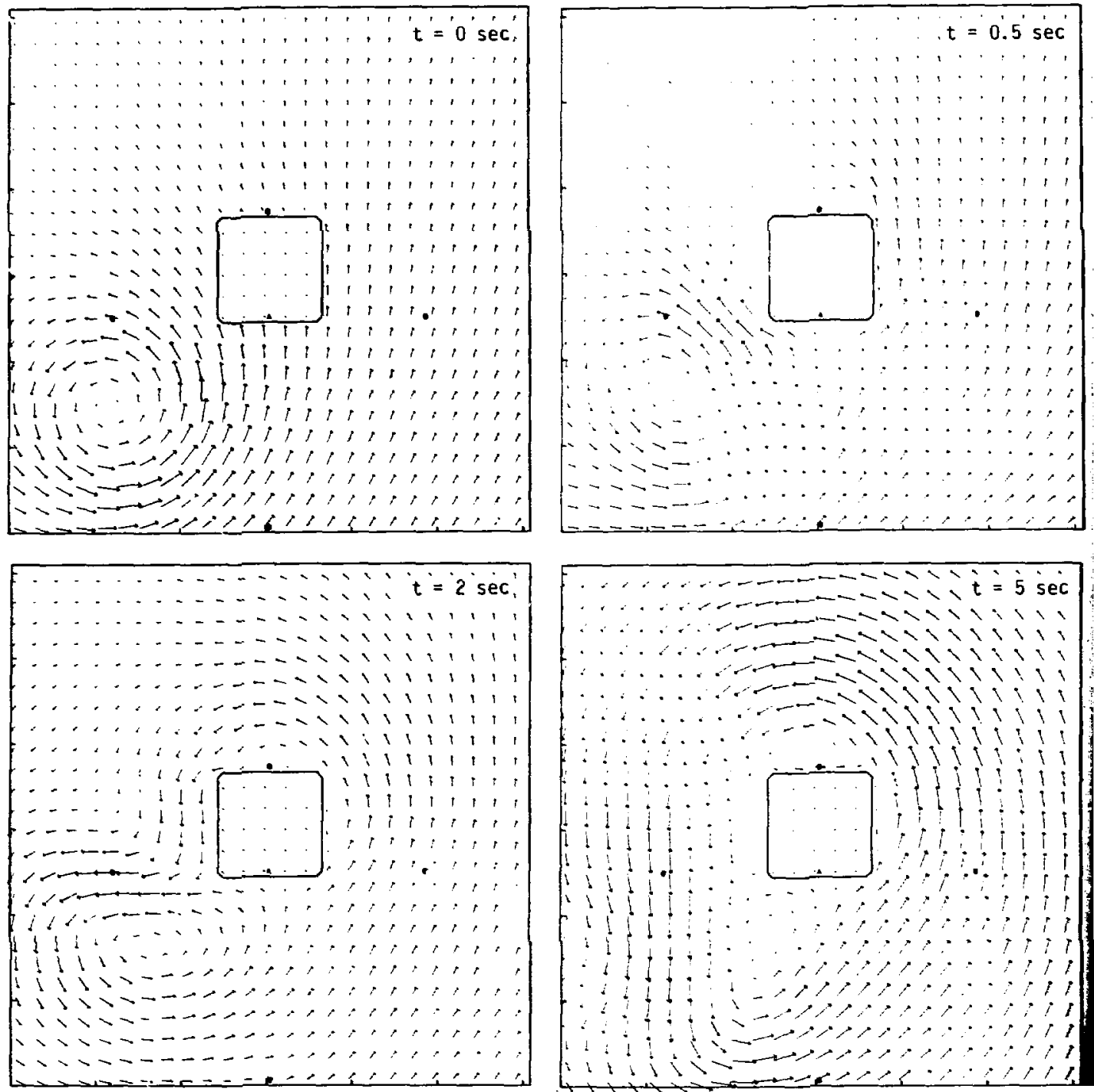


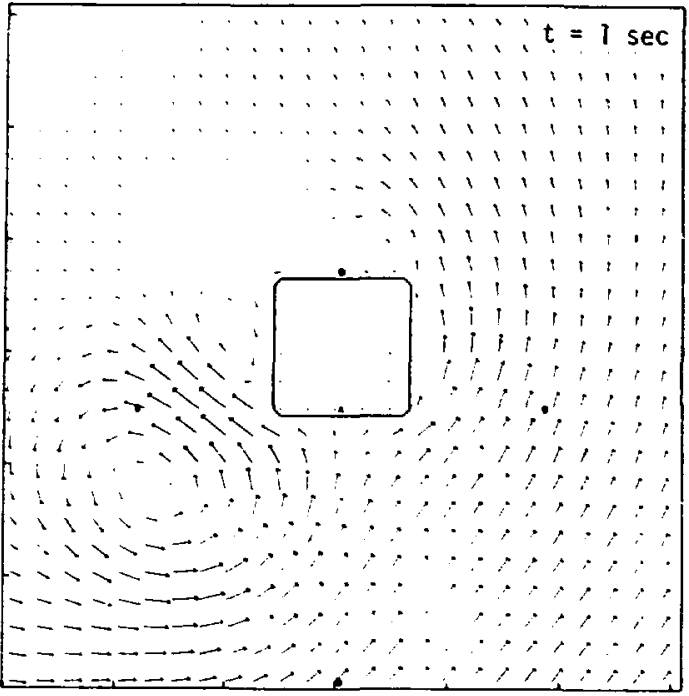

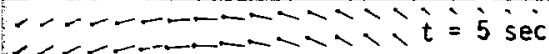

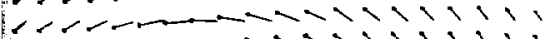

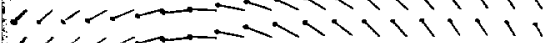

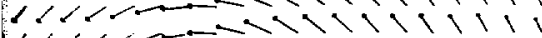
$16 \angle \alpha+2,111111$

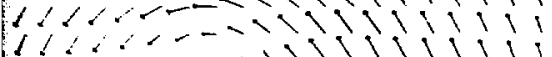
$14 \% 2615111111$

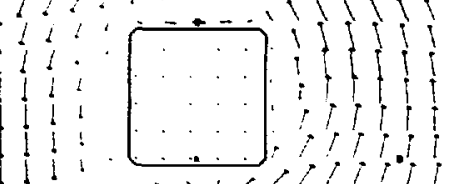

$1+\cdots, \ldots 1 \% 111711$

$11 \cdot,+171 \% 11111$

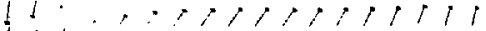

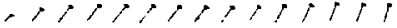
-

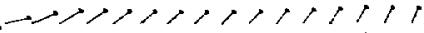

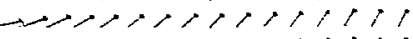


TORNADO STRUCTLRE INTERACT ION:

RUN NO. 6

Building dimensions:

$$
\begin{aligned}
& 300 \mathrm{ft}(\mathrm{x}), \\
& 100 \mathrm{ft}(\mathrm{y}) .
\end{aligned}
$$

Initial yortex characteristics:

$$
\begin{aligned}
& v_{m}=290 \mathrm{mph}, \\
& v_{\text {rot }}=290 \mathrm{mph}, \\
& v_{\text {trans }}=70 \mathrm{mph} \text { (west to east), } \\
& r_{m}=150 \mathrm{ft} .
\end{aligned}
$$

Initial displacement of vortex center from building center:

$300 \mathrm{ft}$ to the west.
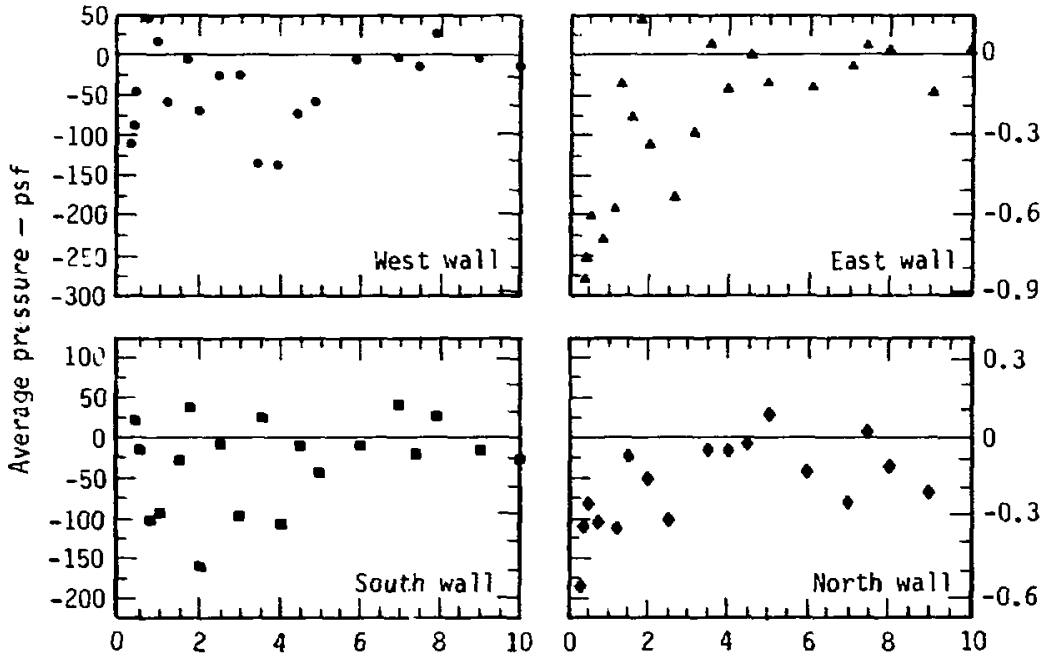

See Figs. 19 and 20 for pressuretime histories and air flow patterns For this run.

Time - sec

Fig. 19. Surface pressures for run No. 6 . 

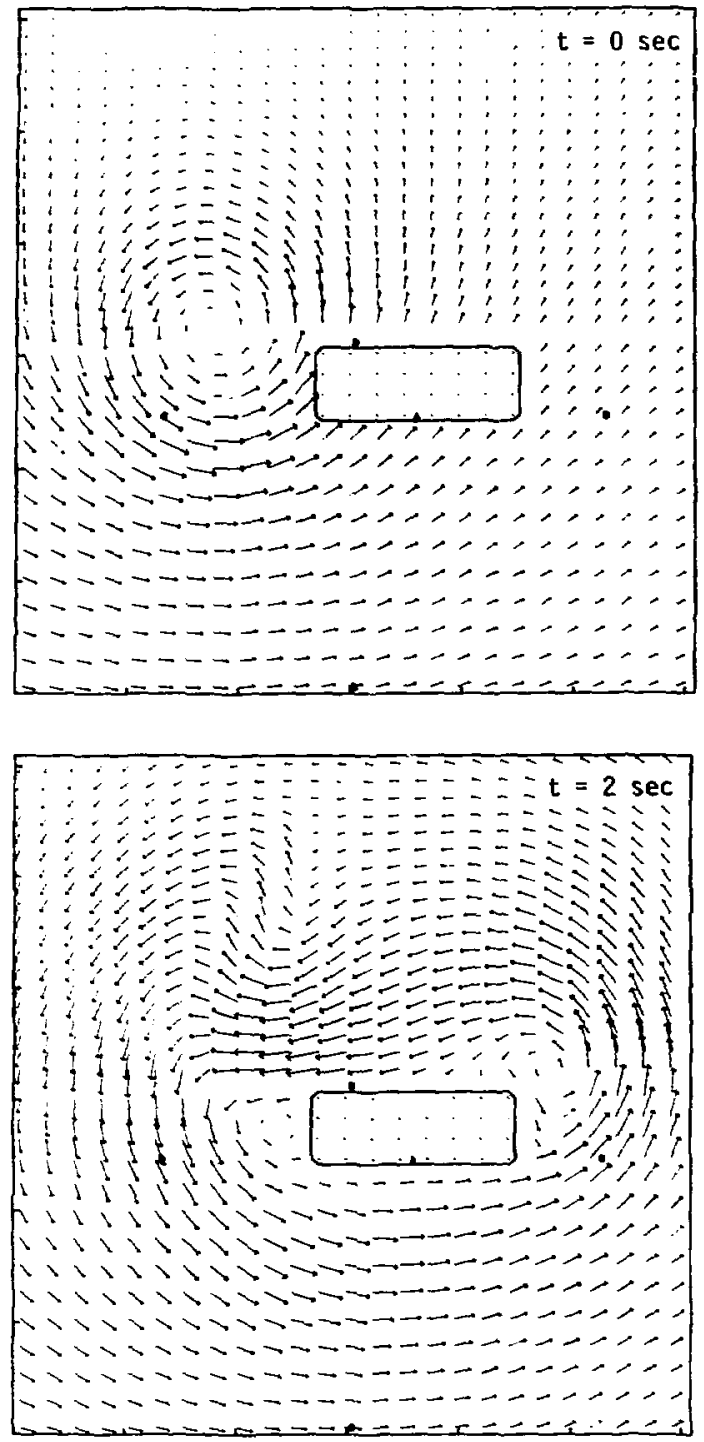
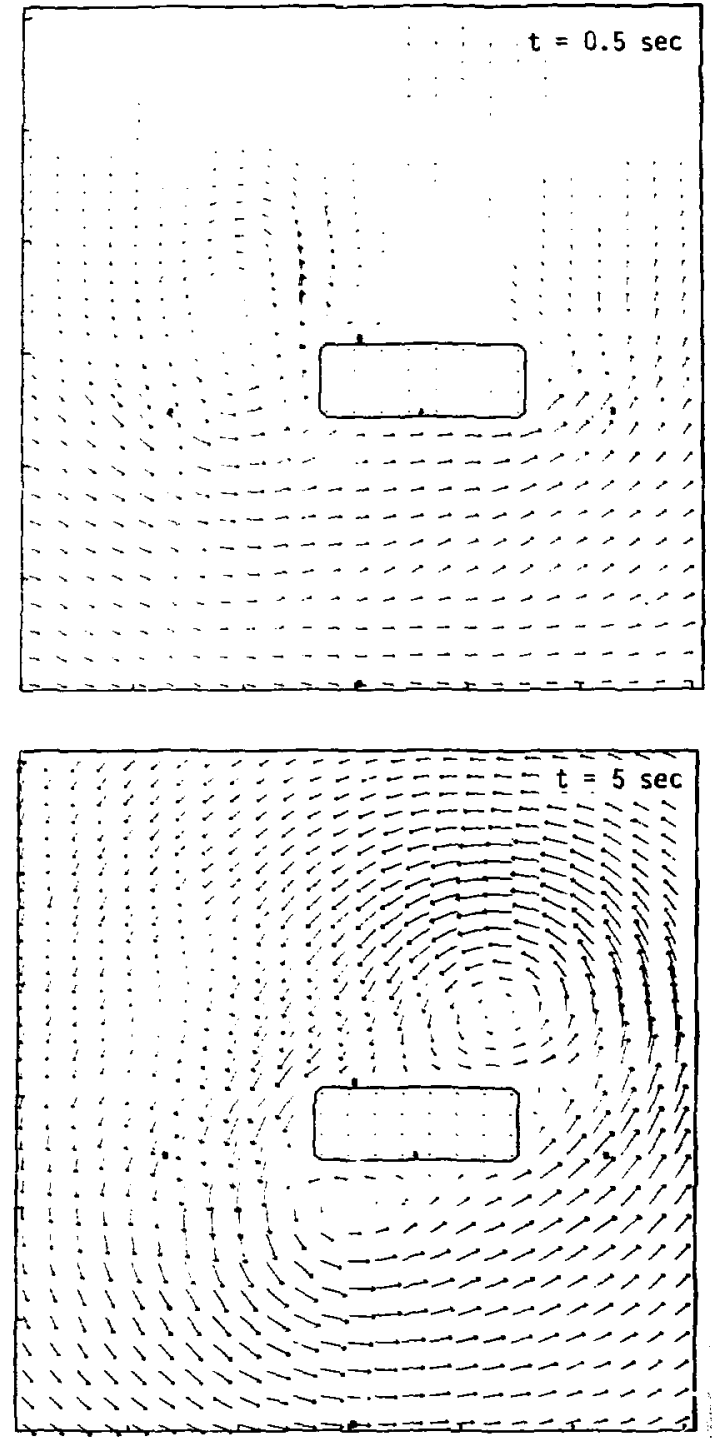

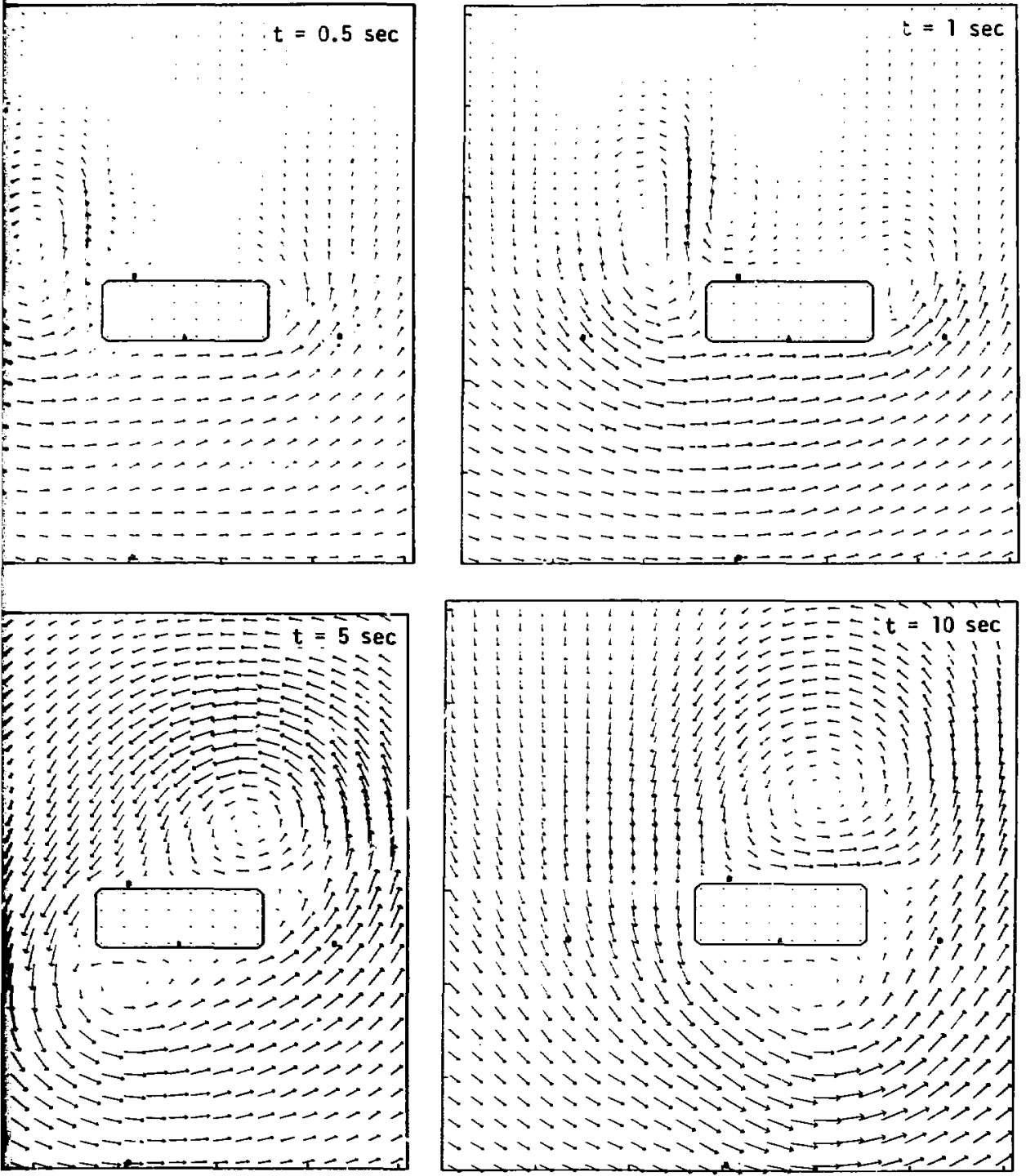

Fig. 20. Velocity vector plots for run No. 6. 
TORNADO STRUCTURE INTERACTION:

RLN NO. 7

Building dimensions:

$$
\begin{aligned}
& 300 \mathrm{ft}(x), \\
& 200 \mathrm{ft}(\mathrm{y}) .
\end{aligned}
$$

Initial vortex characteristics:

$$
\begin{aligned}
& v_{m}=290 \mathrm{mph}, \\
& v_{\text {rot }}=290 \mathrm{mph}, \\
& v_{\text {trans }}=70 \mathrm{mph} \text { (west to east), } \\
& r_{m}=150 \mathrm{ft} .
\end{aligned}
$$

Initial displacement of vortex center fron building center:

300 ft to the west.

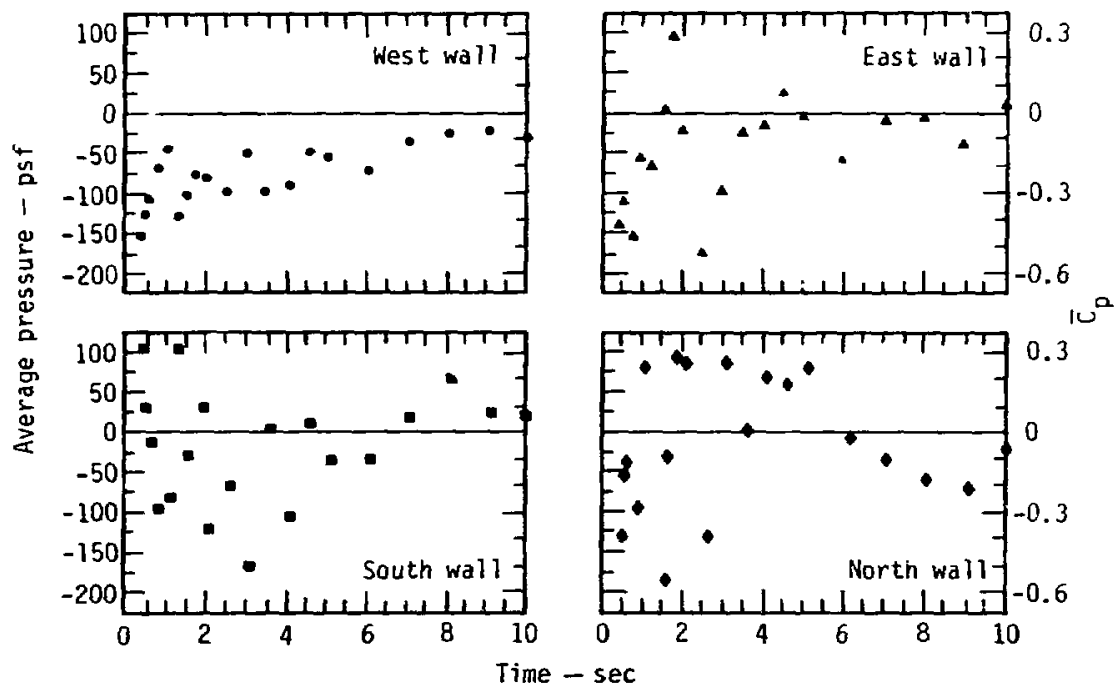

Fig. 21. Surface pressures for run No. 7.
Compuiational zone widih:

$20 \mathrm{ft}$ on all building surfaces.

Start-up geometry, translating vortex:

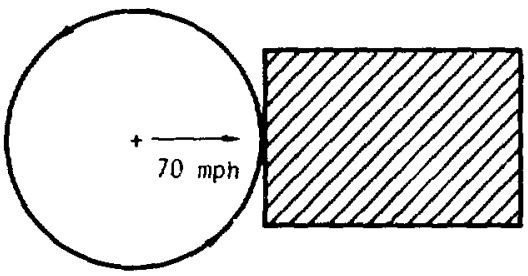

See Figs, 21 and 22 for pressuretime histories and air flow patterns for this run.

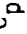

Time - sec 

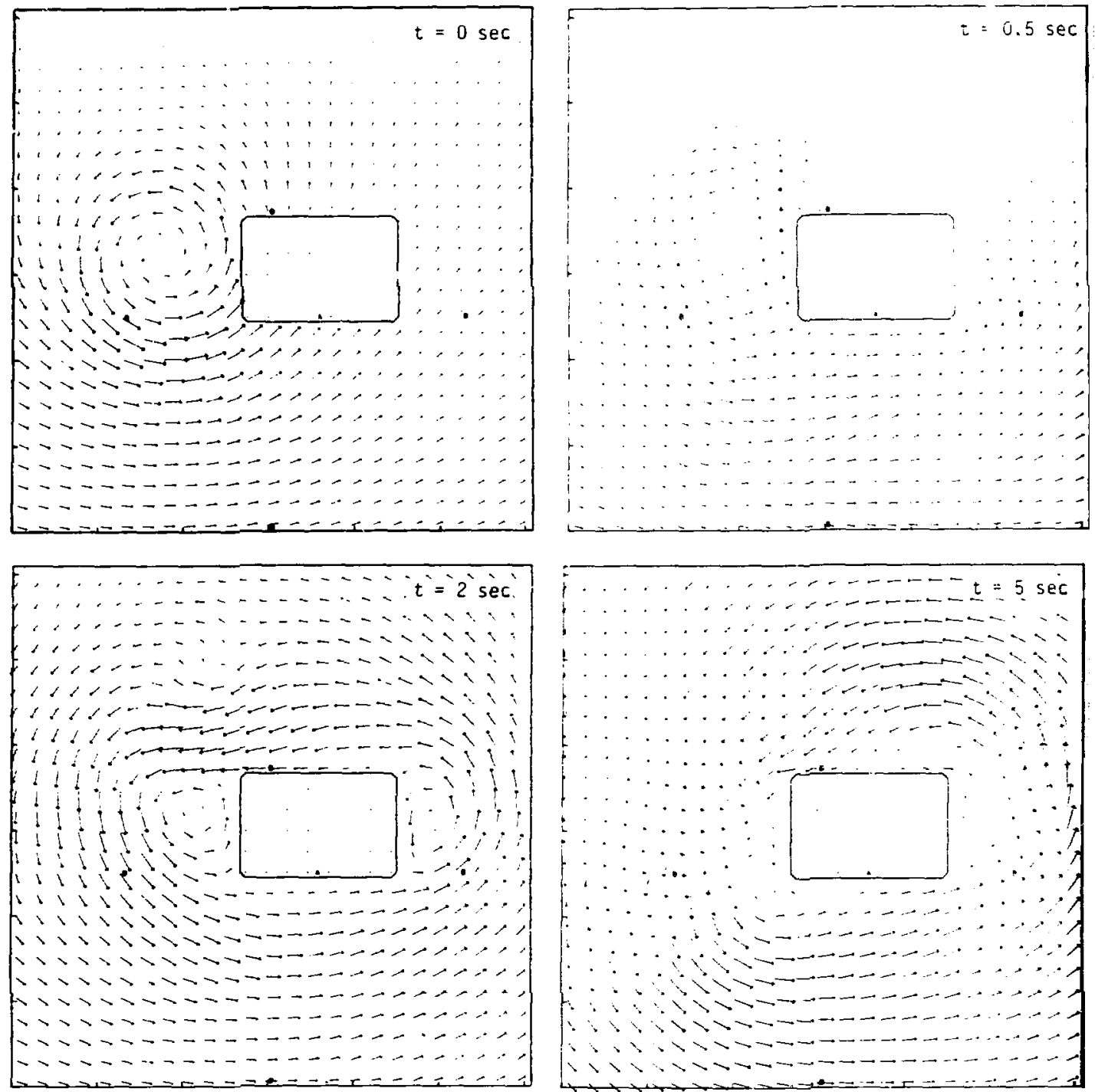

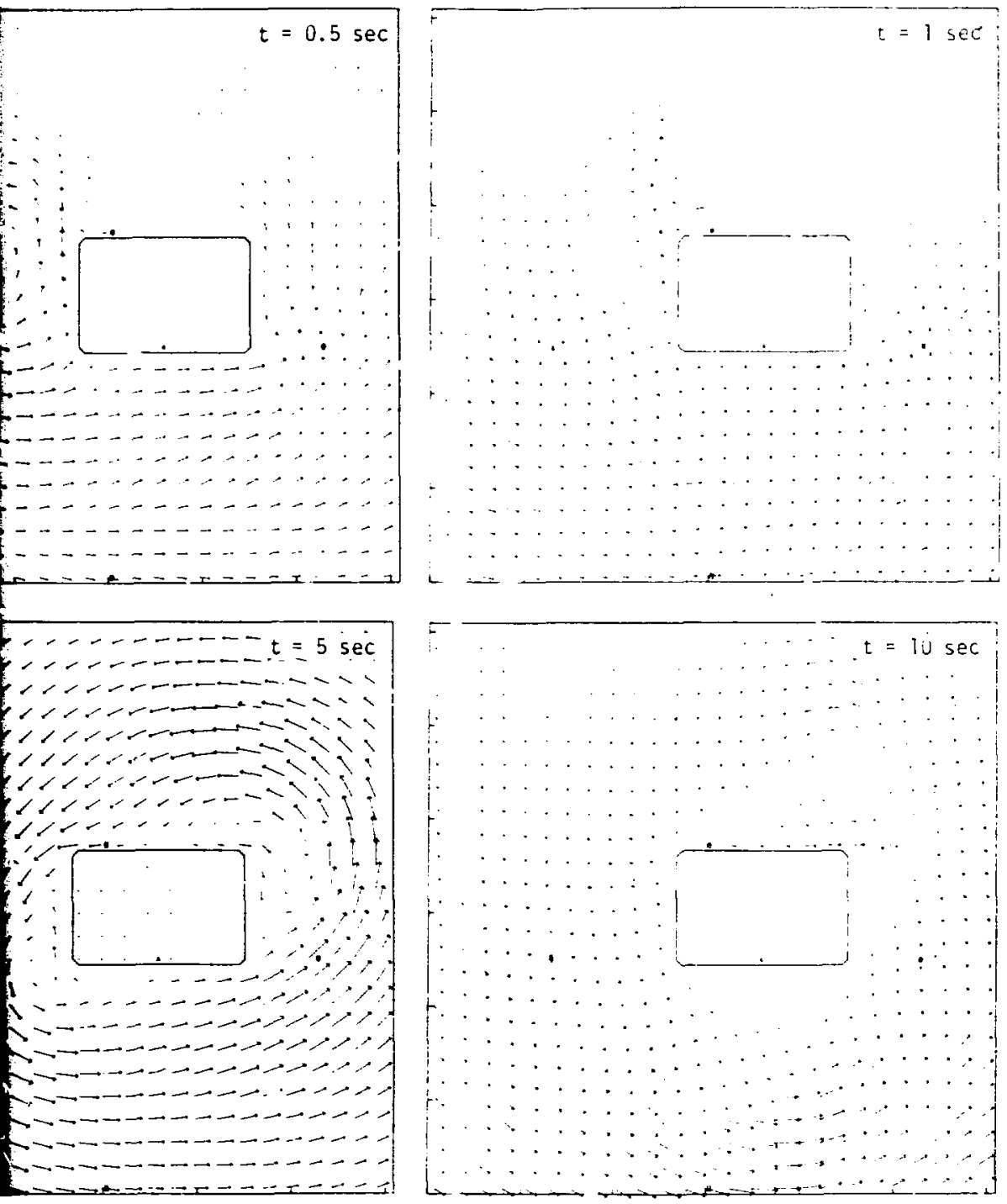

Fig. 22. Velocit: vector plots for run so. 7 . 


\section{Discussion of Results}

l'sing the WSI Standird appeacti as a basis, we cumplted ippropritive design pressures for the seven ISL test runs (see tables 5-il). Sumbers listed in parentieses represiat the percentases of the soveming disl design ralue. Al prossures tre given ia pounds per square tort $(\cdots+t)$, when alkitis a complrison, we must ace that the terms "windwind will." ". vewat

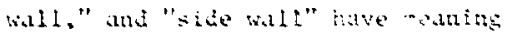

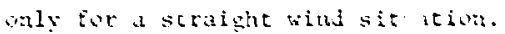
Additionally, when pressures ire guoted for the more common wi.ifeagineering problems, is stedu-state flow is usually tmplied. Xei ser of titese two conventions is diren ty applicuble to the ISL case ma bethe. the sides ot the buildith are simply jenoted as west, east, suth at: nortin. Similarly, a time is qu sed sich reference wo an initial th :field? calition.

The high and low calculated giossures, expressed as a percentage if the this l value. are sumariced:

- Rigid Fraries: 3+\% (rum No. 1 Iit? (rum lio. 1.

- Ir jivicuai

kali panels: 51 (cun No. ?) 326: (run Xi. 3)

- hapl coners: $\rightarrow$ (tun X. 2) $79 \%$ (ru: $\therefore$. 3) he see that for ewt run, pressures have a larse initial magnitude. Most likely. these vakues are extrenes and we resarded as "bigh." he initial velutey tield "sec-un" gives an impulse louding to tite walis that resules in an early eime-pressure spike insediately atter $t=0$. A perion! of cima is iecaled on allow the thom tield to assume a realistic protile; this tire is chken to be $0.3 \mathrm{sew}$. The early time pressures (t $-0.3 \mathrm{sec}$ ) should not be tatally discurded until a detailed anaiysis $\because$ in be made of the mumerical fluid dymaics of that time period. For the present, the edrly time values ire regarded as upper bounds of BBCcomputed pressures for a given problem formulation. A qualitative check on the behavior of the code can be found by examining the results of run $x_{0 .}$. where a "stationary" vortex is pusstioned directy over a square buiding. Figure 15 shuws a nearly identical pressure-time history for all Eour walls. All pressures list ed in Tables 5-11 were calculated at $t>0.3 \mathrm{sec}$.

The structural loadings obtained from the two-dimensional BBC calculations are linited in several respects:

- The vortex dissipates. Initially, it tornadolike flow field is 
Zuble 5. Comarison at jusign pressures (psE) Ior run Xi. I or che tornajostructare interaction study.

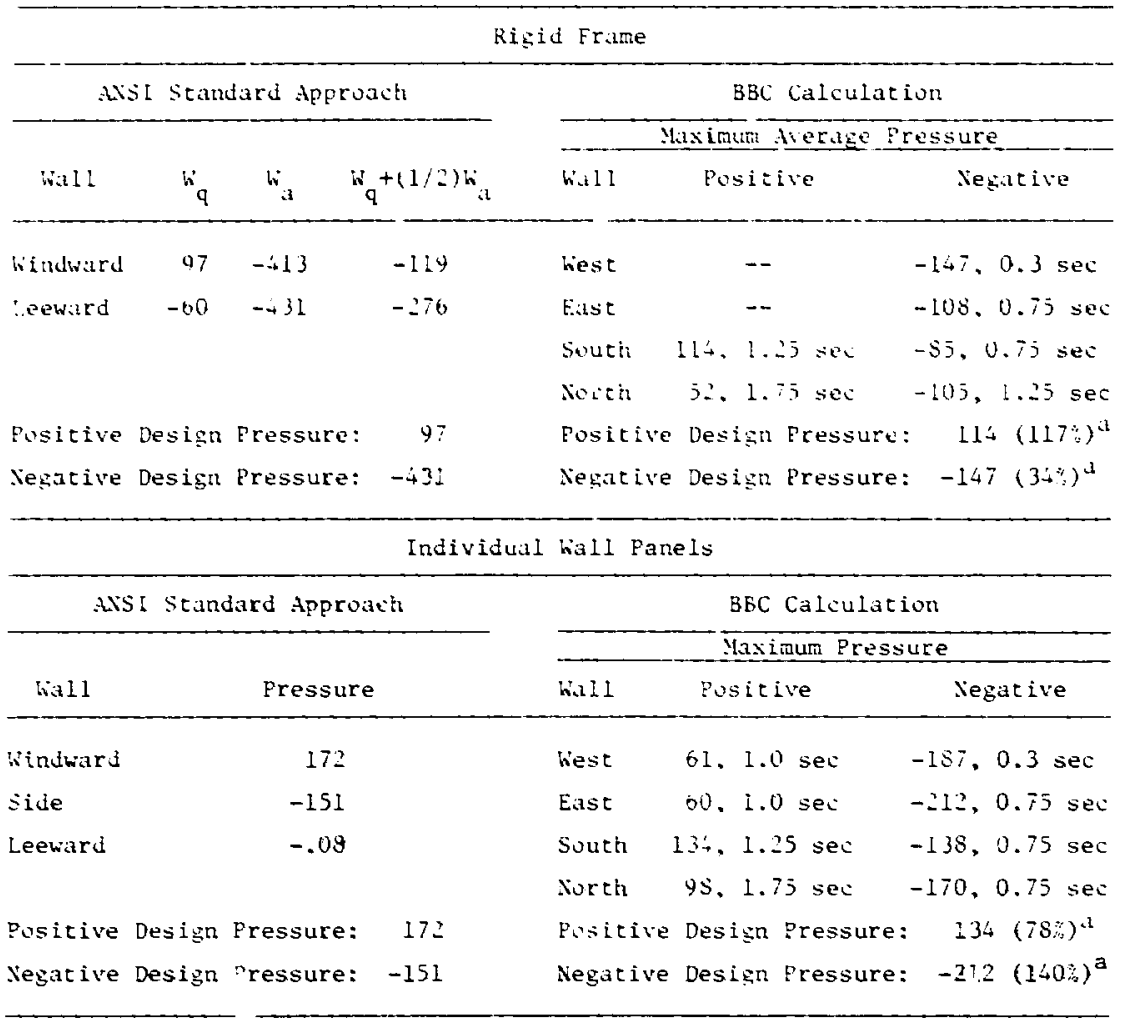

Wall Corners

\begin{tabular}{|c|c|c|c|c|c|}
\hline \multicolumn{3}{|c|}{ AVSI Standard Approach } & \multicolumn{3}{|c|}{ BBC Calculation } \\
\hline \multirow[b]{2}{*}{ Wali } & \multirow[b]{2}{*}{$\mathrm{P}$} & \multirow[b]{2}{*}{ 'ssure } & \multicolumn{3}{|c|}{ Maxigum Pressure } \\
\hline & & & WaII & Positive & Negative \\
\hline All Corners & & -431 & East & -- & $-212,0.75 \mathrm{sec}$ \\
\hline Negative Design & Pres & ssure: -431 & Negative & Design Pressure: & $-212(49 \%)^{3}$ \\
\hline
\end{tabular}

Bercentage of ANSI Standard approach value. 
Table 6. Comparison of design pressures (psf) for run No. 2 of tie tornadostructure interaction study.

\section{Rigid Frame}

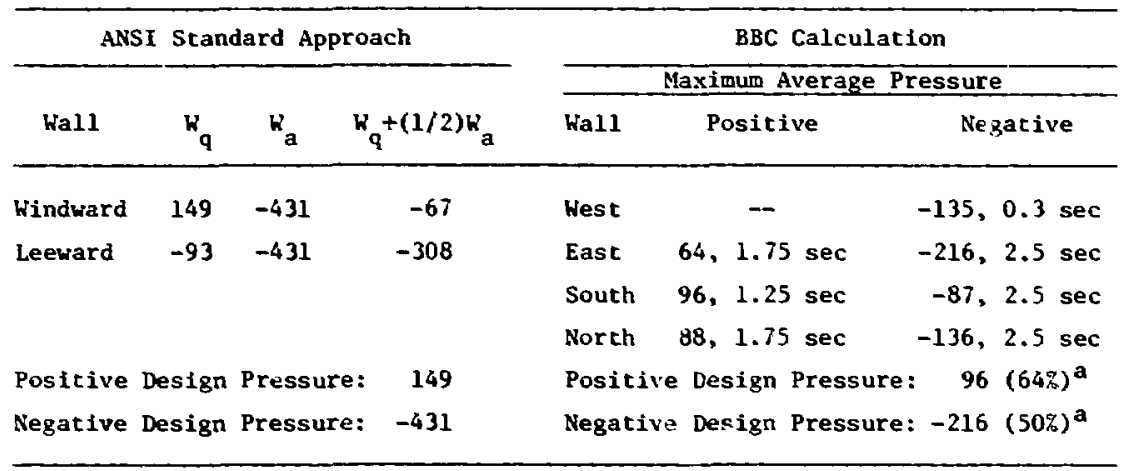

Individual Wall Panels

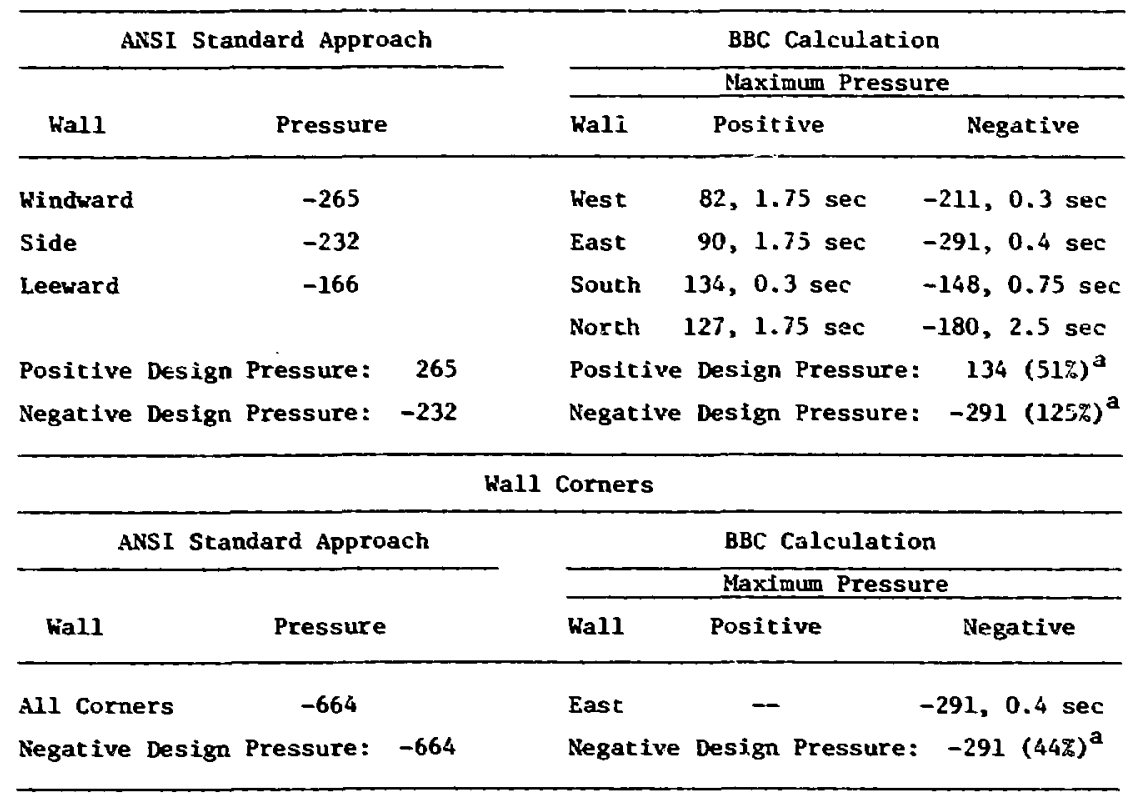

apercentage of ANSI Standard approach value. 
Table 7. Comparison of design pressures (psf) for run No. 3 of the tornadostructure interaction study.

\begin{tabular}{|c|c|c|c|c|c|c|}
\hline \multicolumn{7}{|c|}{ Rigid Frame } \\
\hline \multicolumn{4}{|c|}{ ANSI Standard Approach } & \multicolumn{3}{|c|}{ BBC Calculation } \\
\hline \multirow[b]{2}{*}{ Wall } & \multirow[b]{2}{*}{$W_{q}$} & \multirow[b]{2}{*}{$w_{a}$} & \multirow[b]{2}{*}{$\mathrm{w}_{q}+(1 / 2) \mathrm{w}_{\mathrm{a}}$} & \multicolumn{3}{|c|}{ Maximum Average Pressure } \\
\hline & & & & wall & Positive & Negat1ve \\
\hline Windward & 97 & -413 & -119 & West & $43,2.0 \mathrm{sec}$ & $-211,1.25 \mathrm{sec}$ \\
\hline Leeward & -60 & -431 & -276 & $\begin{array}{l}\text { East } \\
\text { South } \\
\text { North }\end{array}$ & $\begin{array}{c}58,1.25 \mathrm{sec} \\
17,5.0 \mathrm{sec} \\
--\end{array}$ & $\begin{array}{l}-175,1.75 \mathrm{sec} \\
-220,0.75 \mathrm{sec} \\
-210,0.3 \mathrm{sec}\end{array}$ \\
\hline Positive & Design & Pressure: & 97 & Positive & e Design Pressure: & $58(60 \%)^{a}$ \\
\hline Negative & Design & Pressure: & -431 & Negative & Design Pressure: & $=-220(51 \%)^{a}$ \\
\hline
\end{tabular}

Individual Wall Panels

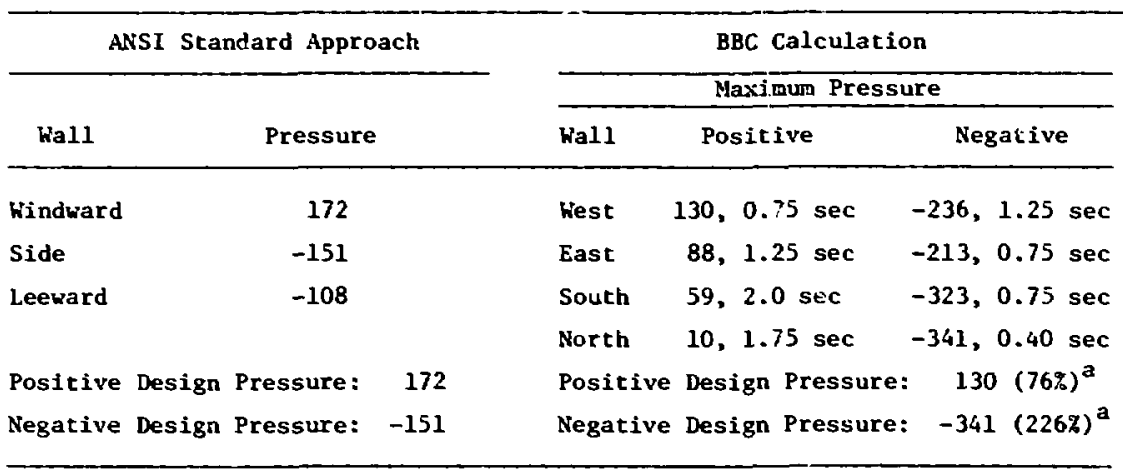

Wall Corners

ANSI Standard Approz.ch

\begin{tabular}{|c|c|c|c|c|c|}
\hline \multirow[b]{2}{*}{ Wall } & \multirow{2}{*}{\multicolumn{2}{|c|}{ Pressure }} & \multicolumn{3}{|c|}{ Maximum Pressure } \\
\hline & & & hall & Positive & Negative \\
\hline All Corners & -431 & & North & -- & $-341,0.75 \mathrm{sec}$ \\
\hline Negative Design & Pressure: & -431 & Negative & Design Pressure: & $-341(79 \%)^{a}$ \\
\hline
\end{tabular}

'Percentage of ANSI Standard approach value. 
Table 8. Comparison of design pressures (pst) for run $X$, it ot the tornadostructure interaction study.

\section{Pigid Frame}

\begin{tabular}{|c|c|c|c|c|c|c|}
\hline \multicolumn{4}{|c|}{ ANSI Scandard Approach } & \multicolumn{3}{|c|}{ BBC Calculation } \\
\hline \multirow[b]{2}{*}{ Wall } & \multirow[b]{2}{*}{$\mathrm{w}_{\mathrm{q}}$} & \multirow[b]{2}{*}{$w_{a}$} & \multirow[b]{2}{*}{$w_{q}+(1 / 2) w_{a}$} & \multicolumn{3}{|c|}{ Maximum Average Pressure } \\
\hline & & & & Wall & Positive & Negative \\
\hline Windward & 97 & -431 & -119 & West & -- & $-171,0.3 \mathrm{sec}$ \\
\hline \multirow[t]{3}{*}{ Leeward } & -60 & -431 & -276 & East & -- & $-161,0.3 \sec$ \\
\hline & & & & South & - & $-171,0.3$ sec \\
\hline & & & & North & -- & $-162,0.3 \mathrm{sec}$ \\
\hline
\end{tabular}

Positive Design Pressure: 97

Negative Design Pressure: -431 Negative Design Pressure: $-131(40 \%)^{\mathbf{a}}$

Individual Wall Panels

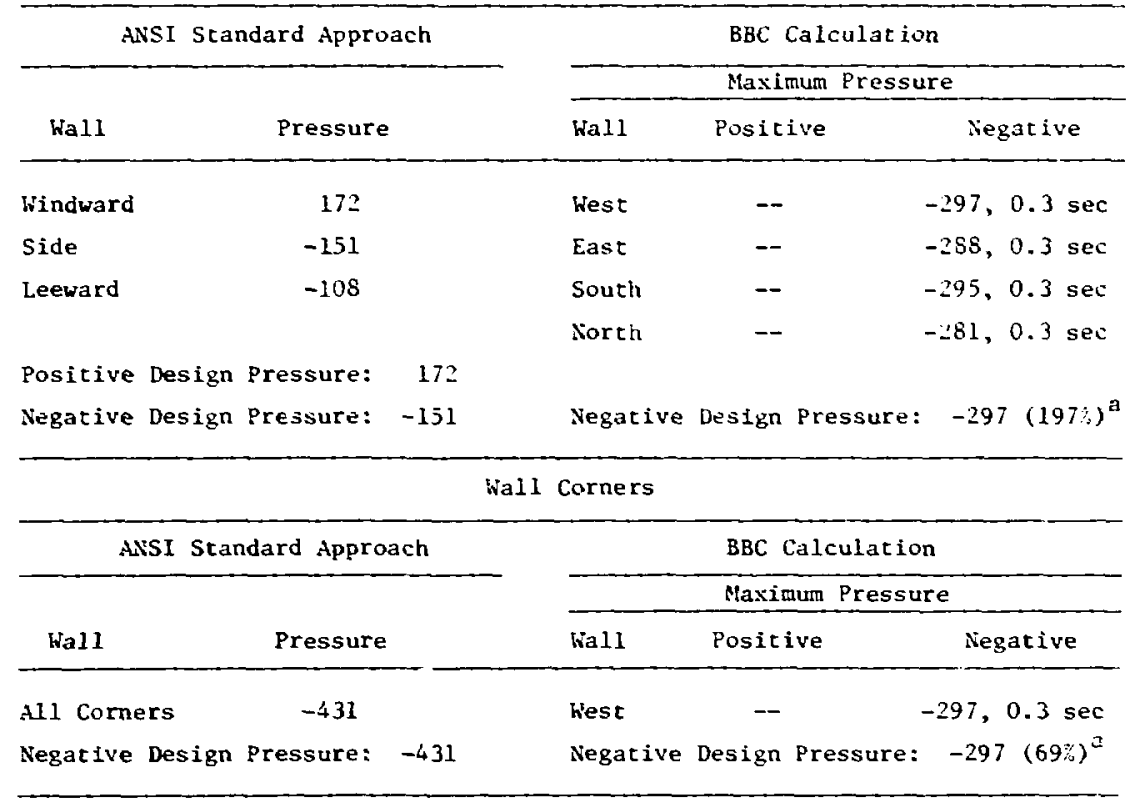

${ }^{a}$ Percentage of ANSI Standard approach value. 
Table 9. Comparison of design pressures (psi) for run to. 5 of the tornadostructure interaction study.

\begin{tabular}{|c|c|c|c|c|c|c|}
\hline \multicolumn{7}{|c|}{ Rigid Frame } \\
\hline \multicolumn{4}{|c|}{ ANSI Standard Approach } & \multicolumn{3}{|c|}{ BBC Calculation } \\
\hline \multirow[b]{2}{*}{ Wall } & \multirow[b]{2}{*}{$h_{q}$} & \multirow[b]{2}{*}{$w_{a}$} & \multirow[b]{2}{*}{$w_{q}+(1 / 2) w_{a}$} & \multicolumn{3}{|c|}{ Maximum Average Pressure } \\
\hline & & & & Wall & Positive & iegative \\
\hline Windivard & 149 & $-i 31$ & -67 & liest & $3,1.75$ sec & $-162,0.3$ se: \\
\hline \multirow[t]{3}{*}{ leeward } & -93 & -431 & -308 & East & $64,1.25 \mathrm{sec}$ & $-103,2.5 \mathrm{sec}$ \\
\hline & & & & South & $133,1.25 \mathrm{sec}$ & $-76,4.0 \mathrm{sec}$ \\
\hline & & & & North & $131,1.75 \mathrm{sec}$ & $-111,2.5 \mathrm{sec}$ \\
\hline Positive & Design & Pressure: & 149 & Posit & e Design Pressu & $133(89 \%)^{a}$ \\
\hline Negative & Design & Pressure: & -431 & Negat & e Design Pressu & $:-162(38 \%)^{a}$ \\
\hline
\end{tabular}

\section{Individual Wall Panels}

\begin{tabular}{|c|c|c|c|c|c|}
\hline \multicolumn{3}{|c|}{ ANSI Standard Approach } & \multicolumn{3}{|c|}{ BBC Calculation } \\
\hline \multirow[b]{2}{*}{ Wall } & \multirow{2}{*}{\multicolumn{2}{|c|}{ Pressure }} & \multicolumn{3}{|c|}{ Maximum Pressure } \\
\hline & & & Kall & Positive & legative \\
\hline Windivard & 265 & & liest & $42,2.0 \mathrm{sec}$ & $-393,0.3 \mathrm{sec}$ \\
\hline Side & -232 & & East & $119,1.75 \mathrm{sec}$ & $-175,0.5 \mathrm{sec}$ \\
\hline \multirow[t]{2}{*}{ Leeward } & -166 & & South & $159,1.25 \mathrm{sec}$ & $-85,4.0 \mathrm{sec}$ \\
\hline & & & North & $150,1.75 \mathrm{sec}$ & $-121,2.5 \mathrm{sec}$ \\
\hline Positive Design & Pressure: & 265 & Positi & e Design Press & $159(60 \%)^{a}$ \\
\hline Negative Design & Pressure: & -232 & Negat $i$ & e Design Press & $:-393(169 \%)^{a}$ \\
\hline
\end{tabular}

Wall Corners

\begin{tabular}{|c|c|c|c|c|c|}
\hline \multicolumn{3}{|c|}{ ANSl Standard Approach } & \multicolumn{3}{|c|}{ BBC Calculation } \\
\hline \multirow[b]{2}{*}{ Kall } & \multirow{2}{*}{\multicolumn{2}{|c|}{ Pressure }} & \multicolumn{3}{|c|}{ Maximum Pressure } \\
\hline & & & WaIl & Pusitive & Negative \\
\hline All Corners & -664 & & West & -- & $-393,0.3 \mathrm{sec}$ \\
\hline Negative Design & Pressure: & -664 & Negative & Design Pressure: & $-393(59 \%)^{a}$ \\
\hline
\end{tabular}

apercentage of ANSI Standard approach value. 
Table 10. Comparison of design pressures (psf) for run No. 6 of the cornadostructure interaction study.

\begin{tabular}{|c|c|c|c|c|c|c|}
\hline \multicolumn{7}{|c|}{ Rigid Frame } \\
\hline \multicolumn{4}{|c|}{ ANSI Standard Approach } & \multicolumn{3}{|c|}{ BBC Calculation } \\
\hline \multirow[b]{2}{*}{ Wall } & \multirow[b]{2}{*}{$\mathrm{w}_{\mathrm{q}}$} & \multirow[b]{2}{*}{$w_{q}$} & \multirow[b]{2}{*}{$\mathrm{w}_{\mathrm{q}}+(1 / 2) \mathrm{w}_{\mathrm{a}}$} & \multicolumn{3}{|c|}{ Maximum Average Pressure } \\
\hline & & & & Wall & Positive & Negative \\
\hline Windward & 194 & -431 & -21 & West & $45,0.75 \mathrm{sec}$ & $-168,1.5 \mathrm{sec}$ \\
\hline \multirow[t]{3}{*}{ Leeward } & -121 & -431 & -337 & East & $44,1.75 \mathrm{sec}$ & $-281,0.4 \mathrm{sec}$ \\
\hline & & & & South & $126,1.25 \mathrm{sec}$ & $-157,2.0 \mathrm{sec}$ \\
\hline & & & & North & $140,1.75 \mathrm{sec}$ & $-186,0.3 \mathrm{sec}$ \\
\hline Positive & Design & Pressure: & 194 & Positive & Resiga Pressur & $=\quad 140(72 \%)^{a}$ \\
\hline Negative & Design & Pressure: & -431 & Negative & e Design Pressur & $=-281(65 \%)^{a}$ \\
\hline
\end{tabular}

Individual hall Panels

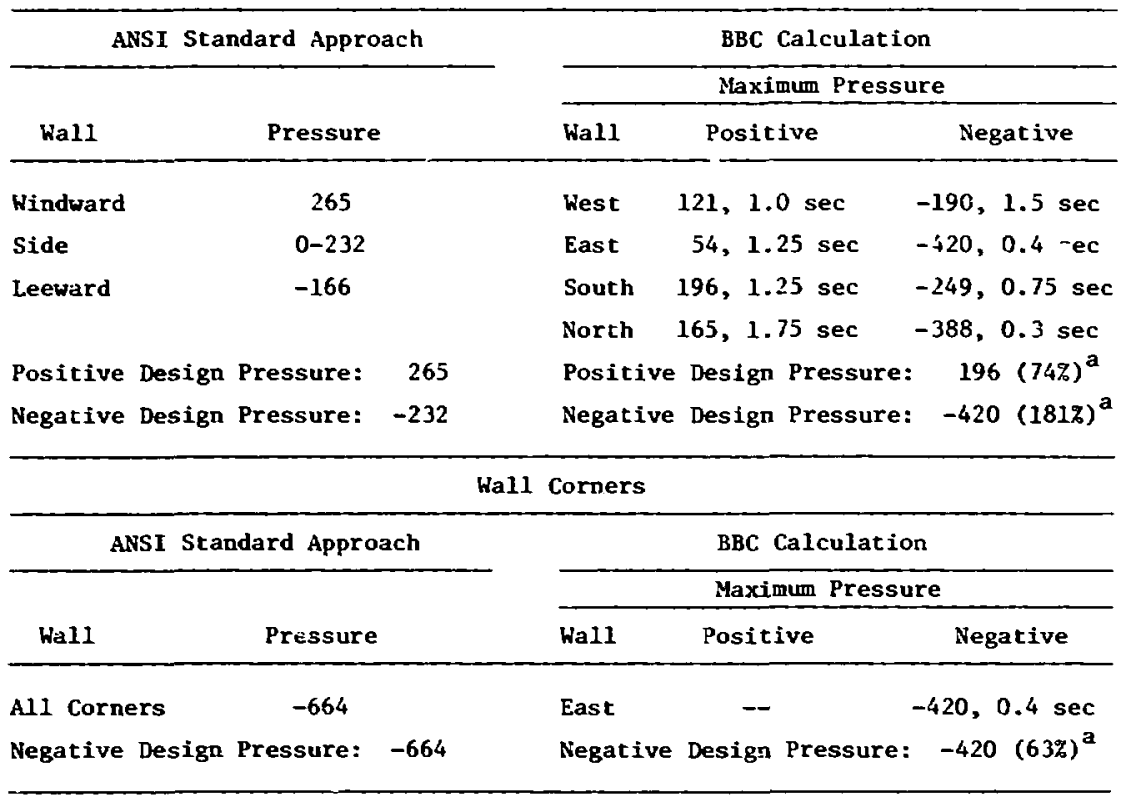

apercentage of ANSI Standard approach value. 
Table 11. Comparison of design pressures (psf) for run No. 7 of the tornadostructure interaction study.

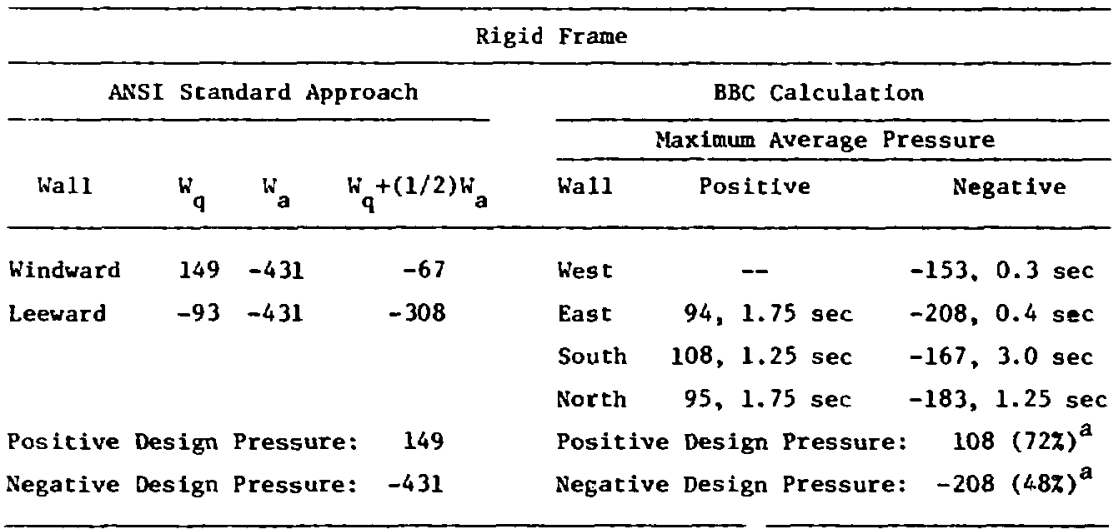

Individual Wall Panels

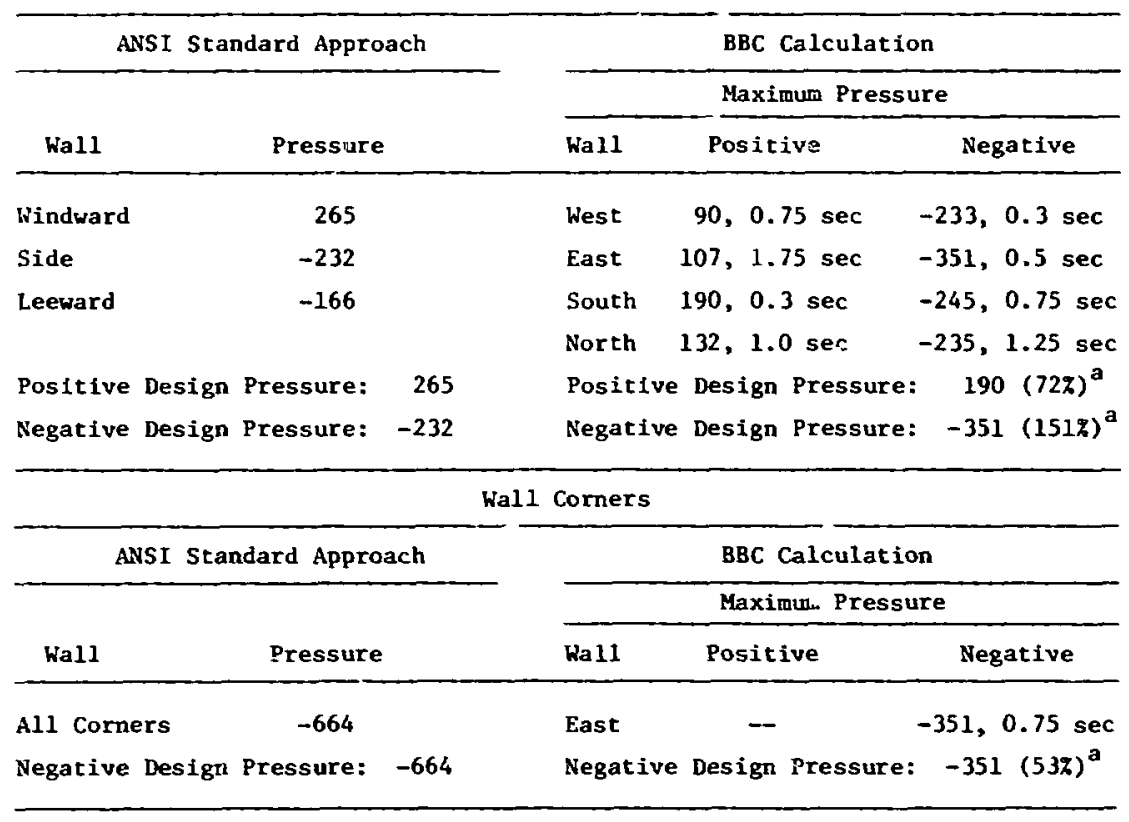

Percentage of ANSI Standard approach value. 
specified for the horizontal plane. Is the problem proceeds in time, the flow field relaxes because the entire computational mesh attempts to come to equilibrium and because numerical viscosity is introduced by the finite-difference equations.

- The vortex is not iriven. The effect described above might not be so apparent if a means to power the vortex could be found. clearly, a real tornado flow is almost entirely dependent on its energy source.

- The vortex does not really exist inside the building. While neglect of the three-dimensional effects of TSI is implied in the two-dimensional formulation of the problem, an obvious incompatability exists when the core passes " $\cdots a c$ " the building. In two dimensions, there is no way (at present) to account for the core flow when this occurs. For a straight wind situation, this paradox does not exist because -he governing influence on the flow may be taken properly as being far removed from the building.

- The initial pressure profile of the vortex is specified from an equation of state for an indeal gas. Because thermal effects are ignored, we are left with a barotropic flow, i.e., pressure and density are related everywhere by a constant.

- The BBC code is inviscid, although some viscosity is introduced numerically. Although viscous effects are not of primary interest here, important phenomena such as separation, reattachment, and vortex shedding all depend on viscosity.

- No turbulence is considered. This follows from the point above but its importance to TSI may not be ipparent. Suitable theoretical models of the tornajo vortex of ter. assume an eddy viscosity value for ' $y$ in the range 1 to $100 \mathrm{ft}^{2} / \mathrm{sec}$ which is four to six orders of magnitude greater than the laminar value of $\checkmark$ for air.

At late times ( 6 to 10 sec), the dissipative effects become apparent and practically all pressure deviations from ambient conditiuns bacome small. This is seen clearly in a pressure-vs-time history of a vortex with no building present. The pressure in the core rises toward ambient oressure and hence, some of the APC effects are diminished.

Positive (compressive) pressures used to calculate positive design pressures for wall panels are about 
75: of the AKI value in all cases. The negative design pressures are, for the most part, $50 \%$ greater than the kiSI value. This results from the fact that extreme pressures are used in the negative pressure comparison. In each case considered here, the extreme negative pressures are always realized at a corner. These negative pressures are also used to compare design values at wall corters and hence, do "double duty" in this analysis. If corner points were excluded from consideration, the negative iesign pressures would be closer to the Alis I values.

The positive and negative pressures used to compare the design of a rigid frame are approximately $75 \%$ and $50 \%$ of dils , respectively. Since pressures over an entire wall must be considered, any comparison with ANCI is not subject to one or two extreme data points.
Wall corners designed by the ANSI approach must use a $C_{p}$ value of -2.0 . When coupled with the high maximum velocitv in a tornado, a design value of -664 psf results. While this value may be defensible, the $B B C$ calculations were generally about half this amount.

Overa11, the computer-generated results give no indication of heretofore neglected pressure loadings in the event of a tornado strike. The results do support the belief held by many that $A P C$ effects are dominant. In view of the limitations and the approximations employed when using the ANSI Standard approach, a definitive statement is not yet possible on how conservative or nonconservative the current design values may be. However, based on these calculations, we conclude that the use of present design loadings is justifiable and that some margin of safety does exist.

\section{Suggestions for Future Effort}

At this point, we should recall the assumptions and approximations that are made with an ANSI Standard approach for calculating tornadowind loadings.

- Steady flow. Although gust loadings which are defined in the ANSI Standards can be taken into account, they are usually ignored because the DBT characteristics themselves are probably conservative.

- One-dimensional flow. The very nature of straight wind flows conveniently permits definition of a set of pressure coefficients 
based on the same free-streau velocity. The ANSI standard pressure coefficients also make the assumption that flow is normal to the windward wall; again, there is no direct correlation to vortex flow.

- Quast-static pressures. The real fluid-dynanic effects near and around a building are assumed to be accounted for by the application of pressure and bukldingsize coeffictents.

- Cyclostrophic balance. This assumption follows from a vortex model such as the Rankine profile. If the region of interest were sufficiently removed from the ground, the cyllostrophic assumption would be justifiable, probably for all engineering applications. However, as noted earlier, the flow in Reaion III is strongly influenced by the ground and thus, cyclostrophic balance cannot be expected to hold. Furthermo-e, there is considerable evidence (Lewellen, 1976; Golden and Purcel1, 1975) chat the maximum tangential-wind velocities are realized near the ground.

- Separate treatment of velocity pressure and APC effects. The validity of the ANSI pressure coefficients is also assumed in most TSI calculations. Again, the ANSI Standard does not represent itselí as being applicable to tornado loadings

Even for straight-wind situations, there is a sizezble range of pressure coefficient values in use. Cermak and Akins (1976) 11st values of $\mathrm{C}_{\mathrm{Fx}}$ obtained by flve workers for a flxed cubic bullding. Values range from 0.81 to 1.6 ; the $C_{F x}$ obtained from ANSI A58.1-1972 is 1.3. Variations In pressure coefficients as a function of building geometry and wind vector angle-of-attack are also discussed.

The effects of turbulence intensity and angle of attack are reported by Crowe et al. (1974). Their experiments yield an average value of $c_{p}=-1.3$ for the side wall, almost twice the ANSI prescribed value of $c_{p}=-0.7$. In view of such uncertainty, we can reasonably argue that the ANSI Standard approach introduces no more uncertainty to tornado loadings than it does in the straightwind case.

There are at least three major areas where significant effort is needed to obtain better tornado design loads: improved analytical techniques, numerical simulation of TSI, and laboratory experiments.

To date, analytical efforts have centered around the application of simple vortex models. Improved models that allow for nonzero $u$ and $w$ have 
been proposed, but, in general, they do not conserve angular momentum. Wen (1975) has attempted to account for the time and spatial features of the wind fleld with a drag coefficient, an inertia coefficient, and Kuo's (1971) vortex model. Details of this approach are discussed in a critical review by Hunt (1975). In general, the calculation of bluff-body flow is complex and unamenable to closed-form solutions. Another source of investigation lies along the lines discussed by Bearman and Fackrell (1975) who model incompressible potential flow with a wake-source model. In this method, the wetted perimeter of a two-dimensional body is represented with a series of discrete point vortices. The effect of the wake is mod $z$ led with sources placed on the rear of the wetted surface. Numerical calculations yield a $C_{p}$ that is in good agreement with experimental results; however, pressures in the separated region must still be obtained experimentally.

Future analytic improvement may depend strongly on better understanding of the nature of turbulence in tornado flow. Lewellen (1976) notes that determining maximum velocities in cornadoes may be closely linked to the role of turbulence. In this regard, USNRC has contracted the Aeronautical Research Associates of Princeton to develop a tornado-turbulence model based on second-order closure.

Numerically, additional effort is needed to develop a computer tool deslgned specifically for TSI. Imnediate improvements in the modeling of buundary conditions and irregular geometry would be seen for the two-dimensional case. The current problem of feeding the flow could be handled, in part, by suitable inflow and outf:ow boundary conditions. Several two-dimenslonal, finitedifference schemes ( $r, z$ coordinates) have successfully de:ined many features of axisymetric cornado flow. These encouraging results tend to support the belief that vorticity and vertical momentum are needed to maintain a concentrated vortex. For TSI applications, a three-dimensional model will probably be required to capture all the important fluid dynamics. As noted earlier, the flow in Region III (Fig. 3) is strongly influenced by the ground; strong gradients exist in all velocity components. The problen is further complicated by the eifects exerted by a building on the local flow field. Although it was once unfeasible to tackle such a protlem computationally, computer speed and numerical fluid-dynamics techniques are now sufficiently improved to permit the development of a threedimensional tornado model. 
Suitable experimental data is needed to serve as a basis of comperison and to corroborate num arical and other aperoximate methods. To date, lat ratory tests have ieen rinducted primarily to study the phenomena of vortex fiow. Chang's '1971) exploratory study with a fixed cubic model is the only known exception. Improved results can be obtained by building a vortex simulator designid expectally for studying TSI. Such a chamber would allow for a wiue range of flow rates and would have a larger capacity than existing apparatus.
A recent expariment by cermak and Akins (1976) is also of interest. A fixed building model, instrumented with pressure taps, was placed in a wind tunnel. A deflector plate was located just upstream of the building to introduce a horizontal (y) velority gradient. A cumparison of results obtafned wth and without the deflector plate shows a signiflicant decrease in pressure and force coeffictents in the presence of the horizontal velocity gradient. Hence, further laboratory modeling of the more complex tornado phenomenon may produce even more surprising results.

\section{Acknowledgments}

The auther acknowledges the assistance of James Costello, U.S. Nuclear Regulatory Commission, office of Standards Development, for guiaance and support throughout this study. Also appreciated are the many helpf suggestions of Jack Cermak, Colorado
State University, and Joseph Golden, National oceanic and Atmospheric Administration. Finally, I thank Bob surray for continuing advice and support as well as Shirley Calvert and Sylvia Falce for typing the manuscript and preparing tine figures. 


\section{References}

i. Abbey, R. F. (1976), "Risk Probabilities Associated with Tornado Windspeeds," presented at $\therefore$;

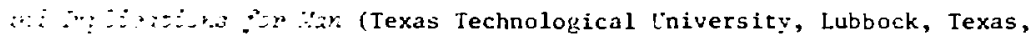
June 1976).

2. Abbey, R. F. and T. T. Fujita (1975), "Use of Tornado Path Lengtis and Gradations of Damage to Assess Tornado Intensity Probabilities," in

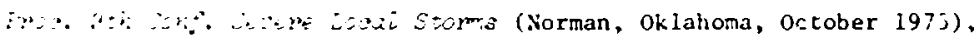
286-293.

3. Agee, E., C. Chuich, C. Yorrts, and J. Snow (1975), "Some Synoptfc Aspects and Dynamic Features of Vortice Associated with the Tornado Outbreak of

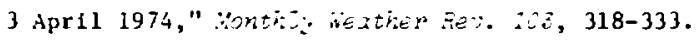

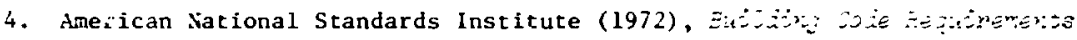

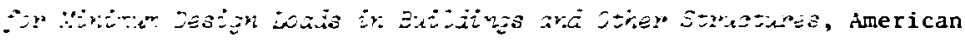
National Standards Institute, New York, ANSI Standard A58.1-1972.

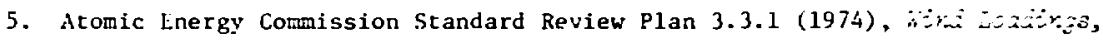
U.S. Atomic Energy Combsion, Directorate of Licensing.

6. Atomic Energy Commission Standard Review Plan 3.3 .2 (1974), = Sazing, U.S. Atomic Energy Commission, Directorate of Licensing.

7. Bearman, P. W. and J. E. Facrell (19;5), "Calculation of Two-Dimensional

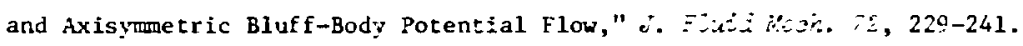

8. Bellamy-Knights, P. G. (1970), "An Unsteady Two-Cell Vcrtex Solution of

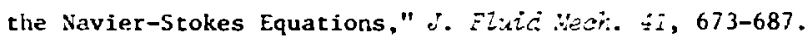

9. Bode, L., L. M. Leslie, and R. K. Smith (1975), "A Numerical Study of Boundary Effects of Concentrated Vortices with Applications to Tornadees and Waterspouts," Guart. J. Foj. "Yet. SO0. 101, 313-324.

10. Burggrif, 0. R., K. Stewartson, and R. Belcher (1971), "Boundary Layer Induced by a Potential Vortex," Phys. Fiuids I4, 1821-1833.

11. Burgers, J. M. (1948), "A Nathemacical Model Illustrating the Theory of Turbilence," Aduarces App Z. Ueen. I, 171-199.

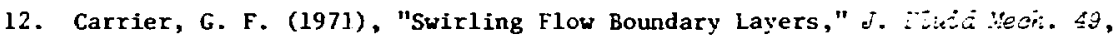
133-1 +4 .

13. Cermak, J. E. (1973), "Fluid Mechanics Applications to Problems of Wind Forses on Structures and Air-Pollution," in Pros. 1zith Wiawestem ¿echariuj Conf. (Pittsburgh, Pennsylvania, August 1973), vol. 7, pp. 37-53. 
14. Cermak, J. E. and R. E. Akims (1976), "Wind Loads of Structures," presented at Syposium on Tomadoes: fosesment of woutatie and Imaticutioxs fon licx: (Texas Technological University, Lubbock, Texas, June 1976).

15. Chang, C. C. (1969), "Recent Labcratory Modei Study of Tornadoes," presented at oth conf. Severe Loct: Storms (Chicago, Illinois).

16. Chang, C. C. (1971), "Tornado Wind Effects on Buildings and structures with Laboratory Simulation," in Proo. Int Internt. Conf. Wind Effects ont Switaings cind Stmitures (Tokyo, Japan) vol. II, pp. 8.1-8.10.

17. Chi, S. K. and W. J. Glowackl (1974), "Applict Bility of Mixing Length Theory to Turbulent Boundary Layars Beneath Intense Vorttces," ASUfE : Apte. thoin. 42, 15-:9.

18. Chi, S. W. and J. Jih (Iý74), "Numerical Modeling of the Three-Dimensional Flows in the Ground Boundary Layer of a Mintained Axisymetrical Vortex," Tetizis $26,444-455$.

19. Chi, S. W., S. J. Ying, and C. C. Chang (1969), "The Ground Turbullent Boundary Layer of a Stacionary Tormado-Like Vortex," Tetilius 21, 693-700.

20. Crove, C. T., A. Barriaga, J. A. Roberson, and W. V. Taylor (1974), "Are the codes Safe for wind Pressures?" ASCE T. Strumtatat Division 100, $1745-1747$.

21. Davies-Jones, R. P. (1973), "The Dependence of Caxe Kadius on SwirI Ratio in a Tornadio Sinulator," $r$. Atmos. Soi. 30, 1427-1438.

22. Davies-Jones, R. P. ( $(276)$, "Laboratory Simulations of Tornadoes," presented at Symosiur on Tomados: Assessment of knouledge und Inotications for hon (Texas Technological University, Lubbock, Texas, June 1976).

23. Davies-Jones, R. P. and E. Kessler (1974), "Tornadoes," in Westinep and Climatei Hodifination, K. X. Hess, Ed. (John killey and Sons, New York) pp. 552-595.

24. Davies-Jones, R. P. and G. T. Vickers (1971), Wuturact Simutation of Comective Vortices, Nacional Severe Storms Laboratory, Norman, Okllahoma. NRAA Techmical Nemotandum ERL-NSSL-5T.

25. Doan, P. L. (1970), "Tornado Constderations for Nuclear goker-Plant Structures," Wot. Safety It, 296-308.

26. Bonaldson, C. duP. and R, D. Sullivan (1960), "Behavior oî the Sollutions of the Navier-Stokes Equations for a Complete Class of Three-Dimensionall viscous Vortices," in Proc. 1960 Hect Tronsfer and Eluid Wechamios Institute (Stanford University Press) pp. 16-30. 
27. Environmental Science Services Administration (1969), Formado (U.S. Dept. Comerce, Hashington D.C.).

28. Fujita, T. T. (1971), Proposed thonaterization of Tomadoes and Hiwpicanes by Area onc Intensitit, Dept. Geophysical Sciences, University of Chicago, SMRP Paper No. 91.

29. Fujita, T. T. and A. D. Pearson (1973), "Results of FPP Classification of 1971 and 1972 Tornadoes," in Proc. Sth Comp. Severe Loaci Storms (Denver, Colorado, October 1973), pp. 244-252.

30. Fulks, J. R. (1962), (m the Hechulios of the Tormado, National Severe Storms Laboratory, Norman, Oklahoma, NOAA Technical Memorandun ERL-TNLNSSL-4.

31. Golden, J. H. (1976), "An Assessment of kindspeeds in Tornadoes," in

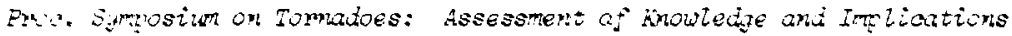
for Wr: (Texas Technological University, lubbock, Texas, June 1976).

32. Golden, J. H. and D. Purcell (1975), "Photogrametric Velocities for the Great Bend, Kansas Tornado: Accelerations and Asymetries," in F2uc. Ith Conf. on Severe Loax? Storms (Norman, Oklahoma, October 1975), Pp. $336-343$.

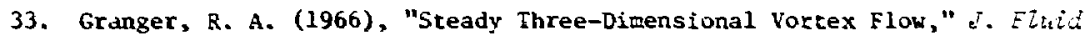
Mecth. 25, 557-576.

34. Granger, R. A. (1972), "A Steady Axisymetric Vortex Flow," ieoping. Eluiti Dymarics 3, 45-88.

35. Gutman, L. N. (1957), "Theoretical Model of a Haterspout," ButL. ACaci. Sci. USSE I, 87-103 (Geophysical series, Pergamon Press Translation).

36. Harlow, F. H. and L. R. Stein (1974), "Structural Analysis of Tornado-Like Vortices," J. thos. Soi. 51, 2081-2098.

37. Hart, G, C. (1976), "Estimstion of Structural Damage Due to Tornadoes," presented at Symosium on Tormidoes: Assessment of bnowiedije and Impliantions for Mam (Fexas Technological University, Lubbock, Texas, June 1976).

38. Hoecker, K. H. (1960), "Wind Speed and Air Flow Patterns in the DaIlas Tornado of April 2, 1957," Honthily Weather Rev. 38, 167-180.

39. Hoecker, W. H. (1961), "Three-Dimensional Pressure Pattern of the Dallas Tornado and Some Resultant Implications," Monthity heather Rev. 09 , 533-542.

40. Howe, G. W. (1974), "Tornado Path Sizes," J. Apt t. Het. 15, 343-347. 
41. Hsu, C. T. (1973), "Laboratory Modeling of the Tornado Suction Mechanism," in Erow. Stin Conf. Severe Loasi St02ms (Denver, Colorado, october 1973), 199-202.

42. Hsu, C. T. and B. Fatrahi (1975), "Tornado Funnel Formation from a

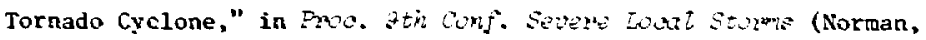
Oklal:oma, October 1975), 358-363.

43. Hsu, C. T. and B. Fattahi (1976), "Mechanism of Tornado Funnel Formation," Fins, Firids $19,1854$.

44. Hsu, C. T. and H. Tesfatuartam (1976), "Computer Simulation of a TornadoLike Vortex Boundary Layer Flow," Engineering Research Institute, Iowa Stace University, Ames, Iowa, Preprint ERI-76231.

45. Hunt, J. C. R. (1975), "Discussion of Dynamic Tornadic Wind Loads on Tall Buildings," J. Striotirat Division, ASUE 101, 2446-2449.

46. Jischke, M. C. and M. Parang (1974), "Properties of Simulated TornadoLike Vortices," J. Aimos. Soi. II, 506-512,

47. Jischke, M. C. and M. Parang (1975), Ftidid dramics of a Tommato-Like Toptex Elow, Universicy of Oklahoma, Final Report NOAA Grant N22-200-72(G) and $04-4-22-13$.

48. Kuo, H. L. (1966), "On the Dynamics of Convective Atmospheric Vortices," J. Atmos. Soi. $23,25-42$.

49. Kue, H. L. (1971), "Axisymetric Flows in the Boundary Layer of a Maintained Vortex," J. Atmos. Sei. 23, 20-41.

50. Leslie, L. M. (1971), "The Development of Concentrated Vortices: A Numerical Study," J. Fltiid Mech. $4 S, 1-21$.

51. Lewellen, K. S. (1962), "A Solution for Three-Dimensional Vortex Flows with Strong Circulation," $T$. Elitid Meot. If, 420-432.

52. Lewellen, K. S. (1976). "Theorecical Models of the Tornado Vortex," presented at Symosium on Tomadoes: Assessment of Knowiedje ana Imications for Man (Texas Technological University, Lubbock, Texas, June 1976).

53. Lilly, Z. K. (1969), Tomado Dimamias, National Center for Atmospheric Research, Boulder, Colorado, NCAR Manuscript 69-117.

54. Long, R. R. (1956), Sourees and Sinks at the Axis of a Rotating Liquid," vizart. 5. Wech. Appt. Math. I, 385-393.

55. Long, R, R, (1958), "Vortex Motion in a viscous Fluid," t. Wet. I5, $100-112$. 


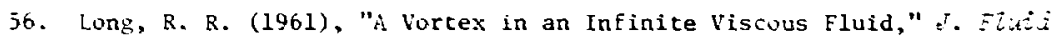

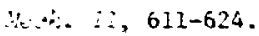

57. Sal'Bakhov, V. M. (1972), "Investigation of the Structure of Tornadoes,"

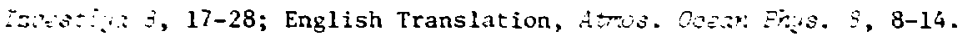

58. Markee, E. H., J. G. Berkerley, and K. E. Sanders (1974), J-3inizat 3asis

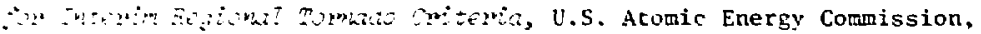
Office of Regulation, Washington, D.C., WASH-1300.

59. McDonald, J. R., K. C. Mehta, and J, E. Minor (1974), "Tornado-Res istant

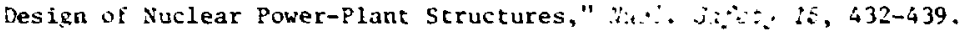

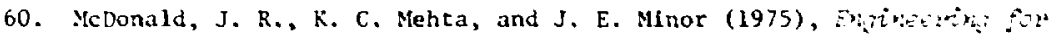
Trmilits, Instituce of Disaster Research and Dept. Civil Engineering (Texis Technology University, Lubbock, Texas).

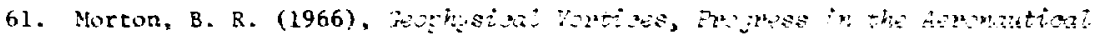
S_Ans:s (Pergamon Press, New York), vol. 7, pp. 145-194.

62. Pearson, A. (1976), "Tornado Prediction," presented at sintester on

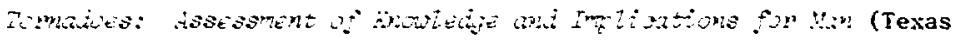
Technological University, Lubbock, Texas, June 1976).

63. Rott, $\triangle$. (1958), "On the Viscous Core of a line Vortex," E. 9, 543-553.

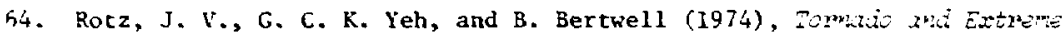

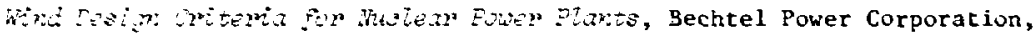
San Francisco, California, Report BC-TOP-3-A, Rev. 3.

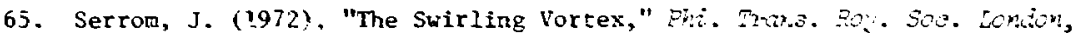
A $272,325-360$.

66. Shanahan, J. A. (1976), "Tornado Structure-Interaction," presented at

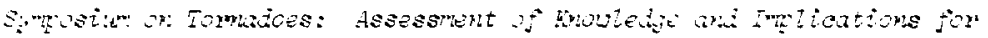
U.: (Texas Technological University, Lubbock, Texas, June 1976).

67. Sinclair, P. C. (1973), "The Lower Structure of Dust Devils," I. Atmos. S.i. 5o, 1599-1619.

6S. Smith, R. C. and P. Smith (1965), "Theoretical Flow Pattern of a vortex in the Neighborhood of a Solid Boundary," IEtike $I \%, 213-219$.

69. Stevenson, J. D. (1976), "Application of Tornado Technology" to the Nucledr Industry," presented at Simositu on Tombios: Assessment of

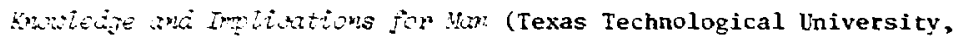
Lubbock, Texas, June 1976).

70. Sullivan, R. D. (1959), "A Two-Cell Vortex Solution of the Navier-Stokes Equations," $J$. Aexosürae Sui. 2\%, 768-769. 
71. Sutcliffe, K. G. (1974), $B B C$ bydrodynamios, Lawrence Liverwore Laboratory, Livermore, California, Report UCIR-716, Rev. 1.

72. Turner, J. S. (1966), "The Constraints Imposed an Tornado-Like Vortices by the Top and Bottom Boundary Conditions," J. Eluid Mech, 25, 377-400.

73. Turner, J. S. and D. K. L.11ly (1963), "The Carbonated-Water Tornado Vortex," J. Atmos. Sci. 20, 468-471.

74. USNRC Regulatory Guide 1.76 (1974), Design Basis Tomado for Kuclear Power Plants, U.S, Atonic Energy Comission, Directorate of Regulatory Standerds.

75. Wan, C. A. and C. C. Chang (1972), "Measurement of the Velocity Field In a Simulated Tornado-Like Vortex Using a Three-Dimensional Velocity Probe," J. Atmos. Sci. 29, 116-127.

76. Ward, N. B. (1972), "The Exploration of Certain Features of Tornado Dynamies U'sing a Laboratory Model," J. Atmos. Sci. 29, 1194-1204.

77. Wen, Y. K. (1975), "Dynamic Tornadic Wind Loads on Tall Buildings," J. Structural Division, ASCE 101, 169-185.

78. Wen, Y. K. and S. I.. Chu (1973), "Tornado Risks and Design and Speed," J. Structural Division, ASCS 99, 2409-2421.

79. Hirid Fones on Structures. Final Feport Task Comittee on Wind Foraes, Countitee on Loads and Stresses, Structural Division, Amerioan Jociety of Civit Engineers, 1961: vol 126, Part II, pp. 1124-1198.

80. Wipperman, F., I. Berkofsky, and A. Szillinzky (1969), "Numerical Experiments of the Formation of a Tormado Funnel Under an Intensifying Vortex," Qtwant. J. Roy. Net. Soc. 95, 689-702.

81. Ying, S. I. and C. C. Chang (1970), "Exploratory Model Study of Tornado-like Vortex Dynamics," J. Atmos. Sct. 27, 3-14. 


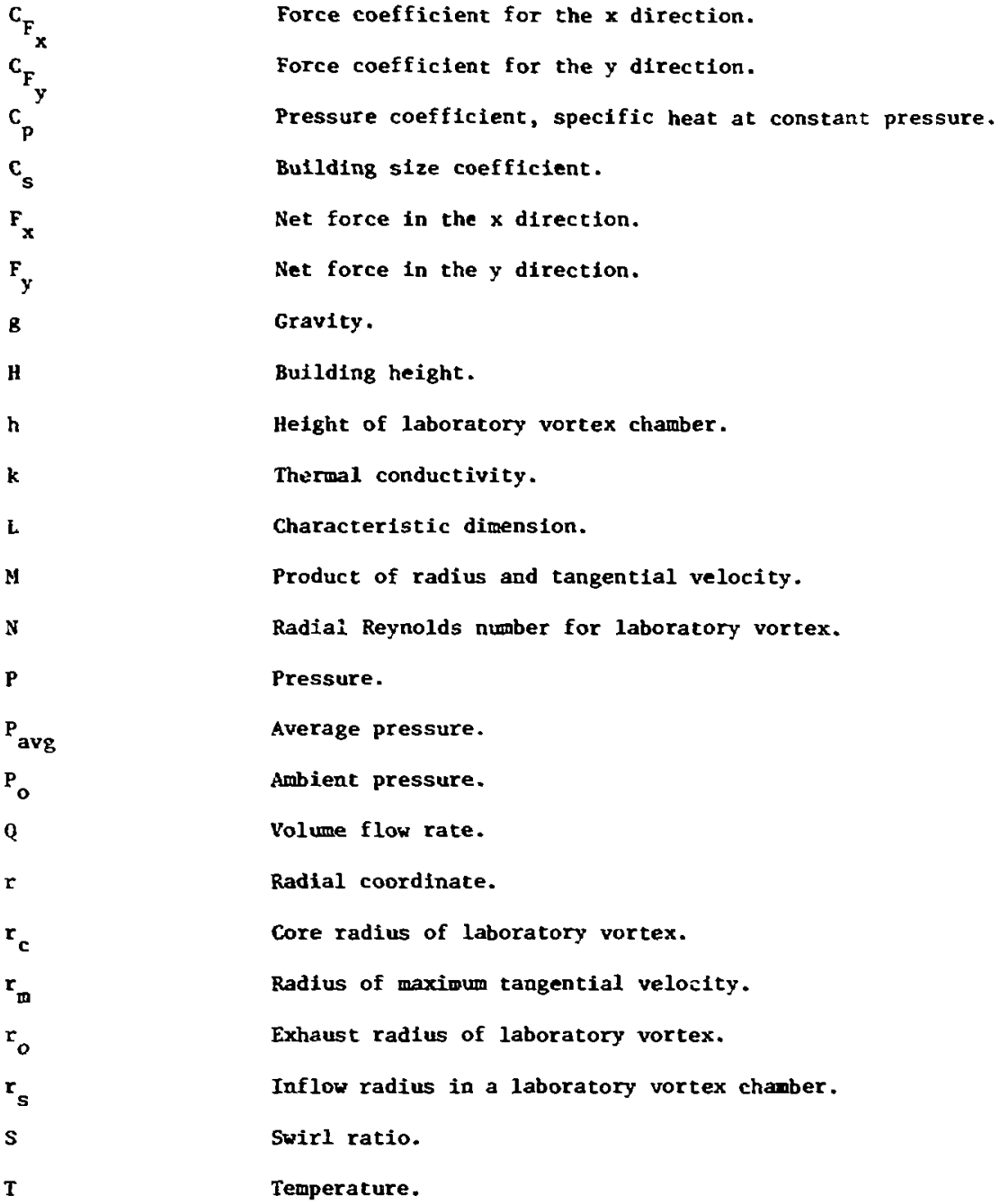


v

II

W

W

$w_{t}$

W

$\mathbf{w}$

$\mathbf{x}$

$y$

$z$

$\Gamma$

$\Omega$

$\rho$

$\theta$

v

Time, tangential.

Free stream velocity.

Radial velocity.

Velocity.

Maximum velocity.

Rotational velocity.

Translational velocity.

Tangential velocity.

Maximum tangential velocity.

Building widtl.

Building load due to atmospheric pressure change.

Design load.

Building load due to velocity pressure.

Vertical velocity.

West to east coordinate.

South to north coordinate.

Vertical coordinate.

Circulation.

Angular velocity.

Density.

Angular displacerent.

Coefficient of kinematic viscosity. 


\section{Appendix B: Procedure for Calculating Wind Loads for Straight Winds}

For most wind loading calculations, the design loads are obtained by the procedure outlined in ANSI A58.11972. A brief summary is given below.

Wind loads on bulldings and other structures are determined with the following procedure:

- A mean recurrence interval shail be selected which depends on the intended operational usage, anticipated life of the structure, degree of sensitivity to wind, and risk to human life and property in case of failure.

- A basic wind speed is selected based on a recurrence interval of 25,50 , or $100 \mathrm{yr}$.

- The basic wind speed is converted to effective velocity pressures $q_{F}$ or $q_{P}$ by the following formulas:

$$
\begin{aligned}
& \mathrm{q}_{F}=K_{z} G_{F} q_{30}, \\
& q_{P}=K_{z} G_{P} q_{30},
\end{aligned}
$$

where $q_{F}=$ effective velocity pressure for ordinary buildings and structures (psf), $q_{p}=$ effective velocity pressure for parts and portions of buildings and structures (psf), $q_{30}=$ $0.00256 v_{30}^{2}$, basic wind pressure (psf), $v_{30}=$ basic wind speed (mph), $G_{G}=$ gust factor for ordinary buildings and structures, $G_{P}=$ gust factor for parts and portions of buildings and structures, and $k_{z}=$ velocity pressure coefficient of height $z$ which depends upon type of exposure.

- The design pressures or design loads are obtained ty multiplying the effective velocity pressures by appropriate pressure coefficients. 


\section{Appendix C: External Pressure Coefificients for Walls for Straight Winds}

\begin{tabular}{lc}
\hline \multicolumn{1}{c}{ Wall Location } & Pressure coefficient \\
\hline Windward wall & 0.8 \\
$\begin{array}{l}\text { Leeward wall (both helght/width and } \\
\text { helght/length ratios of buflding } \geq 2.5 \text { ) }\end{array}$ & -0.6 \\
Other bulldings & -0.5 \\
$\begin{array}{l}\text { Side walls } \\
\text { Wall corners (applies over a width } C .1 \mathrm{w} \text {, where } \\
\text { is the least width of the building) }\end{array}$ & -0.7 \\
\hline
\end{tabular}

${ }_{\text {ANSI ASB.1-1972. }}$ 


\section{Appendix D: Time-History Tabulation of Building Surface Pressures and Force Coefficients}

TORNADO STRUCTURE INTERACTION RUN NO. I

WEST HALL

(SEC)

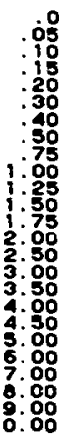
SURFACE PRESSURES (SOUTH TO NORTH)
(PSF)

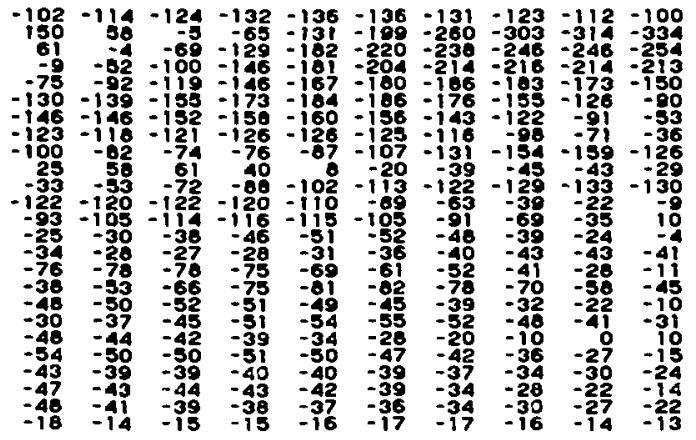

AYERAOE

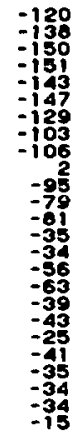

AYERACE

(SIEC)

SIMFACE PRESSURES (SOUTH TO MORTH)

PRESSURE

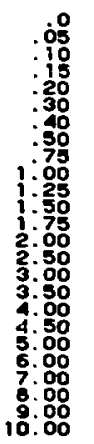

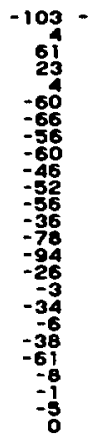

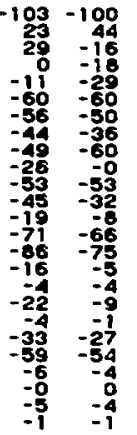

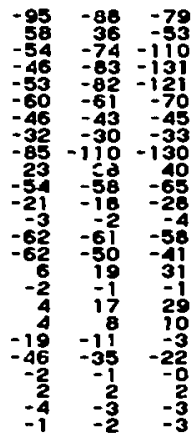


TORNADO STRUCTURE INTERACTION RUN NO. I

MORTH WALL

TIME,

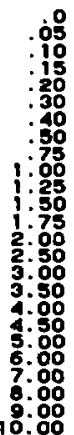

SURFACE PRESSURES

(WEST TO EAST) (PSF)
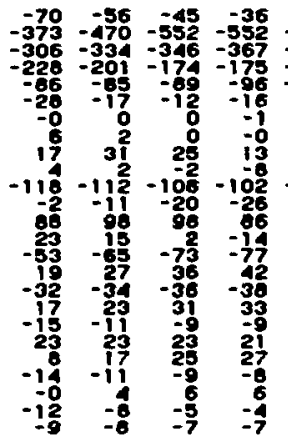

$\begin{aligned}-28 & -8 \\ -526 & -403 \\ -403 & -39\end{aligned}$

$-492$

$-16-11$

$-3 i^{-7}-235$

- $109=126$

-34: -321

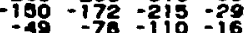

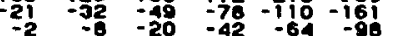

$\begin{array}{rrrrrr}-2 & -6 & -20 & -42 & -64 & -98 \\ -1 & -13 & -27 & -47 & -66 & -79 \\ -i 5 & -27 & -62 & -107 & -136 & -170\end{array}$

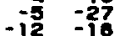

$-18$

$-104-107-107-100$

$-33-42$

$-107-102$

-170
-8

$-84$

$-30$

- 45

465

$-39-36$

27
-58
-70

13
-81
-61

56
-30

1

17
29
-6

is

42

13
27
-6

-6
2
-4
-0

-

-8
-5
-1
4
1
-4
-3

-71
-61
-41

$-4$

-8.

$-20$

35

i7

21

3
-5
-8

SOUTH WALL

(SIME)

SURFACE PRESSURES (WEST TO EAST) (PSF)

average

pressure
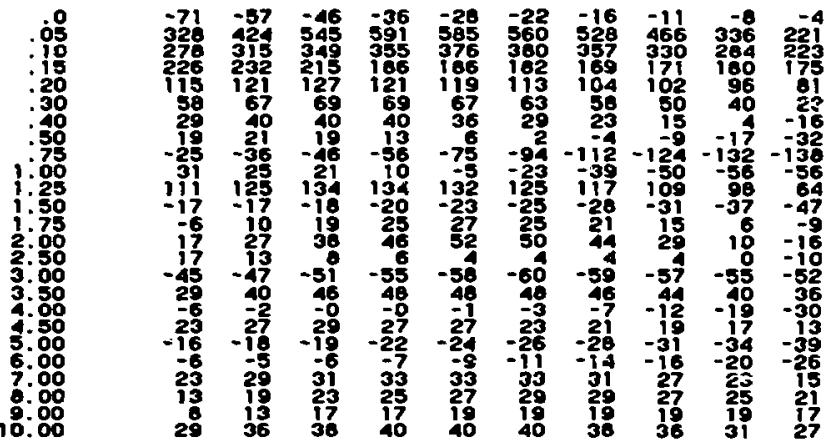

-30
454
320
189
108
54
21
-80
-85
-14
114
-26
12
20
-54
41
-89
22
-26
-13
27
23
16
38 
TORNADO STRUCTURE INTERACTION RUN NO. 1

\section{BUILDING FORCE COEFFICIENTS}

$\underset{\text { TIME }}{\text { (SEC) WEST-EAST }}$

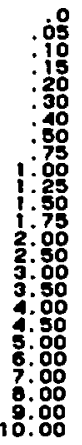

$-14$

$\because 71$

$-.80$

.82

$\because 26$

$-18$

.13

.23

$-.13$

$-.22$

.18

$-10$

.29

$-.07$

.20

.84

$\because 14$

$-16$

$\because .14$

$-.00$

4.14

3.05

1 . is

. 49

10

$\therefore 19$

$\because .05$

.04

.19

.27

$\therefore 46$

.33

.20

.13

$-16$

.16

. 09

.10 
TORNADO STRUCTLRE INTERACTION RUN NO. 2

HEST HALL

(SIME)

.09

is

.20

.38

.80

$1: 00$

$1: 25$

1.75

2.00

2. 50

$3.0 \%$

4.90

4.90

5. 80

7.00

8.00

10.00
SURFACE PRESSURES (SOUTH TO NORTH)

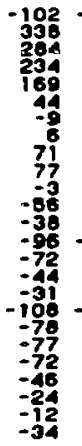

$\begin{array}{rr}114 & -124 \\ 276 & 249 \\ 207 & 130\end{array}$

$-132-136$ 209

150 8.

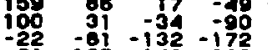

- -104

$-104-79$

$-147-178$

$-134-166-186-200$

$109-211-209=198=204$

$-6107-143-106-102-105-178-102=137$

$-37-76-100-133-146-182-146-128-102$

50 21 - $14-55-50-144-103-204-181$

-42
-47

$\begin{array}{ll}-41 & -72 \\ -78 & -93\end{array}$

$-57-97-120-127-122-100$

$-80-123-120=183-175=170-160$

$-90-81-72-44-17$

$-50$

1

-54

$-4 \overline{2}-20$

$-137-118-93$

$-1$

-5 .

$-90$

$-140-144=137$

$-82$

$-119-110-105$

$-88-92$

$-92-88$

120
-89
-77

-8:

-122
-90
-7

-90
-89

$-89-79$

$\begin{array}{rr}-70 & -59 \\ -57 & -48\end{array}$

$-58$

$-39$

-52
-35

-47
-30

$-64$

$-2$

$-40 \quad-38$

$\begin{array}{lll}-21 & -130 & -35 \\ -21 & -18 & -16 \\ -27 & -26 & -24\end{array}$

$-6 \quad-5$

$-30$

$-29$

$-2$

$\begin{array}{ll}-32 & -3\end{array}$

EAST WALL

T(ME)

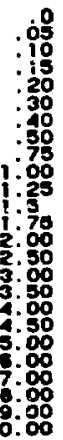
SURFACE PRESSURES (SOUTH TO NORTH)
AVERAOE

PRESSURE

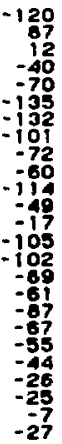

AVERAOE

-90
-215
-176
-137
-129
-134
-127
-148
-127
-50
-55
54
-69
-216
-93
-21
-49
-45
-40
-31
-31
-39
-14 
TORNADO STRUCTURE INTERACTION RUN NO. 2

NORTH WALL

(SIME)

.00
.05
110
120
.30
.90
.90
1.90
1.25
1.75
2.00
2.90
3.00
3.50
4.00
5.90
5.00
7.00
.00

10: SURFACE PRESSURES (HEST TO EAST)

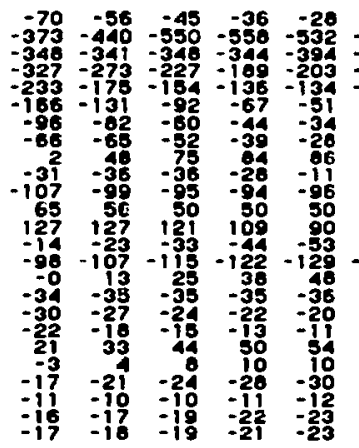

$$
\begin{array}{r}
-22 \\
-504 \\
-413 \\
-199 \\
-129 \\
-41 \\
-20 \\
-23 \\
90 \\
10 \\
-96 \\
48 \\
-63 \\
-137 \\
54 \\
-37 \\
-19 \\
-89 \\
58 \\
-32 \\
-13 \\
-24 \\
-23
\end{array}
$$

$-16-11$

$-33^{-7}-2 \overline{-4}$

$-340-317-203$

-305
$-143-285$
$-47-308-317$

$\begin{array}{llll}-42 & -19 & -26 & -33\end{array}$

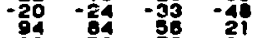

38
-84

88

$-8$

79
-70

21
-55

$-55$

$\begin{array}{rrrr}44 & 42 & 42 & 42 \\ 63 & -56 & 56 & 61 \\ -66 & -70 & -72 & -73\end{array}$

$\begin{array}{rrrr}-66 & -70 & -72 & -73 \\ 36 & -56 & -187 & -180 \\ -38 & -40 & -43 & -47\end{array}$

$-38-40$

$-8$

so

-8.

$-19$

$-10-15$

$-34$

-3
-34

$\begin{array}{rr}-9 & -18 \\ -32 & -20\end{array}$

$\begin{array}{ll}-32 & -29 \\ -12 & -10\end{array}$

$\begin{array}{llll}-24 & -23 & -21 & -20\end{array}$

$\begin{array}{llll}-24 & -23 & -21 & -20 \\ -23 & -22 & -20 & -10\end{array}$

AYERAGE
PRESSURE

-30
-442
-348
-348
-157
-76
-45
-40
61
12
-89
49
-38
-138
-38
-38
-22
-13
47
-28
-12
-21
-20
SOUTH WALL

TIME,

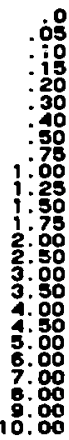

SURFACE PRESSURES (WEST TO EAST) (PSF)
AVERAGE

PRESSURE 
TERNADO SIRUCTURE INTERACTIOA RUN NO. 2

\begin{tabular}{|c|c|c|}
\hline \multicolumn{3}{|c|}{ BUILOINO FORCE COEFFICIENTS } \\
\hline $\begin{array}{l}\text { TIME, } \\
\text { (SEE) }\end{array}$ & WEST-EAST & SOUTH -NORTH \\
\hline 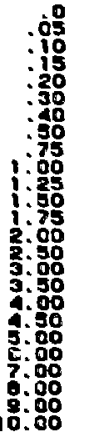 & 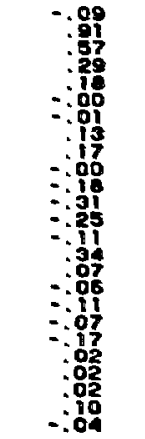 & 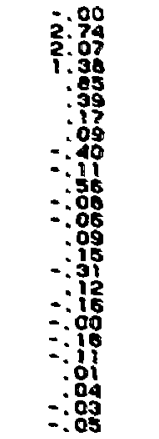 \\
\hline
\end{tabular}


TORNADO STRUCTURE INTERACTION RUN NO. 3

WEST HALL

TIMEC)

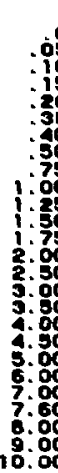
SURFACE PRESSURES (SOUTH TO MORTH)
AVERAOE

PREsSURE

EAST HALL

(ISE)

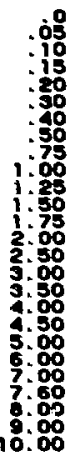

SURFACE PRESSURES (SOUTH TO NORTH) (PSF)

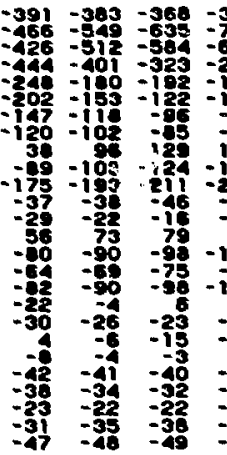

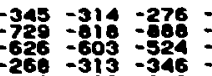

$-231-178-133-102$

$-955=738-656$

$-470-507-614$

$-105-109-222-256-305-369-463$

$-109-100-101-110-133-168-221$

$-80$

$-19$

$-62$

$-86$

$-109$

$-110$

$1353-2 \quad-61-98-116-143$

140

$-136-131-122-107-04$

$-236-231-220-205-192$

$-56-63-66$

$-10-10$

$\$ 6$

$03-105-105-104$

$-64$

28

192

-31

$-101-107$ -

109

$-80$

$-78$

-96
-86
-109

is

$\begin{array}{lll}20 & -21 & -21 \\ -20 & -30\end{array}$

-105
-25

$-31 \quad-33$

$-34 \quad-32$

$-39$

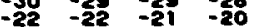

$\begin{array}{llll}-41 & -43 & -45 & -46\end{array}$

-35
-18
-28

$\begin{array}{lll}-16 & -21 & -27 \\ -28 & -25 & -22 \\ -27 & -27 & -26\end{array}$

$-46-18=18$

-271
-716
-960
-39
-259
-790
-103
-91
-117
-211
-96
-93
-97
-100
10
-28
-24
-11
-31
-30
-21
-41
-48 
TORNADO STRUCTURE INTERACTION RUN NO.

3

NORTH WALL

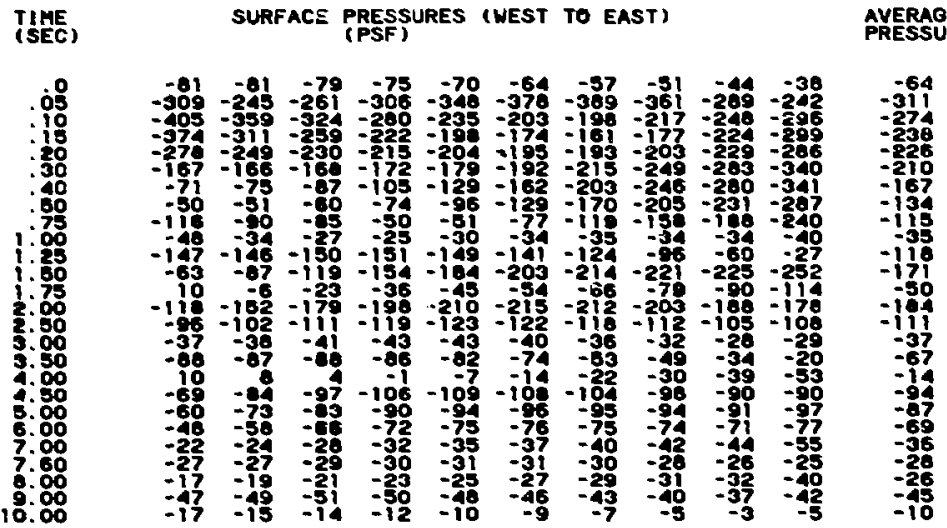

SOUTH WALL

TINEE)

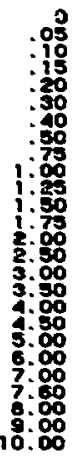

SURFACE PRESSURES (WEST TO EAST)
AVERAGE

PRESSURE

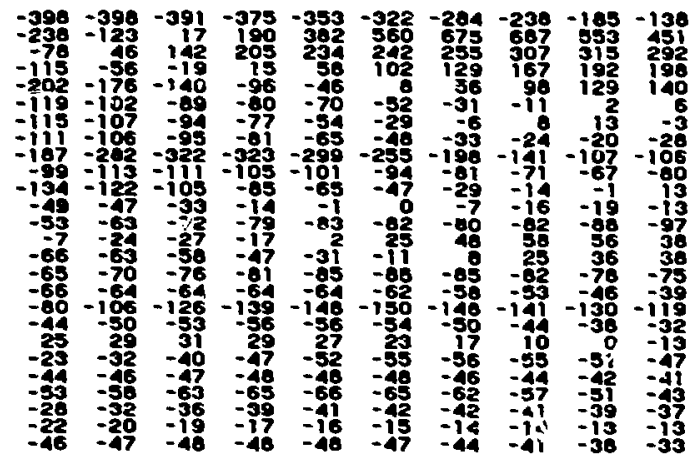

-307
308
190
-23
-58
-48
-62
-220
-93
-58
-20
-78
-15
-78
-158
-128
-47
-47
-46
-38
-38
-16
-44 
TORNADO STRUCTURE INTERACTION RUN NO. 3 BUILDING FORCE COEFFICIENTS

TIME) WEST-EAST CFX SOUTH-NORTH

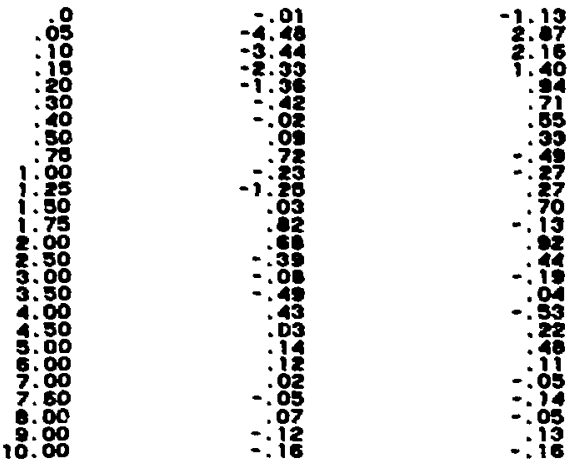


TORNADO STRUCTURE INTERACTION RUN NO. 4

WEST WALL

SURFACE PRESSURES (SOUTH TO NORTH) (PSF)
AVERAGE

PRESSURE

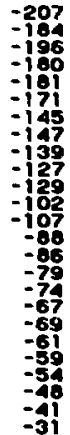

$-31$
TINE

.$\dot{0}$

11

.20

.30

40

1.80

1:

1.70

2.00

2.50
2.50

3.00

3.50

4.00

4.50

8.90

7.60

6.00

10.00
EAST MALL

TINE)

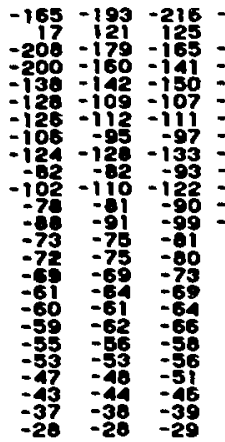

$15-238=$
-137

$-238$

$-274$

$-138=190$

-216
-422
-220
-168

-195
-449

$3=165$

78 -

$-178$

- 180

132

$-118-132-155-183-220-248-297$

$83-209-224=274$

$-130-142-143-143-140=136=167$

$-12-131-149-156-154-147-165$

$-135-141-146-143-134-124-136$

$-101-110-116-114-107-103-121$

$-106-111-114-114-115-112-120$

$-85-8$

$\begin{array}{ll}-78 & -90 \\ -78 & -78\end{array}$

$-93$

$-92$

$-909$

$-90-105$
$-90-102$

$-81$

$-77=79$

$-71=78$

$-71$

$-69-7$

-

$-63$

$-64$

$-72$

$-71$

$-62$

$-51$

$-56$

- -33

-81
-58
-50

-50 -

$-40 \quad-59$

$-42 \quad-42$

$-11-42$

$-32$

$\begin{array}{llll}-31 & -31 & -31 & -35\end{array}$
AYERACE SURFACE PRESSURES (SOUTH TO MORTH)

PRESSURE

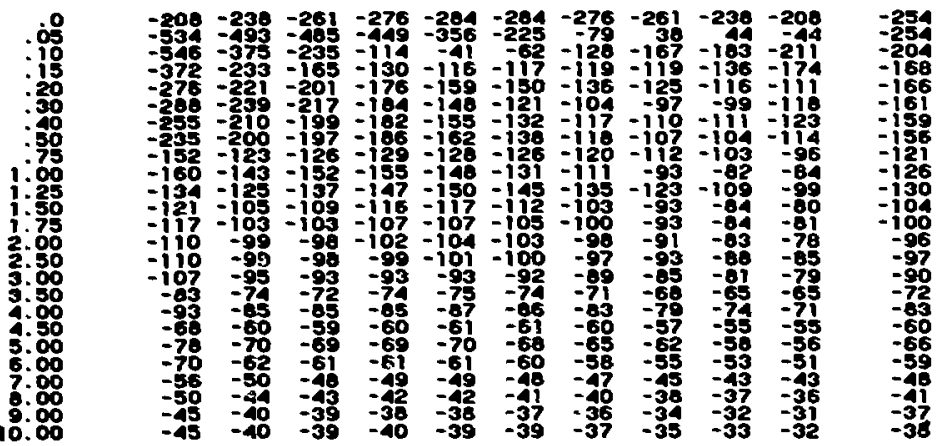


TORNADO STRUCTURE INTERACTION RUN NO.

MORTH MALL

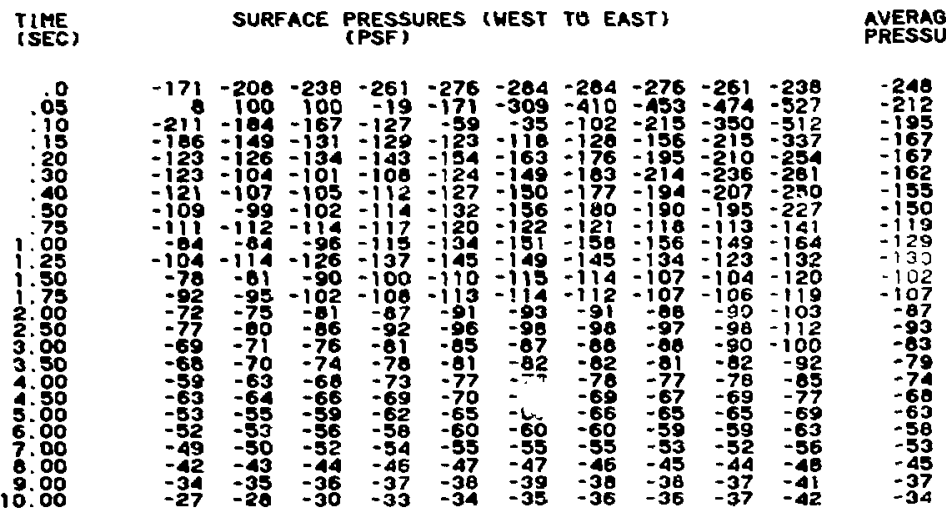

SOUTH WALL

(SIME)

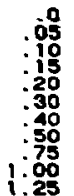

1.:30

1.75

2..50

3.00

3.50

4.00

5.00

6.00

7.00

s: 0

10.00
SURFACE PRESSURES (HEST TO EAST)

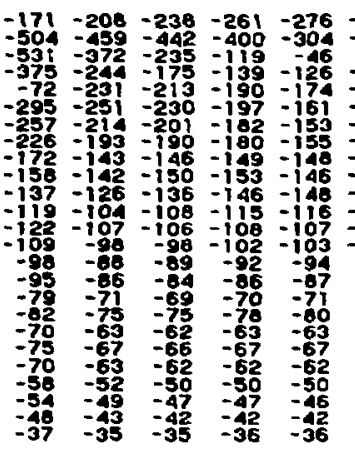

$-284-284-276-261-238$

$\begin{array}{rrrr}-284 & -276 & -261 & -238 \\ -120 & -88 & 92 & -5 \\ -130 & -170 & -178 & -208\end{array}$

$-123=160-178$

$128-133-136=154-192$

$133-115-106=108=124$

$-120-113-100-108-121$

$131-113-103-101-113$

$-143-135-126-116-108$

$-142-132-120-105-96$

$-102$

$-93$

-90
-90

-80
-89

-97
-93

$-$

$-70$

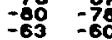

$-67$

$-61-50 \quad-56$

$\begin{array}{llll}-49 & -47 & -44 & -53\end{array}$

$\begin{array}{lllll}-45 & -43 & -44 & -42 & -41\end{array}$

$\begin{array}{lllll}-45 & -43 & -41 & -39 & -38 \\ -41 & -39 & -37 & -35 & -34 \\ -36 & -35 & -34 & -33 & -33\end{array}$
AVERAGE

PREsSuRE

$-246$

$-210$

$-180$

$-17 i$

- 150

$-130$

$-123$

$-129$

- 103

$-100$

$-90$

$-85$

-68
-77

-77
-61

$-65$

$-60$

$-48$

-45
-40

$-4 C$
-35 
TORNADO STRUCTURE INTERACTION RUN MO. 4

BUILDING FORCE COEFFICIENTS

TIME, MEST-EAST SOUTH-MORTH

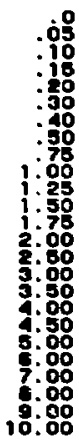

23

.03

$\because: 05$

$\because 04$

.07

-o

-ogi

:ơ

$-.04$

.os

- .01

.07

$-.04$

.02

$-.03$

$-.03$

$-.02$

.o

$\because .03$

$-.08$

$-.84$

$\because$ of

.o

-.09

.03

. 이

.03
-.89

o

$-\because 81$

- ói

.o4

$-.81$

$-.81$

ó

$\because .01$ 
TORNADO STRUCTURE INTERACTION RUN NO. 5

WEST WALL

TIME)

SUAFACE PAESSUAES (SOUTH TO MORTH)

AYERAOE

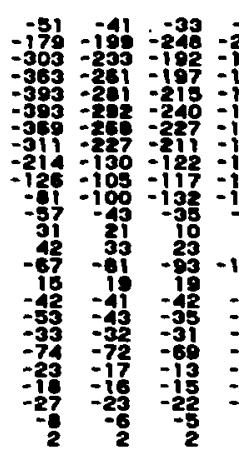

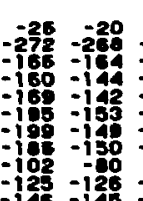

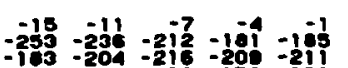

$-133-130-130$ - 150 - 1100

-12 - $121=12=124-121$

$-120-84$

$-70-81-05$

30

: : 75

i: $: 50$

1.78

2.50

3.00

3.:00

A.

8.00

$7 . \%$

8.00

10.00

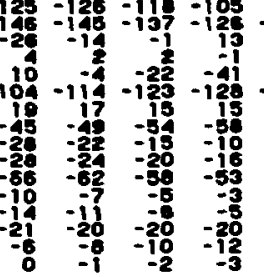

$-36$

$-90$

$-32$

$-6 \frac{4}{-69}$

$-115-105-102$

$\begin{array}{rrr}-62 & -15 & -139 \\ -62 & -13 & -123\end{array}$

$\begin{array}{rrr}-62 & -13 & -123 \\ -131 & -134 & -143 \\ 17 & 19 \\ -61 & -62 & -62 \\ -14 & -6 & -2\end{array}$

AVESTURE

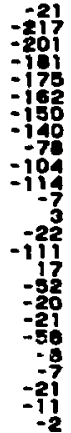

EAST WALL

TINE)

SURFACE PRESSURES (SOUTH TO NORTH)

AYERAOE

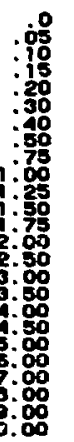
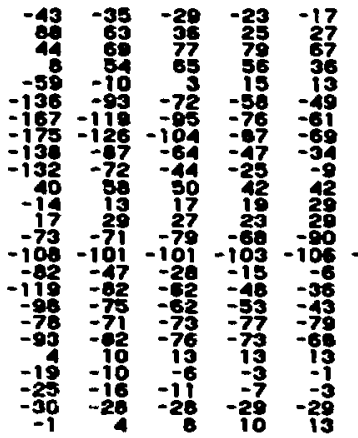

-13
31
18
-42
$-32=$
-55

-8
-8
-1
-10
-35
-47

$-35$

-2
-60
-50

-60
-82
-82

$=-83$

$-70$

$-30-30$

30

-30 -35 -36

$-36$

을

39

4

21
67

하

ㅇํำ

119

$\begin{array}{llll}-66 & -76 & -62 & -46\end{array}$

-107
-27
-27

-105
-21
-10

-108
-17

$-100-101$

PressuRE

-31
-77

-61
ig

$-72$

$-6$

$\begin{array}{ll}-18 & -21 \\ -58 & -21\end{array}$

21
-52
-26
13

$-30$

18
-30
17

15
-30
15

-3i

-16
30
20
-16
-56
-56
-72
-74
-95
-14
64
45
-65
-69
-103
-17
-44
-35
-70
-60
11
-2
-24
-29
11 
TORNADO STRUCTURE INTERACTION RUN MO. S

MORTH WALL

\section{TIMEC)}

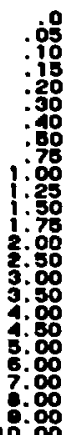

SURFACE PRESSURES (HEST TO EAST) (PSF)
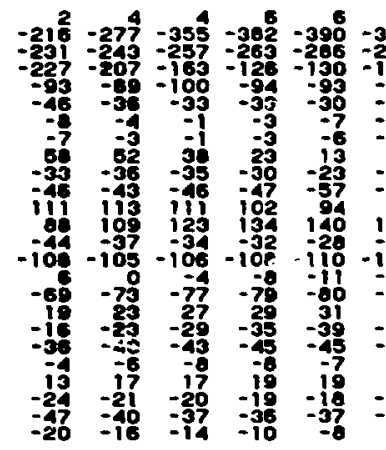

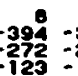

$-39 i$
-239
-30

-30
-360
-232

$\begin{aligned}-268 & -208 \\ -202 & -208 \\ -20 & -20\end{aligned}$

$120-164-107-220$

$-95-100-110-150$

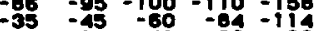

$-12$

$\begin{array}{ll}-23 & -41 \\ -21 & -34\end{array}$

$-21-34$

$-62-80$

$-40-64$

$\begin{array}{rrr}-10 & -15 & -8 \\ -60 & -56 & -43\end{array}$

$-60$

$146 \quad 1470$

$\begin{array}{rr}-16 & 23 \\ -16 & 23\end{array}$

$-16 \quad 23$

$140 \quad 140$

$-10$

$118-1$

$-116-121$

$\begin{array}{rrrrr}-12 & -113 & -115 & -176 & -121 \\ -78 & -74 & -67 & -15 & -16 \\ -39 & -56 & -43\end{array}$

$\begin{array}{rrr}-33 & -36 & -67 \\ -41 & -42 & -48\end{array}$

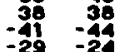

$\begin{array}{rr}-5 & -4 \\ -17 & -15 \\ -37 & -3\end{array}$

-2
-13
-13

-11
-37

$-38$

-6
-1
-8

-1
-30

AYERAOE

PRESSURE

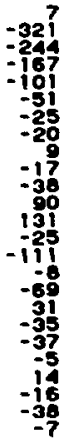

SOUTH WALL

TINEC)

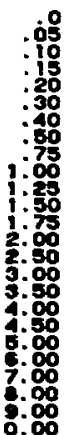

SURFACE PRESSURES (WEST TO EAST) (PSF)
AVERAoE

PRESSURE 
TORNADO STRUCTURE INTERACTION RUN NO. 5

\begin{tabular}{|c|c|c|}
\hline \multicolumn{3}{|c|}{ BUILDINS FORCE COEFFICIENTS } \\
\hline $\begin{array}{l}\text { TIME } \\
\text { (SEC) }\end{array}$ & $\begin{array}{c}\text { HEST-EAST } \\
\text { CFX }\end{array}$ & SOUTH-NORTH \\
\hline 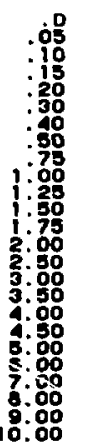 & 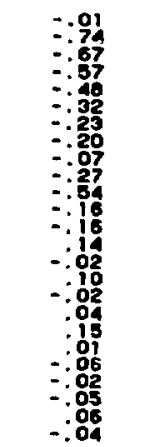 & 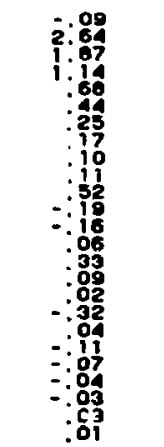 \\
\hline
\end{tabular}


TORNADO STRUCTURE INTERACTION RUN NO. 6

WEST WALL

(SIEC)

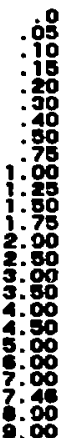

10.00
SURFACE PRESSURES (SOUTH TO NORTH)

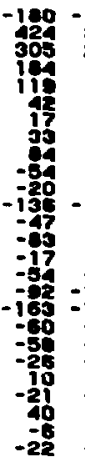

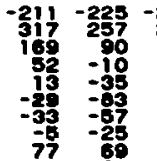

$-30-26$

$-3 \quad-3 i$

$-168$

$-71 \quad-33$

$-24$

$-27$

$-37-30$

$-110-128$
$-150-145$
$-67-70$

$-67-70-72$

$-1$

$-1$

$-1$

8
-18
33

$-5 \quad-6$

$-27$
-8
-3
-1

$-18$

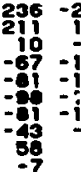

-2
-1
-1
$-i$
$-i$

$45-252-250-261-263$

$63-135$

- i69

$-198-261-331$

$-210-260-330$

$212-260-314$

$-198-233-273$

$-12$

81

$-7 \quad 17 \quad-44$

$-17$

$\begin{array}{ll}-17 & -4 \\ -68 & -8\end{array}$

$\begin{array}{ll}-20 & -27 \\ -31 & -72\end{array}$

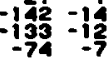

$-74-78$

$\begin{array}{rr}-8 & -3 \\ -15 & -11 \\ -12 & -7\end{array}$

2

$-15$

$-15$

$-92-10 z-118$

$\begin{array}{rrr}19 & 8 \\ -71 & 98 & -8\end{array}$

$-781-i 88-188$

$13-33-58$
$-64-65-78$

$\begin{array}{lll}-26 & -24 & -24\end{array}$

$183-160-179$

$-120-117=119$

$-81-88-103$

$\begin{array}{rrr}-38 & -60 & -68 \\ -18 & -23 & -9\end{array}$

$-9 \quad-7$

$19 \quad 13$

$-18$

$-17$

$-19$

$-22$

EAST WALL

\section{(I)EE)}

.09

:19

.20

30

.40

1.80

1.

1.00

1. 30

.60

3.00

3.00

4.00

5.00

6.0

7.9

$7 . \%$

8.00

10.90 SURFACE PRESSURES (SOUTH TO NORTH)
AYERAGE
PRESSURE

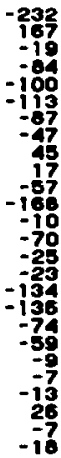

AYERAOE

SSURE

-176
-195
-93
-112
-131
-253
-201
-205
-204
-290
-190
-40
-74
-107
-196
-100
111
-44
-34
-36
-41
-17
12
-50
-50
-5 
TORMDO STRUCTUNE INTERACTION RUN No. 6

NOATH WALL

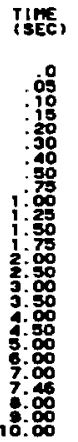

SURFACE PRESSUNES (WEST TO EAST

ANERAOE

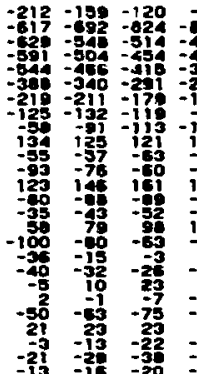

IPa

SOUTH WALL

Tine,

SUAface PRESSUnES (WEST TO EAST)

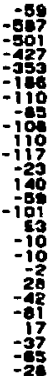

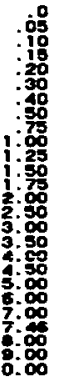

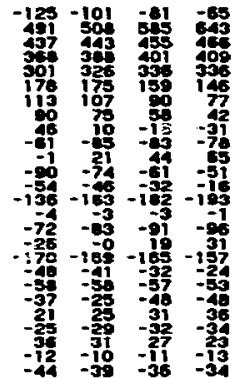

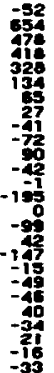

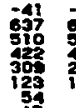

-33
6045
416
204
114

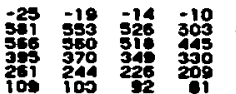

375

-3
200
205
164
-38

20214

161 is

226

67

$-490-3 e^{-2}-201$

27 -2:1

$127-19$

$-97-125$

iog $-77=7$

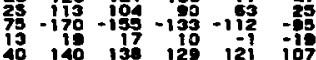

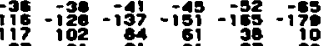

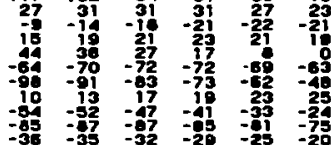

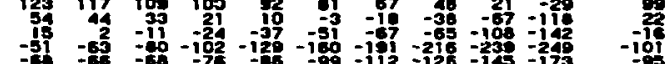

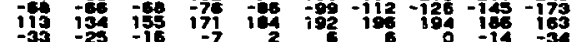

AYERTE

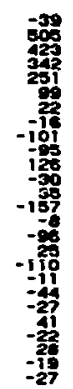


TORNADO STRUCTURE INTERACTION RUN MO. 6

DUILDING FORCE COEFFICIENTS

TIME, WEST-EAST GFX SOUTH-NORTH

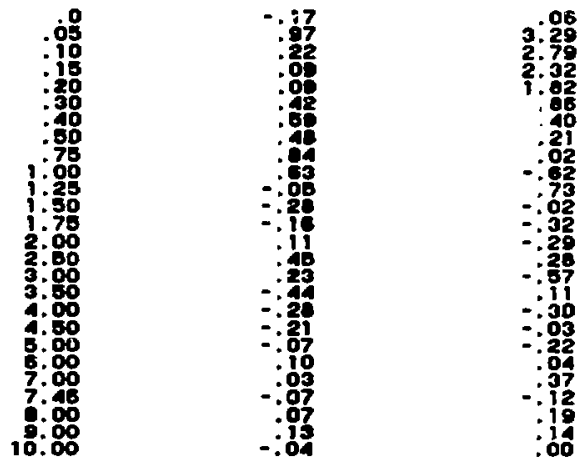


TORNADO STRUCTURE INTERACTION RUN NO. 7

WEST WALL SURFACE PRESSURES (SOUTH TO NORTH)
AVERAGE

-230
-58
-99
-121
-153
-133
-110
-68
-45
-127
-197
-77
-80
-97
-89
-89
-90
-51
-58
-71
-39
-29
-27
-29
( I SEC)

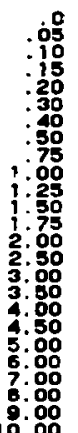

EAST HALL

(SEE)

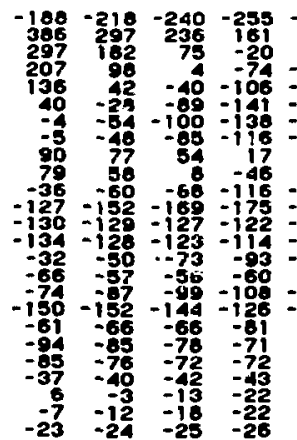

$$
-2
$$$$
262
$$$$
-261
$$$$
-49
$$$$
\begin{array}{r}
-253 \\
-153 \\
-183
\end{array}
$$$$
-230
$$$$
137-162-212
$$$$
3-204
$$

$-214-103$

$-289$

-350
-242

$56-192-216 \quad-229-234-238$

$-211-230-240-241-233$

$-184-160-156-141=11$

$-30-83-130-109-227-237$

$-87-111-119-112-88-43$

$-13$.

$-86$

$-72$

$-70-39$

$-14$

$-18$

46

o8 - $117-123-126-125-123$

$-68-79-119-197$

$-55-48-42-38$

$-63$

$-73$

$\begin{array}{ll}-44 & -43 \\ -29 & -36\end{array}$

$\begin{array}{lll}-30 & -42 & -47\end{array}$

$\begin{array}{llll}-26 & -39 & -34 & -37\end{array}$

$-39=$

$-27-25$

$-37-45$

$\begin{array}{ll}-30 & -29 \\ -34 & -30\end{array}$

$\begin{array}{ll}-33 & -30 \\ -51 & -59\end{array}$

$-39-42$

$-35-42$

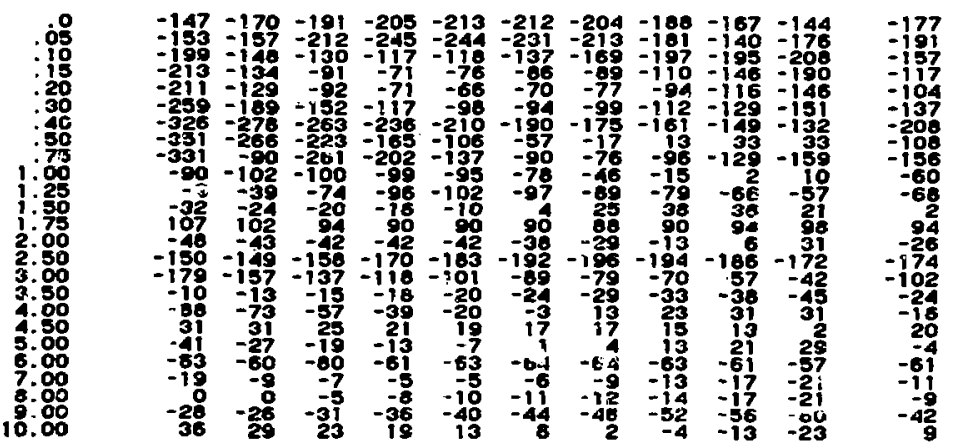




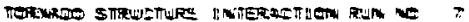

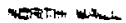

ising

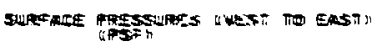

AISTHOS

PRSOSURE
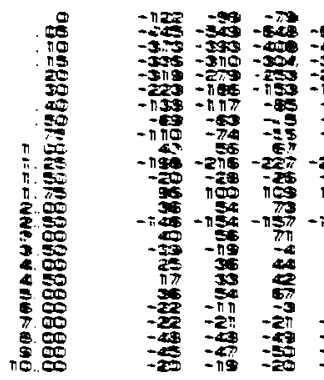

$-640-5 \pi$

$=4 \pi+2-25-79-114$

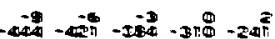

$-3 x$

$-419$

$-345$

$-\pi 3$

$-5$

$-95$

$-\pi \frac{9 \pi}{8}$

$-2$

as

$\pi$

5

苗

$-\pi \pi$

$-30$

$-50$
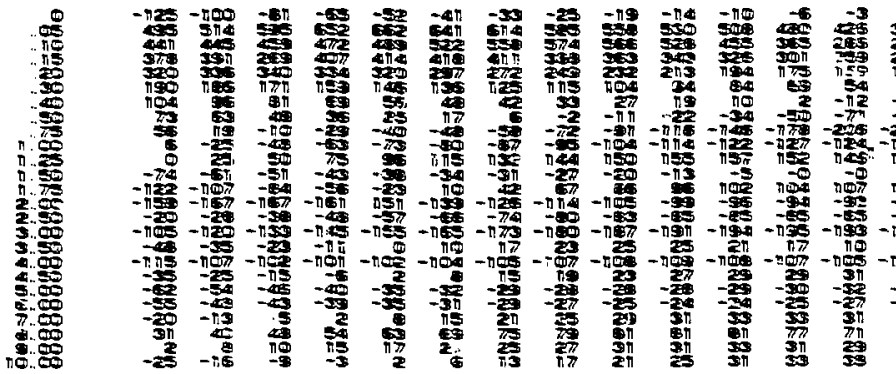

2ns

The

int 90 $\pi \operatorname{lis}^{2}$

5

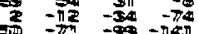

女 -390

$-\pi \pi$

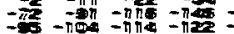

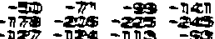

in

$+3$

$-30$

$-3 \pi-2 \frac{\pi}{3 \pi}$

100

$-\pi+\pi 5 \pi$

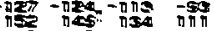

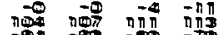

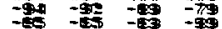

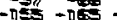

$-74-00-105$ - -50 - -5

$-\pi 90-\pi 5-i=0$

5

$2070 \pi-\pi 9$

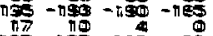

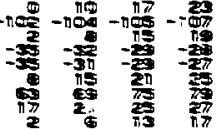

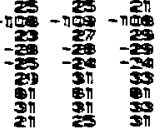

-207
-30
-25
$\frac{25}{77}$
$3 \pi$
30

-10
-35
$-3 \pi$
-27
$3 \pi$
$7 \pi$
$\frac{3 \pi}{30}$

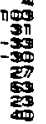

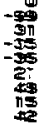

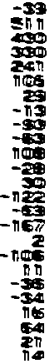




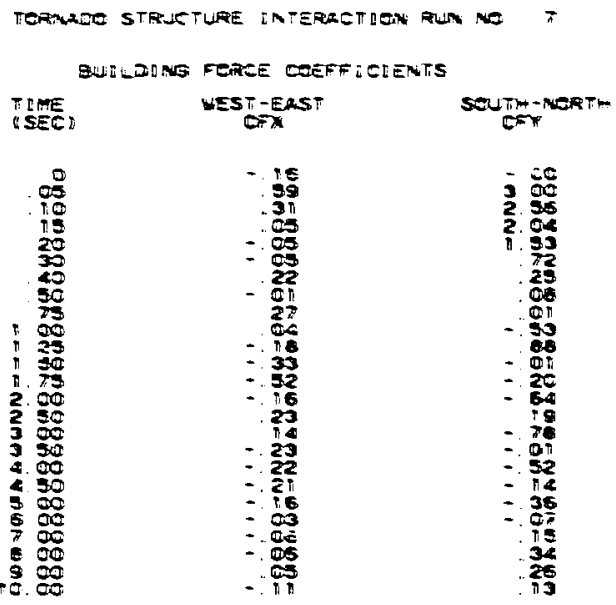

